\title{
CAMA
}

Centre for Applied Macroeconomic Analysis

\section{The Coming U.S. Interest Rate Tightening Cycle: Smooth Sailing or Stormy Waters?}

\section{CAMA Working Paper 37/2015 October 2015}

\section{Carlos Arteta}

World Bank, Development Prospects Group

\section{Ayhan Kose}

World Bank, Development Prospects Group and

Centre for Applied Macroeconomic Analysis (CAMA), ANU

\section{Franziska Ohnsorge}

World Bank, Development Prospects Group

Marc Stocker

World Bank, Development Prospects Group

\section{Abstract}

The U.S. Federal Reserve (Fed) is expected to start raising policy interest rates in the near term and thus commence a tightening cycle for the first time in nearly a decade. The taper tantrum episode of May-June 2013 is a reminder that even a long anticipated change in Fed policies can trigger substantial financial market volatility in Emerging and Frontier Market Economies (EFEs). This paper provides a comprehensive analysis of the potential implications of the Fed tightening cycle for EFEs. We report three major findings: First, since the tightening cycle will take place in the context of a robust U.S. economy, it could be associated with positive real spillovers to EFEs. Second, while the tightening cycle is expected to proceed smoothly, there are risks of a disorderly adjustment of market expectations. The sudden realization of these risks could lead to a significant decline in EFE capital flows. For example, a 100 basis point jump in U.S. long-term yields could temporarily reduce aggregate capital flows to EFEs by up to 2.2 percentage point of their combined GDP. Third, in anticipation of the risks surrounding the tightening cycle, EFEs should prioritize monetary and fiscal policies that reduce vulnerabilities and implement structural policy measures that improve growth prospects. 


\section{Keywords}

Federal Reserve, liftoff, tightening, interest rates, monetary policy, emerging markets, frontier markets, capital flows, sudden stops, crises.

\section{JEL Classification}

E52, E58, F30, F65, G15

\section{Address for correspondence:}

(E) cama.admin@anu.edu.au

The Centre for Applied Macroeconomic Analysis in the Crawford School of Public Policy has been established to build strong links between professional macroeconomists. It provides a forum for quality macroeconomic research and discussion of policy issues between academia, government and the private sector.

The Crawford School of Public Policy is the Australian National University's public policy school, serving and influencing Australia, Asia and the Pacific through advanced policy research, graduate and executive education, and policy impact. 


\title{
The Coming U.S. Interest Rate Tightening Cycle: Smooth Sailing or Stormy Waters?
}

\author{
Carlos Arteta, M. Ayhan Kose, Franziska Ohnsorge, and Marc Stocker ${ }^{1}$
}

\begin{abstract}
The U.S. Federal Reserve (Fed) is expected to start raising policy interest rates in the near term and thus commence a tightening cycle for the first time in nearly a decade. The taper tantrum episode of May-June 2013 is a reminder that even a long anticipated change in Fed policies can trigger substantial financial market volatility in Emerging and Frontier Market Economies (EFEs). This paper provides a comprehensive analysis of the potential implications of the Fed tightening cycle for EFEs. We report three major findings: First, since the tightening cycle will take place in the context of a robust U.S. economy, it could be associated with positive real spillovers to EFEs. Second, while the tightening cycle is expected to proceed smoothly, there are risks of a disorderly adjustment of market expectations. The sudden realization of these risks could lead to a significant decline in EFE capital flows. For example, a 100 basis point jump in U.S. long-term yields could temporarily reduce aggregate capital flows to EFEs by up to 2.2 percentage point of their combined GDP. Third, in anticipation of the risks surrounding the tightening cycle, EFEs should prioritize monetary and fiscal policies that reduce vulnerabilities and implement structural policy measures that improve growth prospects.
\end{abstract}

JEL Classification Numbers: E52, E58, F30, F65, G15

Keywords: Federal Reserve, liftoff, tightening, interest rates, monetary policy, emerging markets, frontier markets, capital flows, sudden stops, crises.

\footnotetext{
1 World Bank, Development Prospects Group. Arteta (carteta@worldbank.org); Kose (akose@worldbank.org); Ohnsorge (fohnsorge@worldbank.org); Stocker (mstocker1@worldbank.org). Kose is a Research Associate of the CAMA. The paper was produced with inputs from Derek Chen, Raju Huidrom, Ergys Islamaj, Eung Ju Kim, and Tianli Zhao. Research assistance was provided by Trang Nguyen and Jiayi Zhang. It has benefited from valuable comments and suggestions from Kaushik Basu, Selim Cakir, Jay Chopra, Charles Collyns, Krishna Guha, Poonam Gupta, Eswar Prasad, David Robinson, David Rosenblatt, Murat Ucer, Kamil Yilmaz, and seminar participants at the Institute of International Finance, and Bank of Korea Washington Office. This Working Paper represents the views of the authors and does not necessarily represent World Bank Group views or policy. The views expressed herein should be attributed to the authors and not to the World Bank Group, its Board of Executive Directors, or its management.
} 


\section{The Coming U.S. Interest Rate Tightening Cycle: Smooth Sailing or Stormy Waters?}

\section{CONTENTS}

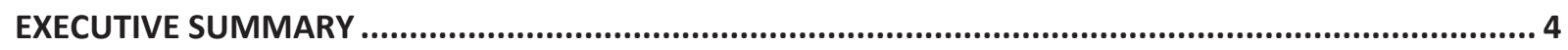

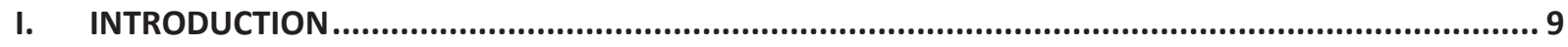

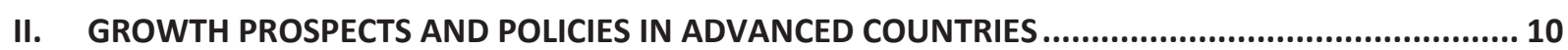

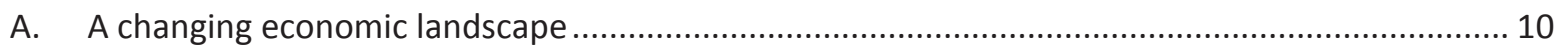

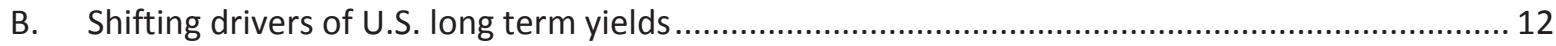

III. GROWTH PROSPECTS AND VULNERABILITIES IN EMERGING AND FRONTIER MARKETS (EFES) .... 15

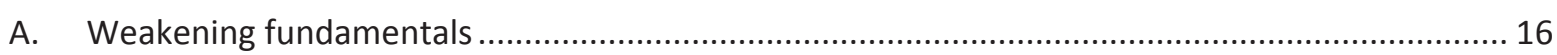

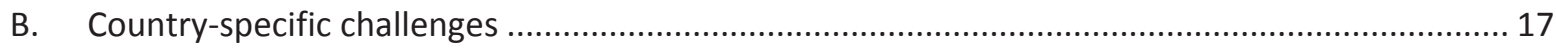

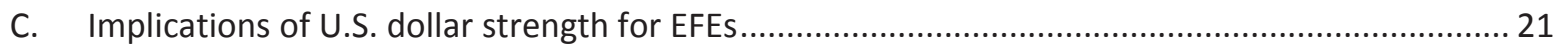

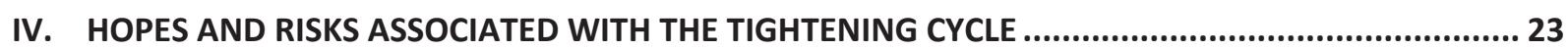

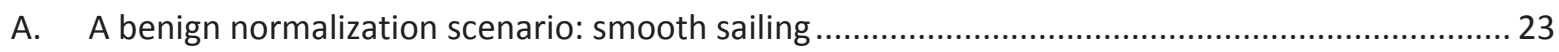

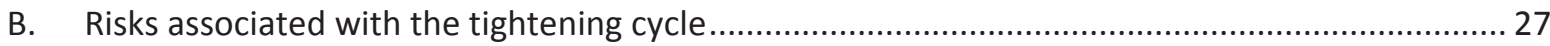

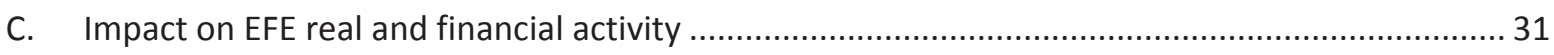

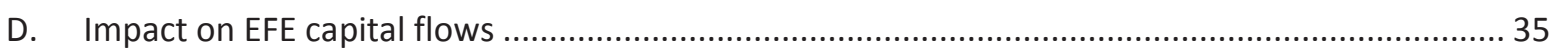

E. Multiple sudden stops in EFEs: a perfect storm?

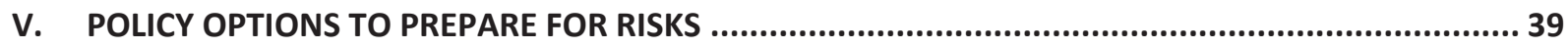

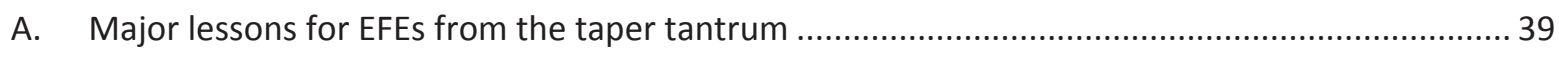

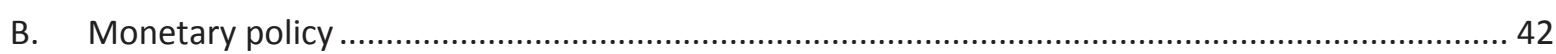

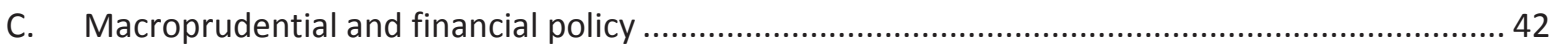

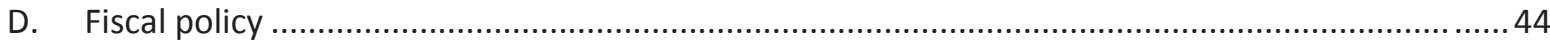

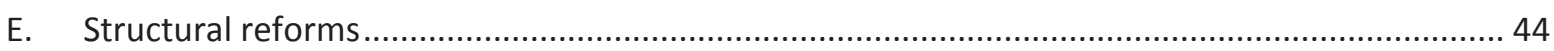

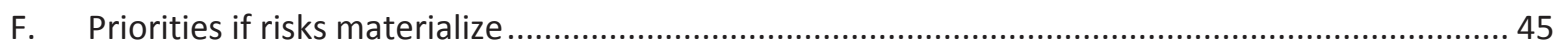

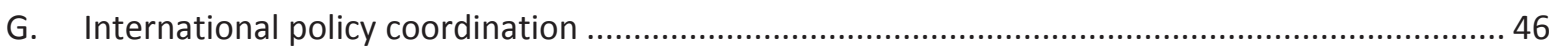

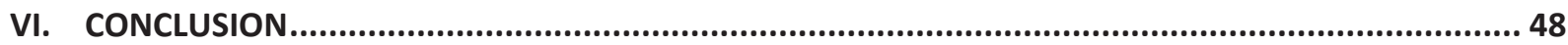

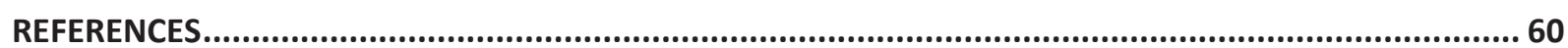




\section{APPENDIX TABLES}

Appendix Table 1. List of Emerging and Frontier Economies (EFEs) ...........................................5 50

Appendix Table 2. Studies on the effects of sudden stops ..................................................... 51

Appendix Table 3. Studies on the implications of the taper tantrum ..........................................55

\section{FIGURES}

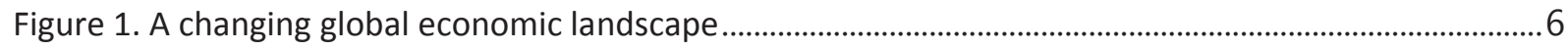

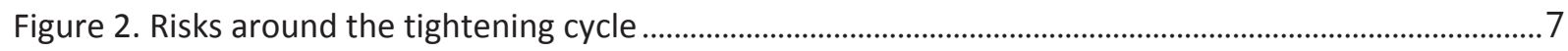

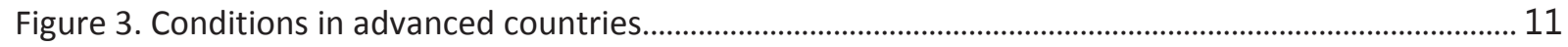

Figure 4. Movements in U.S. bond yields: monetary and real shocks....................................................... 14

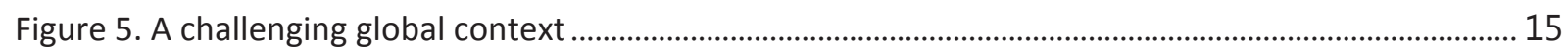

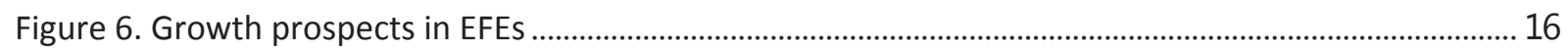

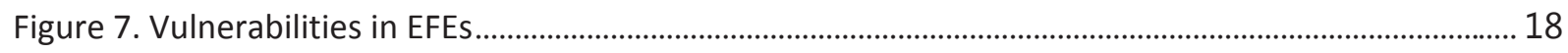

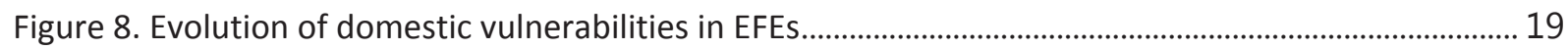

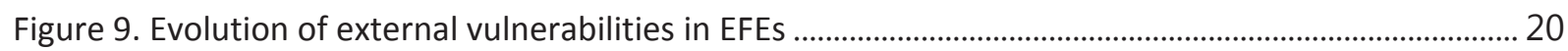

Figure 10. U.S. dollar, financial crises, and recent currency developments in EFEs ..................................... 21

Figure 11. Foreign currency exposure and corporate debt in EFEs .............................................................22

Figure 12. Policy rates and bond yields around previous tightening cycles................................................... 24

Figure 13. Adjustments in EFEs around previous tightening cycles.............................................................. 25

Figure 14. Global economic conditions around previous tightening cycles.................................................. 26

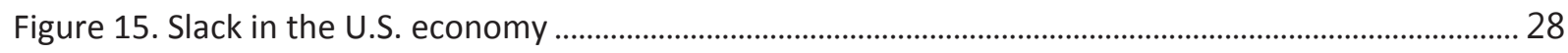

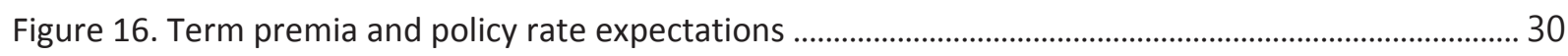

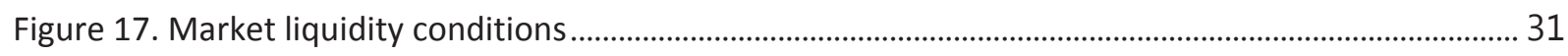

Figure 18. Impact of U.S. shocks on activity and financial markets in EFEs ............................................... 32

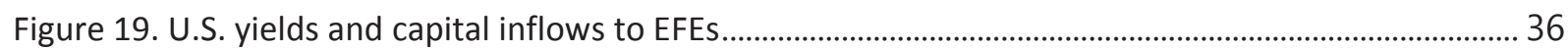

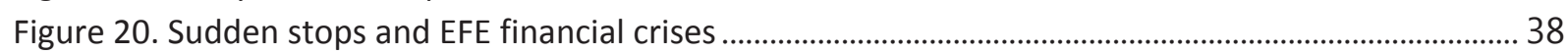

Figure 21. U.S. bond yields and EFE capital flows during the taper tantrum...............................................40

Figure 22. Current account positions and policy space in EFEs ...................................................................43

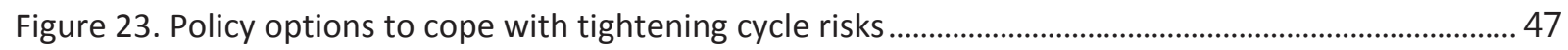




\section{EXECUTIVE SUMMARY}

Context: a long-anticipated event, but still with substantial risks. Since the global financial crisis, the exceptionally accommodative monetary policy stance of the U.S. Federal Reserve (Fed) has helped support activity, bolstered asset valuations, and reduced risk premia. In addition, it has been instrumental in boosting capital flows to emerging and frontier market economies (EFEs). As the U.S. economy improves, the Fed is expected to start raising policy interest rates in the near term (an event widely referred to as "liftoff") and thus commence a tightening cycle for the first time in nearly a decade. The mid-2013 "taper tantrum" episode is a painful reminder that even a long-anticipated change in Fed policies can surprise markets in its specifics, and lead to significant financial market volatility and disruptive movements in capital flows to EFEs. Recent debates have focused on the potential impact of the liftoff on EFEs, but there are also significant risks associated with the pace of subsequent rate increases, which is currently expected to be very gradual, but could accelerate at a time when EFE policy buffers are eroding.

This paper presents a comprehensive analysis of the changes in global conditions since the taper tantrum, risks of disruptions during the upcoming Fed tightening cycle, potential implications for EFEs, and policy options. Specifically, it addresses the following questions:

- How have growth prospects and policies in advanced countries changed since the taper tantrum?

- How have growth prospects and vulnerabilities in EFEs changed since the taper tantrum?

- What are the major risks associated with the tightening cycle for EFEs?

- What policy options are available for EFEs to cope with the potentially adverse effects of the tightening cycle?

Gradual healing in advanced economies. Activity in the United States continues to pick up, and labor markets are strengthening. While the recovery remains fragile in other major advanced economies, it has gradually firmed since 2013 (Figure 1). Despite the recent volatility, global long-term interest rates remain low, and the European Central Bank and the Bank of Japan are continuing to employ exceptionally accommodative monetary policies.

Growing vulnerabilities in EFEs. Since the taper tantrum, EFE growth prospects and credit worthiness have deteriorated, while vulnerabilities have risen in many countries (Figure 1).

- Domestic vulnerabilities. Activity has slowed in many EFEs, and growth in 2015 is expected to be the weakest since the financial crisis. On average, private debt has increased and fiscal positions have generally deteriorated.

- External vulnerabilities. Current account balances among several oil importing countries have improved somewhat but they have deteriorated among many oil exporters. EFEs with high levels of total external debt or with a large share of short-term external debt have made only limited progress in reducing such vulnerabilities. Foreign currency exposures remain elevated in some EFEs. Corporate debt has increased notably in several countries, with a significant share denominated in dollars.

Baseline: $a$ smooth tightening cycle. There are multiple reasons to expect a smooth tightening cycle with only modest impact on EFEs:

- The tightening cycle has long been anticipated and will most likely proceed very gradually.

- It will take place in the context of a robust U.S. economy, which, according to a vector autoregression analysis, will have positive real spillovers to EFEs. 
- The term spread in the United States is likely to remain narrow as happened during some of the past tightening episodes.

- Other major central banks are expected to continue pursuing exceptionally accommodative policies that would shore up global liquidity and help keep global interest rates low.

Significant risks around the baseline. The tightening cycle carries significant risks. Five factors heighten the risk of volatility in financial markets with adverse implications for activity in EFEs:

- Uncertainty about the underlying strength of the U.S. economy creates ambiguity about how far the Fed actually is from achieving its dual objectives.

- U.S. term premia are well below their historical average and could correct abruptly.

- Market expectations of future interest rates are below those of the U.S. Federal Open Market Committee.

- Market liquidity conditions are fragile.

- An increasingly challenging external environment is eroding EFE resilience: global growth is soft, world trade growth is subdued, and commodity prices remain low.

Risk of a large decline in capital flows. Movements in U.S. yields play a significant role in driving fluctuations in capital flows to EFEs. If the tightening cycle were accompanied by a surge in U.S. longterm yields, as happened during the taper tantrum, the reduction in capital flows to EFEs could be substantial (Figure 2). According to a vector autoregression model, a 100 basis point jump in U.S. longterm yields (as occurred during the taper tantrum) could temporarily reduce aggregate capital flows to EFEs by up to 2.2 percentage point of their combined GDP. Such a large drop in capital flows could create significant policy challenges for vulnerable EFEs.

A perfect storm? Financial stress in global markets tends to disproportionately affect those EFEs that have weak growth prospects, sizable vulnerabilities, and challenging policy environments. Financial market volatility during the tightening cycle could potentially combine with domestic fragilities into a perfect storm that could lead to a sharp reduction in capital flows to more vulnerable countries. Over time, this risk could intensify as modest growth prospects become entrenched and vulnerabilities widen in some major EFEs. Furthermore, an abrupt change in risk appetite for EFE assets could lead to contagion affecting capital flows to many countries, even if they have limited vulnerabilities. This could turn a manageable slowdown in capital inflows to EFEs into an episode of multiple sudden stops, with significant adverse implications for growth and financial stability. An event study exercise suggests that growth in EFEs declines, on average, almost 7 percentage points in the two years following such sudden stop episodes.

Policy options: hoping for the best but preparing for the worst. EFEs should prioritize monetary and fiscal policies that reduce vulnerabilities and strengthen policy credibility and structural policy agendas that can improve growth. In countries facing elevated inflation, buttressing monetary policy credibility may be a priority. Banks with large foreign currency liabilities may merit close monitoring. Fiscal policy can support growth if sufficient fiscal space is available. Although the benefits of structural reforms take time to materialize, decisive actions to implement ambitious reform agendas signal likely improvements in growth prospects to investors. In the event that risks surrounding the upcoming tightening cycle materialize, exchange rate flexibility could buffer shocks in some countries but may need to be complemented by monetary policy measures and targeted interventions to support orderly market functioning. Emerging and frontier market economies may hope for the best during the upcoming tightening cycle but, given the substantial risks involved, they need to prepare for the worst. 


\section{Figure 1. A changing global economic landscape}

Despite recent volatility, global long-term interest rates remain low. U.S. economy activity continues to pick up and U.S. labor markets are strengthening. Conditions in other advanced economies are also improving but remain fragile. On the other hand, growth prospects and credit worthiness in emerging and frontier markets (EFEs) have deteriorated, while both domestic and external vulnerabilities linger.

A. Interest rates in $\mathbf{G} 4$ countries

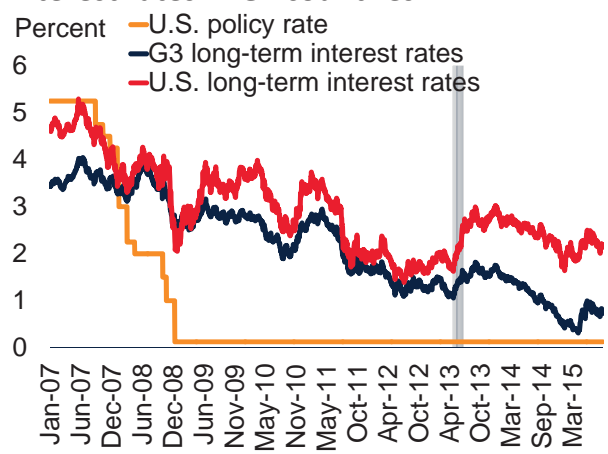

C. GDP Growth in EFEs

\section{Percent}

- Emerging and frontier markets (excluding China) 6 - Emerging and frontier markets

$$
\text { Average since } 2000
$$

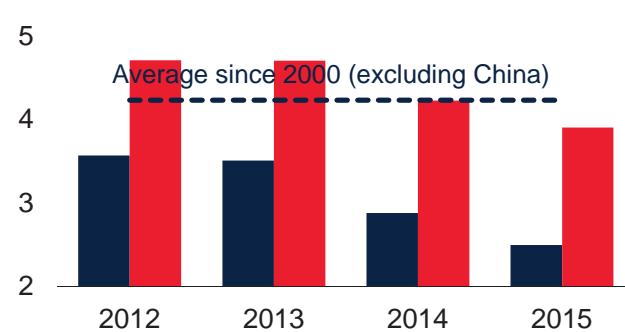

E. Domestic vulnerabilities of EFEs

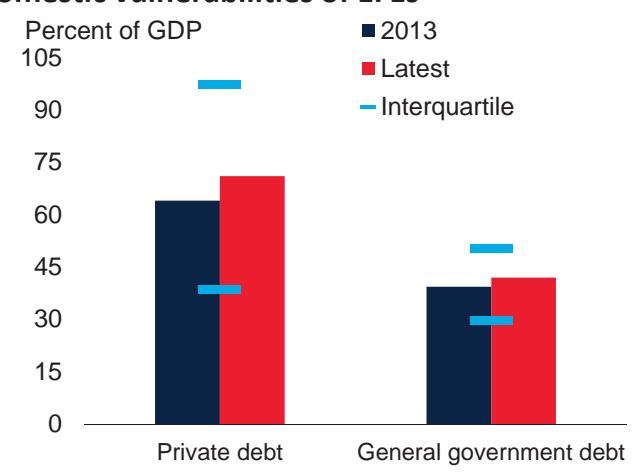

B. GDP growth in $\mathbf{G} 4$ countries
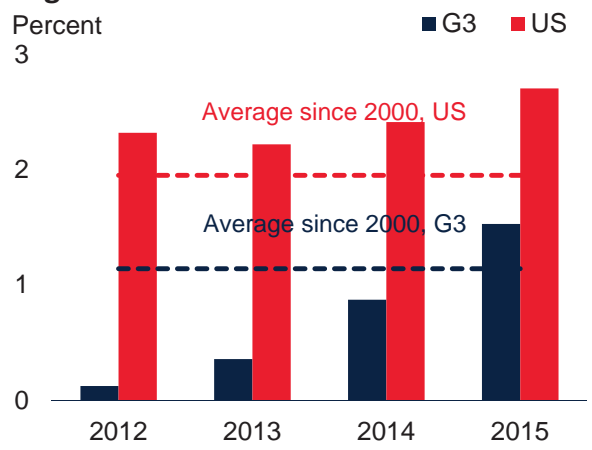

D. Currencies and credit ratings of EFEs

$\begin{array}{lr}\text { Credit rating } & \text { Index } \\ - \text { Average EM sovereign rating (LHS) } & 120\end{array}$ BBB- -EM currency index (RHS)

$\mathrm{BB}$

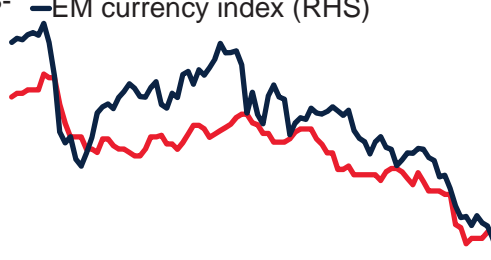

$\mathrm{B}+$

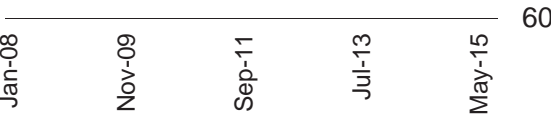

F. External vulnerabilities of EFEs

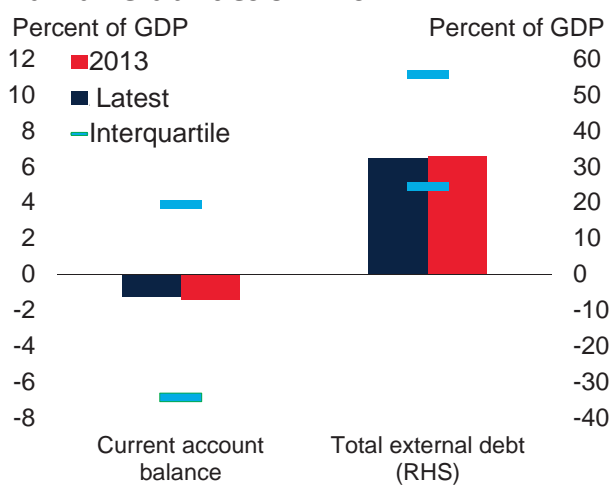

Source: IMF, Haver, World Bank.

A.Average of 10-year government bond yields of G3 countries (Euro Area, Japan, and United Kingdom) weighted by GDP. Blue bar shows the taper tantrum period in May-June 2013. Last observation: September, 2015

C. G3 GDP growth refers to aggregate GDP growth in the Euro Area, Japan, and United Kingdom. 2015 is forecast.

D. The sovereign rating is calculated based on the simple average of long-term foreign-currency credit ratings of countries by Standard \& Poor's Rating Service. A decline in the EM currency index denotes a depreciation.

E. F: bars stand for median values across 24 EFEs as listed in Figure 9 and 10. Latest values are 2014H2 for private debt, 2015 estimates for government debt, $2015 \mathrm{H} 1$ for current account balances, 2014 for external debt. 


\section{Figure 2. Risks around the tightening cycle}

Should the tightening cycle proceed smoothly, the U.S. term spread could remain narrow as in some past episodes, but currencies in EFEs would likely stay under pressure. However, there is a risk that U.S. long-term yields suddenly spike, either driven by an abrupt rise in term premia or by a closing of the gap in policy rate expectations between markets and Fed policymakers. A surge in U.S. yields could lead to a substantial drop in EFE capital flows, increasing the risk of sudden stops in vulnerable countries.

\section{A. U.S. term spreads around tightening cycles}

Basis points; deviations from $\mathrm{t}=0$

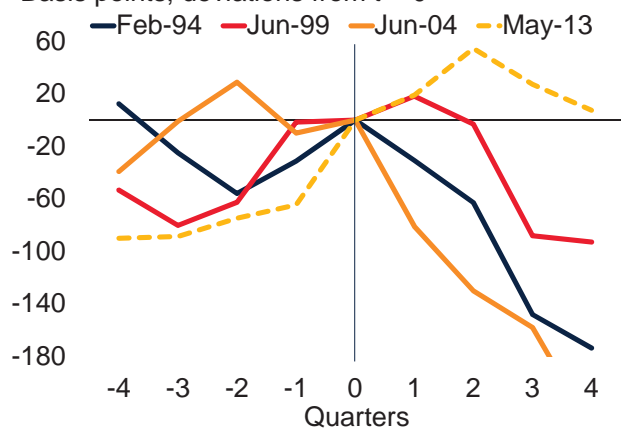

\section{U.S. 10-year treasury term premium}

\section{Percent}

6

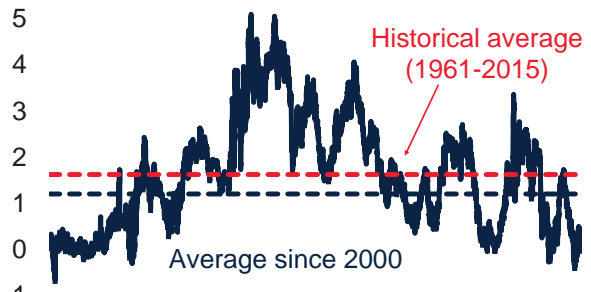

$-1$

귱 \&

\section{E. Sudden stops and EFE GDP growth}

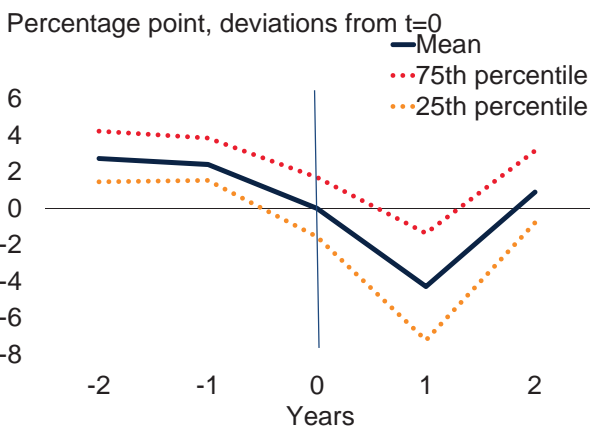

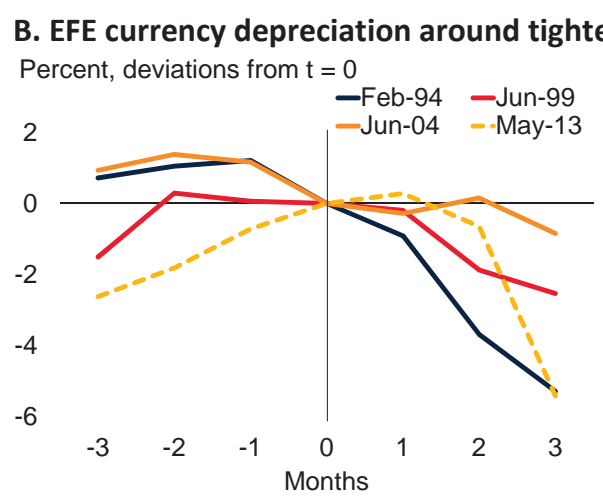

D. G4 interest rates and EFE capital inflows

Deviation from baseline, percentage points -G4 long-term yields

-Capital inflows (percentage points of GDP)
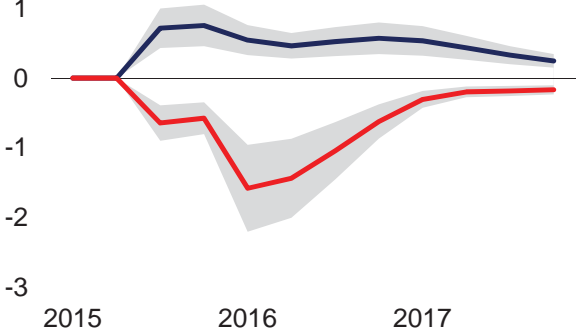

F. Sudden stops and EFE currency depreciation

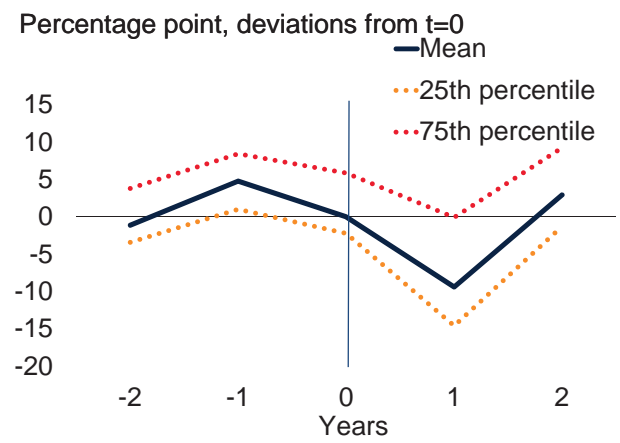

Source: IMF, Haver Analytics, Bloomberg, Federal Reserve Bank of New York, World Bank.

A. Term spread denotes the difference between 10-year U.S. Treasury and 6-month T-bill yields.

B. A decline denotes a depreciation of the nominal effective exchange rate. The $x$-axis shows the number of monhts before and after $t=0$, where $t=0$ is February 1994, June 1999, June 2004, and May 2013.

C. Term premium estimates obtained from the model described in Adrian, Crump, and Moench (2013b). Last observation: August 2015.

D. The $100 \mathrm{bp}$ shock on the U.S. term spread was applied to the VAR model assuming a range of pass-through rates to Euro Area, U.K. and Japanese bond yields, from zero to 100 percent. Grey area shows the range of estimated effects on capital inflows depending on pass-through rates (the lower bound corresponds to a zero pass-through rate, implying a 40 basis points shock to global bond yields, while the upper bound corresponds to a 100 percent passthrough rates, or a 100 basis points shock to global bond yields). In the median case, global bond yields increase initially by $70 b p$, which corresponds to the observed pass-through rate during the taper tantrum.

E.F. Blue line denotes averages for EFEs that experienced systemic sudden stops. Red and orange lines denote 75 th and 25th percentiles. A systemic sudden stop is a period when capital flows fall one standard deviation below their historical mean and, at the same time, the VIX index surpasses by one standard deviation its historical mean. The calculations include 21 nonconsecutive systemic sudden stop episodes for 58 EFEs in $1995-2014$.

F. A decline denotes a depreciation. 
"We face a risk that longer-term interest rates will rise sharply at some point." (Ben Bernanke, former Federal Reserve Chair, March 1, 2013a)

"A more practical solution, at least for now, would be for source-country central banks to reinterpret their mandates to consider the medium-term effects of recipient countries' policy responses, such as sustained exchange-rate intervention."

(Raghuram Rajan, Governor of the Reserve Bank of India, April 28, 2014a)

"While tightening cycles by the Fed can pose challenges for emerging market economies (EMES), these need not be disruptive." (William Dudley, Federal Reserve Bank of New York President, April 20, 2015)

"Long-term interest rates are at very low levels, and that would appear to embody low term premiums, which can move, and can move very rapidly..." (Janet Yellen, Federal Reserve Chair, May 6, 2015a)

"If the economy continues to improve as I expect, I think it will be appropriate at some point this year to take the initial step to raise the federal funds rate target."

(Janet Yellen, Federal Reserve Chair, May 22, 2015)

"The actual raising of policy rates could trigger further bouts of volatility, but my best estimate is that the normalization of our policy should prove manageable for the EMEs."

(Stanley Fischer, Federal Reserve Vice Chairman, May 26, 2015)

"I think the anticipation of the liftoff is creating more volatility [than the event itself]. I think when it actually happens, conditions will stabilize."

(Zeti Akhtar Aziz, Governor of the Bank Negara Malaysia, August 7, 2015)

"We ... need to be mindful that the uncertainties surrounding the US Federal Reserve's monetary policy normalization ... could heighten financial market volatility at home and abroad." (Juyeol Lee, Governor of the Bank of Korea, June 12, 2015)

"[T]he Fed's exit from zero policy rates will cause serious problems for those emerging market economies that have large internal and external borrowing needs, large stocks of dollar-denominated debt, and macroeconomic and policy fragilities."

(Nouriel Roubini, Chairman of Roubini Global Economics, June 29, 2015)

"In a highly uncertain world, the Fed cannot be both data dependent and predictable with respect to its future actions. Much better that it stick with data dependence than that it put its credibility at risk by seeking to mitigate a current rash action by trying to reassure with respect to future steps." (Lawrence Summers, Former U.S. Treasury Secretary, September 9, 2015) 


\section{INTRODUCTION}

Since the global financial crisis, the policy accommodation by the U.S. Federal Reserve has helped support activity, bolstered asset valuations, and reduced risk premia. In addition, it has been instrumental in lowering long-term interest rates in the United States and other advanced economies. As investors search for higher yields, this policy accommodation has also contributed to an increase in capital inflows to emerging and frontier market economies (EFEs-roughly speaking, developing countries with either substantial or partial access to international capital markets). ${ }^{2}$ As a result, borrowing conditions in EFEs have remained particularly favorable.

As the U.S. economy improves, the Fed is expected to start raising policy interest rates in the near term (an event widely referred to as "liftoff") and thus commence a tightening cycle. ${ }^{3}$ This would be the first increase in U.S. policy rates since 2006. Since the tightening cycle has been widely anticipated and will take place gradually in the context of a robust U.S. economy, it is expected to have a benign impact on capital inflows to EFEs (Fischer 2015).

However, the timeframe of the tightening cycle remains uncertain and vulnerabilities in many EFEs have been rising especially over the past two years. The "taper tantrum" episode of May-June 2013 is a painful reminder that even a long-anticipated change in Fed policies can surprise markets in its specifics, and lead to significant financial market volatility and disruptive movements in capital flows to EFEs. This episode was sparked by a statement that became known as "taper talk," when Fed Chairman Ben Bernanke mentioned the possibility of the Fed slowing its asset purchases "in the next few meetings" on May 22, 2013 (Bernanke 2013b). While financial markets had expected such an action at some point in the future, they were surprised by the mention of an approximate timeframe.

Within a couple months of the initial taper talk, U.S. 10-year Treasury yields increased by 100 basis points. The jump in U.S. yields was quickly followed by a spike in financial market volatility in EFEs. Specifically, EFE currencies depreciated, bond spreads rose steeply, foreign portfolio inflows to EFE bond and equity funds fell sharply, and liquidity tightened, while the volatility in bond markets and capital flows intensified. This forced many EFEs to tighten monetary policy, intervene in currency markets, and, in some cases, introduce exceptional measures to prevent capital outflows. ${ }^{4}$

\footnotetext{
2 Emerging Market Economies generally include countries with a record of significant access to international financial markets. Frontier Market Economies include countries that are usually smaller and less financially developed than emerging market economies. Therefore, the emerging and frontier market group excludes low-income countries with minimal or no access to international capital markets, for which changes in international capital flows due to higher U.S. rates would have little direct impact. This study includes 24 emerging markets and 40 frontier market economies. A full country list and details on the classification methodology is presented in Appendix Table 1.

${ }^{3}$ In a recent speech, Federal Reserve Chair Janet Yellen (2015c) stated that, if economic conditions continue to improve as expected, the liftoff would be appropriate sometime in 2015, but it would be contingent on evidence of further improvement in the labor market and that inflation will move back up to 2 percent in the medium term.

${ }^{4}$ Recent studies-such as Sánchez (2013); Díez (2014); Dahlhaus and Vasishtha (2014); Ikeda, Medvedev, and Rama (2015); and Koepke (2015b) -emphasize the critical role of expectations in determining the scale of macroeconomic adjustments in developing countries in the event of a U.S. interest rate hike. They report that the large macroeconomic adjustments in developing countries during the taper tantrum reflected the fact that the consequences of Fed tapering had not yet been "priced in." In contrast, the relatively milder movements in developing country financial markets during the actual taper period
} 
The upcoming tightening cycle will take place in a challenging environment for EFEs, marked by weak global growth, subdued world trade, and low commodity prices, as well as heightened financial market volatility and concerns about growth prospects in major emerging markets. In this context, the potential impact of the tightening cycle on capital flows to EFEs depends on both "push" factors (economic and financial conditions in advanced economies) and "pull" factors (country-specific prospects, vulnerabilities, and policies). ${ }^{5}$

- Push factors. As growth prospects improve in advanced countries relative to EFEs, investment returns are likely to rise and advanced country monetary policies will become gradually less accommodative. Although positive growth spillovers from advanced countries would support activity in EFEs, higher interest rates would likely shift the relative return differential on financial assets in favor of advanced countries.

- Pull factors. While EFEs as a group continue to grow faster than advanced economies, prospects have softened and several EFEs face significant vulnerabilities. In some of them, uncertainty about policy direction is elevated and weighing on investor sentiment. These factors increase the likelihood of a sudden market reappraisal of the inherent riskiness of EFE financial assets.

This paper presents a comprehensive analysis of the changes in the major push and pull factors since the taper tantrum, risks of disruptions during the upcoming Fed tightening cycle, potential implications for EFEs, and possible policy options. Specifically, it addresses the following four questions:

- How have growth prospects and policies in advanced countries changed since the taper tantrum?

- How have growth prospects and vulnerabilities in EFEs changed since the taper tantrum?

- What are the major risks associated with the tightening cycle for EFEs?

- What policy options are available for EFEs cope with the potentially adverse effects of the tightening cycle?

\section{GROWTH PROSPECTS AND POLICIES IN ADVANCED COUNTRIES}

Since the taper tantrum, there have been notable changes in economic conditions in advanced economies and in the policy stance of some major central banks.

\section{A. A changing economic landscape}

Advanced-economy growth, monetary policy, and broader financial conditions are key global push factors driving capital flows to EFEs. The economic and policy context in advanced countries has evolved notably since the taper tantrum (Figure 3 ).

(December 2013-October 2014) suggested that markets had already adjusted their expectations accordingly.

${ }^{5}$ Several recent studies have examined the links between capital flows to EFEs and "pull" and "push" factors, including U.S. monetary policy and global risk aversion (Koepke 2015a; Fratzscher 2012). 


\section{Figure 3. Conditions in advanced countries}

Long-term interest rates across major advanced economies remain at historic lows. Global financial markets have been bolstered by a prolonged period of monetary policy accommodation in the United States, followed recently by more expansionary monetary policies by the European Central Bank and Bank of Japan. The U.S. economy is strengthening, with labor markets healing and credit conditions improving, while other advanced economies are experiencing a more fragile recovery. Reflecting increasingly divergent monetary policies across major reserve currencies, the U.S. dollar has appreciated markedly since mid-2014.

\section{a. Selected interest rates}

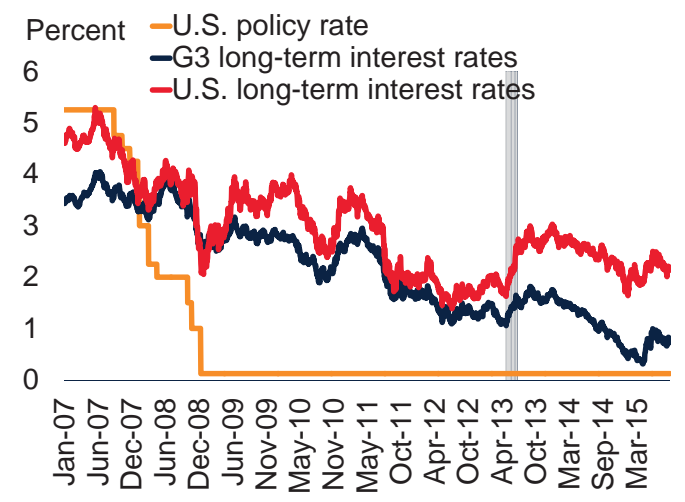

c. GDP growth in $\mathrm{G} 4$ countries

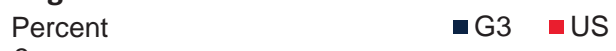

3

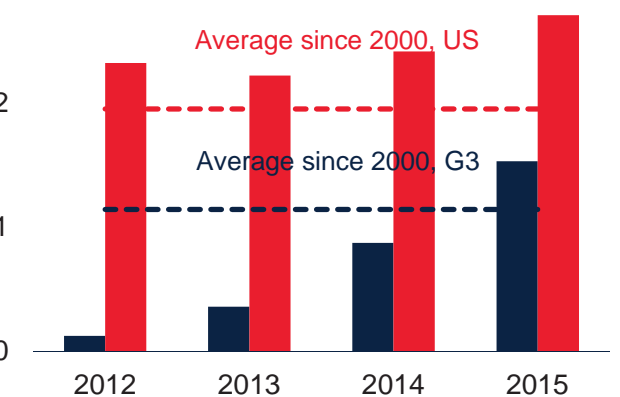

e. Credit to the private sector

Percent, year-on-year 15

-US -G3

10

10

5

$y$

0

$-5$
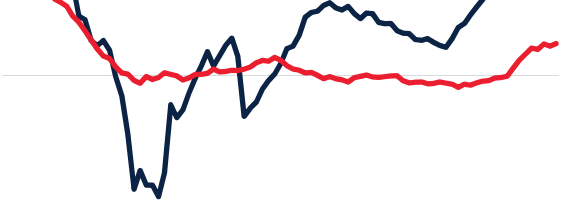

$-10$

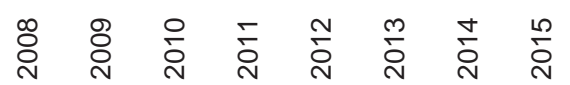

b. Central bank balance sheets

Index = 100 in January 2010

400

350

300

250

200

150

100

50

0

2010201120122013201420152016

d. U.S. labor market conditions

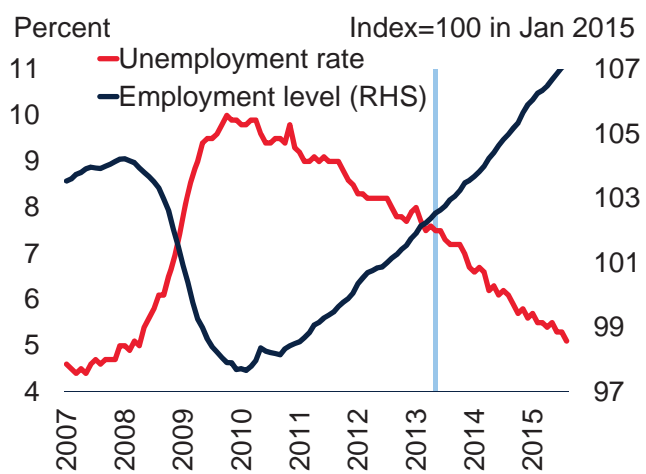

F. Selected broad trade-weighted currency indices

Index, Jan 2nd $2013=100$

$125-$ Euro -USD -JPY

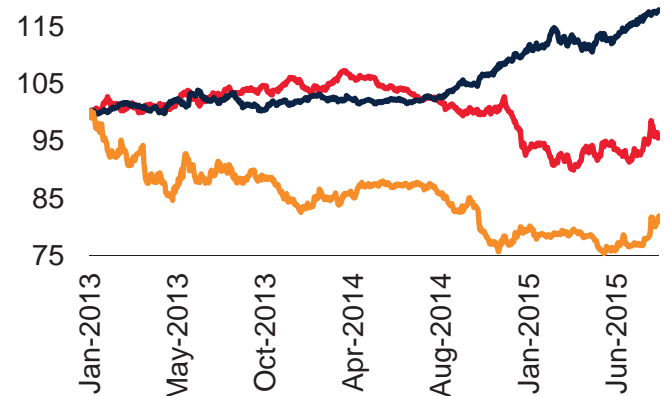

Source: Bloomberg, Haver, World Bank.

A.Average of 10-year government bond yields of G3 countries (Euro Area, Japan, and United Kingdom) weighted by GDP. Blue bar shows the taper tantrum period in May-June 2013. Last observation: September 8, 2015.

B. Grey area shows the forecast period. Last observation: August, 2015.

C. G3 GDP growth refers to aggregate GDP growth in the Euro Area, Japan, and United Kingdom.

D. Blue bar shows the taper tantrum period in May-June 2013. Last observation: August 2015.

E. Average of credits to private sectors of G3 countries (Euro Area, Japan, and United Kingdom) weighted by GDP. Last observation: July 2015.

F. Last observation: September, 2015 
- Persistently low interest rates. Policy rates of major central banks remain at or near zero-and, in some cases, below zero (World Bank 2015b). ${ }^{6}$ Despite the approaching tightening cycle in the United States, long-term interest rates in major economies are still exceptionally low. These low rates have been accompanied by further policy accommodation by the European Central Bank (ECB) and the Bank of Japan, which continue to seek a significant expansion of their balance sheets. Monetary stimulus measures by these central banks should continue to shore up global liquidity and help keep global interest rates low even as the U.S. starts raising policy rates. ${ }^{7}$

- Gathering momentum for the U.S. economy. Since 2013, the U.S. economy has further strengthened, with growth above its average of the past 15 years and continuing to outperform other advanced economies. U.S. labor markets have improved notably since the taper tantrum. This suggests that fulfillment of the Fed's "full employment" mandate does not stand in the way of a nearing liftoff (Yellen 2015c).

- An ongoing but fragile recovery in other advanced economies. Although the recovery in other major advanced economies firmed since 2013-supported by accommodative monetary policy, currency depreciation, low oil prices, and slowing fiscal consolidation-it remains fragile, as suggested by recent indicators from the Euro Area and Japan. Moreover, bank lending conditions and credit to non-financial corporations and households have experienced only modest improvements across other major advanced economies.

One of the most remarkable developments since the taper tantrum has been the sharp run-up of the value of the dollar against most major currencies. Reflecting in part the asynchronous nature of monetary policy stances among major central banks, the U.S. dollar has appreciated more than 15 percent in nominal effective terms since mid-2013, while the euro and yen depreciated significantly over the same period. To the extent that the broad-based dollar appreciation reflects strong growth in the United States and prospects of successful monetary policy accommodation in the Euro Area and Japan, developments across major reserve currencies since 2013 should be supportive of global economic recovery (World Bank 2015b). However, there is a risk that the dollar appreciation is more than warranted by improved U.S. growth prospects, or that a weakening Euro and Yen do not re-invigorate activity in the Euro Area and Japan as expected. In this case, a strong dollar might hamper growth among advanced economies. As we discuss below in Section III, it may also add considerable challenges to EFEs.

\section{B. Shifting drivers of U.S. long term yields}

Going forward, a rise in U.S. long-term yields could reflect either continued improvements in the U.S. economy, with potentially positive growth spillovers for the rest of the world, or alternatively reflect changes in market expectations regarding U.S. monetary policy or medium-term inflation risks.

\footnotetext{
${ }^{6}$ A number of major central banks in Europe have set key policy rates at negative levels in order to further encourage lending by making it costly for banks to hold excess reserves at their central banks. Amid negative policy rates, nominal yields on some bonds of highly-rated European governments also dropped below zero. Explanations for the phenomenon of negative yields include very low inflation, further "flight to safety" toward fixed income assets in Europe's core, and-perhaps the main proximate cause - the increased scarcity of highly-rated sovereign bonds eligible for the European Central Bank's asset purchase program. Potential implications for EFEs include a search for yield supporting capital inflows, which could help offset the impact of the approaching U.S. tightening cycle.

7 The Bank of England is also expected to embark on a policy rate tightening cycle sometime in 2016.
} 
Continued improvements in U.S. activity (a favorable "real shock"), especially if surprisingly repeated on the upside, could bolster equity valuations and would reduce the need for the highly accommodative monetary policy stance. In tandem with rising returns on equity, bond prices could fall and yields could rise on market expectations of nearing monetary tightening.

Alternatively, financial markets could be surprised by even a modestly less accommodative stance of monetary policy: it could appear as an accelerated tightening to investors if their views about the U.S. economy differ from the Fed's (an adverse "monetary shock"). Similarly, the persistence of slower productivity and potential output growth could lead markets to anticipate a more rapid narrowing of the output gap, justifying a faster normalization of policy rates. ${ }^{8}$

A structural vector autoregression (VAR) model is employed to disentangle the contribution of real and monetary shocks to movements in the long-term U.S. yields: those associated with changes in U.S. growth prospects (proxied by the S\&P 500 index), and those reflecting changes in market perceptions of U.S. monetary conditions (proxied by the 10-year sovereign bond yield). The exercise assumes that an adverse monetary shock (such as perceived accelerated monetary tightening) increases yields and reduces stock prices in the United States, while a favorable real shock (such as one reflecting better growth prospects) increases both yields and stock prices (see Box 1 for technical details).

The results suggest that the initial increase in long-term yields after May 2013 largely reflected unfavorable monetary shocks: against the backdrop of concerns about the strength of the U.S. economy, financial markets perceived the taper-talk as signaling an accelerated tightening of monetary conditions (Figure 4). In early 2013, economic data releases surprised on the downside and provided little indication that suggested sufficiently strong U.S. growth momentum to warrant rising long-term bond yields. As a result, real shocks contributed little to movements in 10-year U.S. bond yields.

Since the taper tantrum, however, perceived monetary shocks, reflecting both domestic and external factors, have turned increasingly favorable. Financial conditions remained highly accommodative even as Fed asset purchases were unwound between December 2013 and October 2014, revealing that the expected impact of tapering had been already priced in. In late 2014, perceived monetary shocks began to push yields below May 2013 levels. Following ECB President Mario Draghi's speech in Jackson Hole in August 2014, market speculation intensified and was eventually proven right about the use of ECB's quantitative easing. ${ }^{9}$ The decline in Euro Area long-term bond yields also spilled over to U.S. long-term bond yields.

\footnotetext{
8 Accounting for different ways of linking the growth potential of the U.S. economy and the natural rate of interest, some Taylor Rule estimates already prescribe higher policy rates than the current target range of the Federal Funds rate (Dupor 2015).

9 During the Federal Reserve Bank of Kansas City's annual economic symposium in August 2014, President Draghi suggested that the ECB was moving closer to QE, emphasizing that it would "use all the available instruments needed to ensure price stability" and that it stood "ready to adjust (the) policy stance further."
} 
Figure 4. Movements in U.S. bond yields: monetary and real shocks

The sudden rise in U.S. long term yields after May 2013 was mainly due to adverse "monetary shocks," as markets interpreted taper talk as signaling accelerated monetary tightening. Since then, market expectations of a very gradual tightening cycle contributed to keeping yields low, offsetting upward pressure from positive "real shocks" reflecting the strengthening labor markets and improving real U.S. activity.

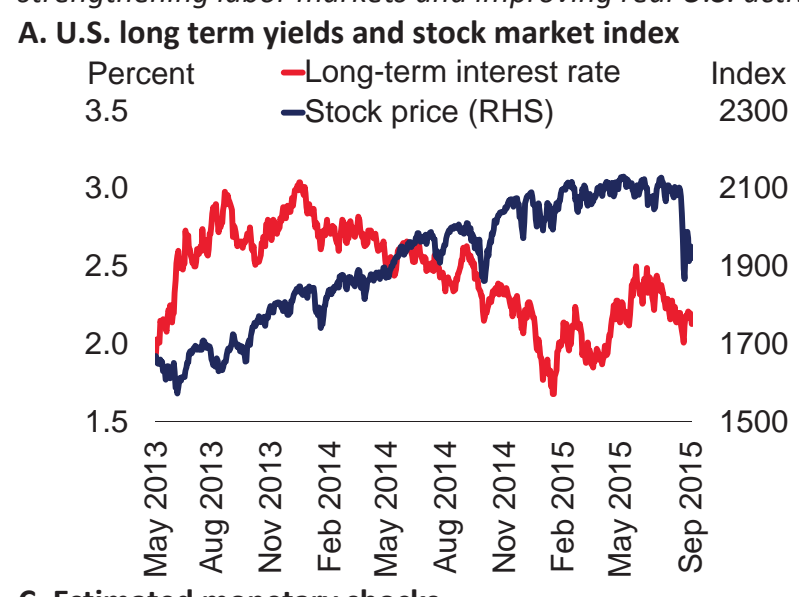

C. Estimated monetary shocks

Percent
20

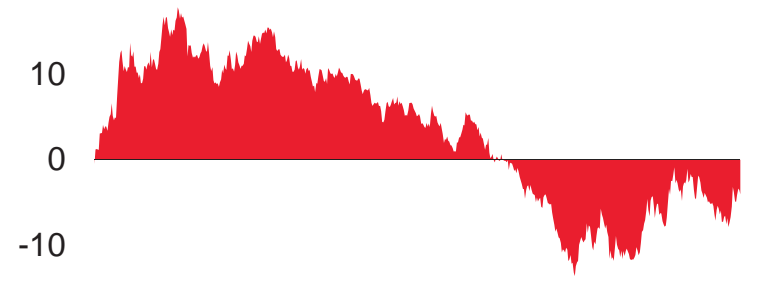

B. U.S. long term yields - counterfactual

Percentage point change since May 21, 2013

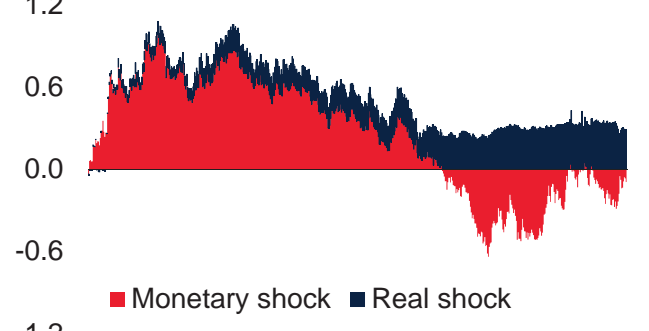

$-1.2$

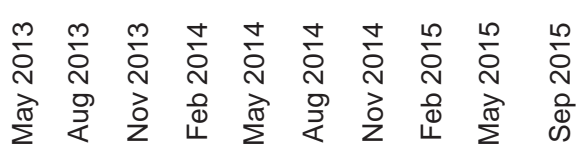

D. Estimated real shocks

Percent

8

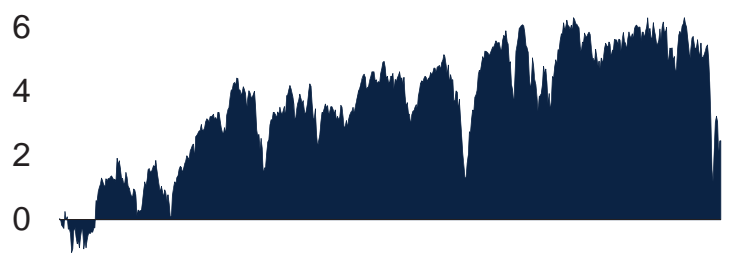

$-20$

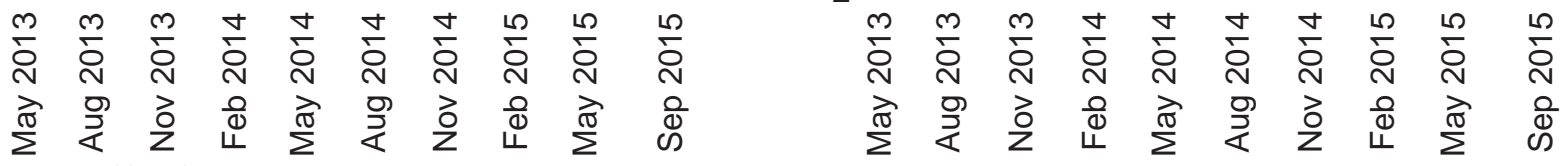

Source: Haver, World Bank estimates.

A.Long-term interest rate is the 10-year U.S. Treasury yield and stock price refers to the S\&P 500. Last observation: September 2015.

B. Based on estimates from the model, identifying monetary and real shocks using sign restrictions. All shocks except the shock in focus are shut down by setting them to zeros and the model is used to trace out the counterfactual long rate. The exercise is performed separately for monetary and real shocks. The orange (green) counterfactual shows how long rates would have evolved only with the estimated monetary (real) shocks. Numbers shown are in percentage points. Last observation: September 2015.

C. D. These are the time series of monetary and real shocks as estimated from the VAR model. Numbers shown are in cumulative percentages. The shock signs are such that whenever positive, they result in a an increase in the long rate. Last observation: September 2015.

At the same time, indications of an increasingly robust labor markets contributed to positive real shocks that exerted upward pressure on long-term yields. Since reaching a multiyear low of 1.6 percent in January 2015, U.S. long term interest rates have recovered somewhat, as labor market conditions continued to improve and yields in Europe bounced back following unusually low levels in previous months. However, a further strengthening of the U.S. dollar, declining oil prices and concerns about growth in the rest of the world maintained U.S. long term interest rates at historically low levels, hovering in a range of between 2 to 2.2 percent. 


\section{GROWTH PROSPECTS AND VULNERABILITIES IN EMERGING AND FRONTIER MARKETS (EFES)}

Although some of the "push" factors emanating from advanced economies generally remain supportive for EFEs, and even if the drivers of U.S. long-term yields are more benign compared to mid-2013, the upcoming Fed tightening cycle will take place in an increasingly challenging global environment for EFEs. First, global GDP growth has persistently disappointed in the past few years, with multiple forecast downgrades since 2012 (Figure 5). Second, growth in world trade has also been subdued in recent years, with both cyclical and structural factors accounting for the marked post-crisis slowdown (World Bank 2015a). Third, commodity prices have experienced a substantial decline of late. Furthermore, recent spikes in global financial market volatility suggest that market participants are increasingly concerned about weakening growth prospects in some major emerging markets.

\section{Figure 5 . A challenging global context}

The external environment for EFEs is increasingly challenging. A moderate upturn in advanced economies is ongoing, but prospects of a durable global recovery have been repeatedly disappointing in recent years, world trade remains on a weak post-crisis trend, and declining commodity prices are putting commodity exporters under pressure.

A. Global GDP growth forecast

Percent

$4 \quad \square$ June (previous year) $\quad$ January $\square$ June $\square$ January (next year)

3

2

1

0

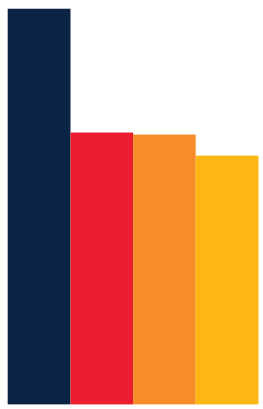

2012

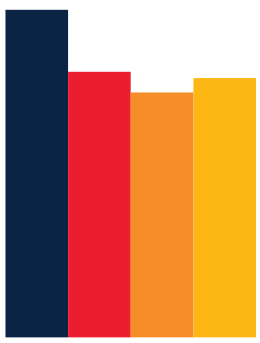

2013
B. Global trade volume

Index = 100 in 2008

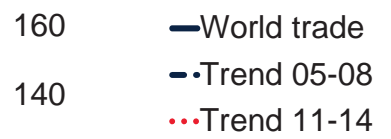

120

100

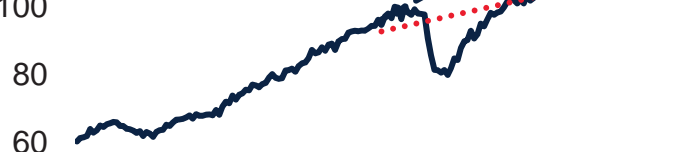

60

40

$\begin{array}{llllllll}2000 & 02 & 04 & 06 & 08 & 10 & 12 & 14\end{array}$

Source: World Bank, World Trade Monitor.

B. Last observation: June 2015.

C. Last observation: August 2015.

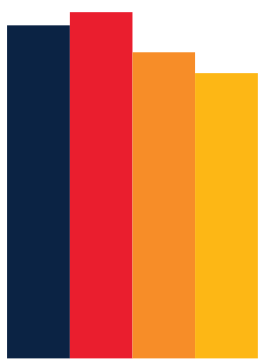

2014

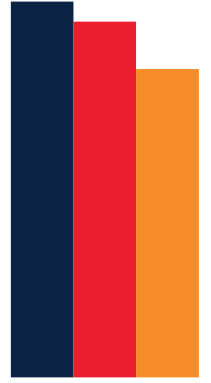

2015
C. Change in commodity prices

Percent change since Jan-2011

Metal

$-10$ Agriculture Energy

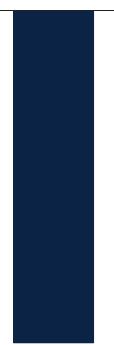

$-50$ 
While global factors, including U.S. long-term yields, may affect EFE capital flows, country specific "pull" factors, including macroeconomic fundamentals and policies, also play an important role.

\section{A. Weakening fundamentals}

Since the taper tantrum, macroeconomic fundamentals in a number of EFEs have weakened (Figure 6). As a result, their credit ratings have on average deteriorated. Rating downgrades have coincided with depreciating currencies and rising credit default swap spreads. Since 2010, growth has slowed steadily and repeatedly fallen short of expectations. The pattern of weak growth has become increasingly more visible in a larger number of EFEs over time. In fact, this year will mark the slowest pace of EFE growth since the global financial crisis, contributing to bouts of financial market volatility. Productivity growth in EFEs has also slowed down, suggesting that the pattern of disappointing growth may continue.

\section{Figure 6. Growth prospects in EFEs}

Since the taper tantrum, growth prospects and credit ratings have deteriorated in EFEs. Credit rating downgrades have coincided with depreciating currencies and rising credit default swap (CDS) and bond spreads. A large share of countries are facing slowing growth, and some emerging markets are facing greater policy uncertainty.

\section{A. GDP Growth in EFEs \\ Percent \\ - Emerging and frontier markets (excluding China) \\ 6 Emerging and frontier markets}

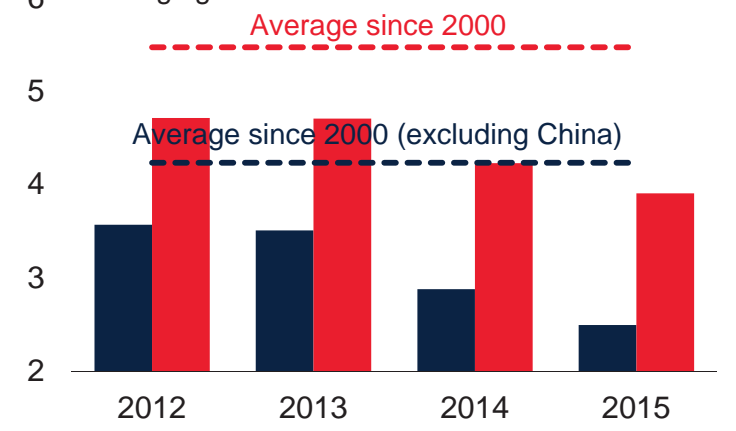

C. Fraction of EFEs with slower growth than 1990-2008 average

Percent

100

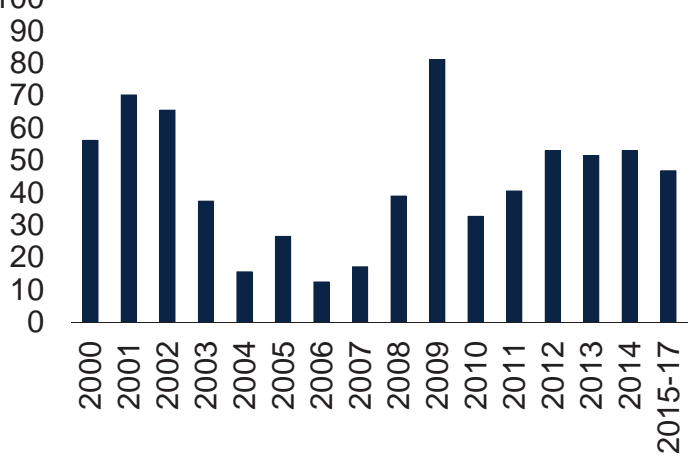

B. Currencies and credit ratings of EFEs

Credit rating

-Average EM sov

BBB- -EM currency index (RHS)

$\mathrm{BB}$

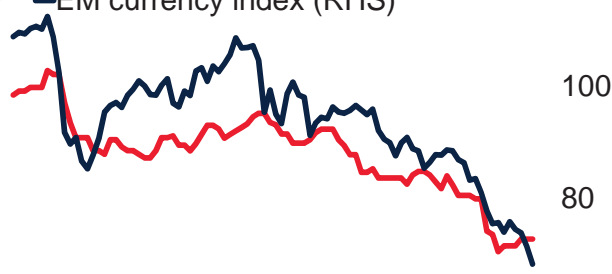

$\mathrm{B}+$

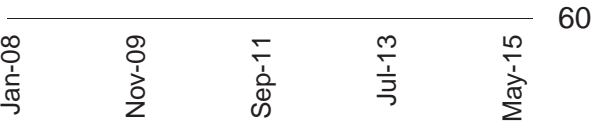

D. EFE volatility index

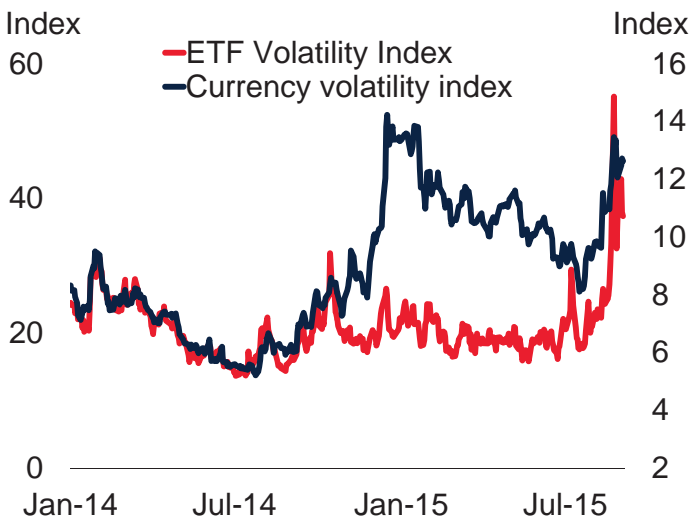

Source: Bloomberg, Haver, World Bank estimates, CBOE, JP Morgan.

B. The sovereign rating is calculated based on the simple average of long-term foreign-currency credit ratings of countries by Standard \& Poor's Rating Service. Last observation: August 2015. A decline in the EM currency index denotes a depreciation.

C. Fraction of EFE countries in which growth is slower than its historical average for 1990-2008. For 2015-17, the average of three years is shown.

D. The CBOE Emerging Markets ETF Volatility Index measures implied volatility for options on select exchange-traded funds (ETFs). 
In general, EFE vulnerabilities have seen little improvement since 2013, as suggested by median values of some key vulnerability indicators (Figure 7). Median inflation has increased, while the primary balance has worsened. These movements, however, mask differences between commodity exporters and importers. Among oil importers, fiscal deficits are expected to narrow as a result of declining expenditures on fuel subsidies following last year's significant drop in oil prices; moreover, inflation in oil importers has generally fallen, allowing central banks in some countries to reduce monetary policy rates to support growth. In contrast, fiscal and monetary policy room has shrunk in oil-exporting countries as revenue shortfalls have weakened fiscal positions and depreciation pressures have pushed inflation up. While government debt levels in EFEs are moderate, they have increased in frontier markets since the global financial crisis, amid a rapid rise in bond issuance in global capital markets. In some frontier markets, rising government debt has been accompanied by rapidly growing private sector credit (World Bank 2015a). And, after years of rapid credit expansion, many countries struggle with high levels of private sector indebtedness, as weakening domestic demand, prospects of rising interest rates and currency pressures complicate the necessary balance sheet adjustments.

Current account deficits have shown little improvement since the taper tantrum, generally improving in commodity importers but worsening in several exporters; on the other hand, foreign reserves have on average edged up. Highlighting the continued need for external financing, total external debt and shortterm debt have changed little. Real exchange rate overvaluation has fallen sharply, reflecting recent nominal currency movements. And foreign currency exposures remain elevated for many EFEs.

These external and currency-related vulnerabilities in EFEs suggest that rapid shifts in capital flows and currency markets can lead to significant pressures on their external balances. Moreover, deeper integration of EFEs in international debt markets, and a shift from cross-border bank lending to record bond issuance by sovereigns and corporates, appear to have heightened the sensitivity of long-term interest rates in EFEs to global bond yields (Sobrun and Turner 2015).

\section{B. Country-specific challenges}

Considering the much larger magnitude of domestic and external vulnerabilities they experienced during the 1980 s and 1990s, the aggregate vulnerabilities listed above appear manageable for EFEs. However, weak growth could reduce the resilience of some EFEs over time, particularly commodity exporters. Moreover, there are considerable differences in the evolution of external and domestic vulnerabilities across individual EFEs. ${ }^{10}$

- Domestic vulnerabilities (Figure 8). Although some countries with weak GDP growth in 2013 have seen some improvements more recently, the pace of expansion has slowed in most others. Inflation has moderated for some oil-importing countries, but is still at or above (formal or informal) inflation targets in several of them. Private debt levels have edged up despite slower credit growth in some countries. Public debt has also increased in some EFEs and primary balances have deteriorated somewhat, particularly among commodity exporters. Countries facing bank asset quality problems have seen little improvement since mid-2013.

\footnotetext{
10 In addition to simple median values and individual indicators of emerging market vulnerabilities, a number of aggregate indicators have been developed in recent years, such as the index of emerging market vulnerabilities used in the Federal Reserve Board's Monetary Policy Report in February 2014, the heat map index of external vulnerabilities computed by the Institute of International Finance (2015), or Santacreu (2015).
} 


\section{Figure 7. Vulnerabilities in EFEs}

EFE vulnerabilities have seen generally little improvement since 2013. Median inflation has increased despite slowing growth, while fiscal positions and private debt generally deteriorated. Median current account deficits remain broadly unchanged and only limited progress has been made in reducing external or short-term debt. Foreign currency exposures remain elevated in some EFEs.

\section{A. Domestic Vulnerabilities \\ Percent}

$8 \quad-2013$

- Latest

6

- Interquartile

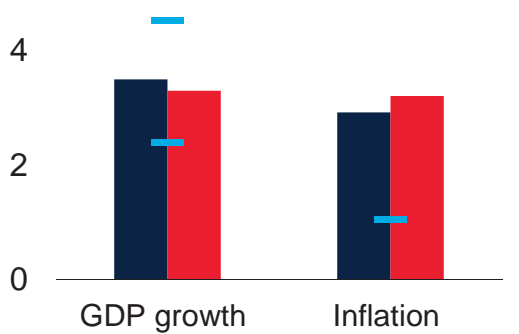

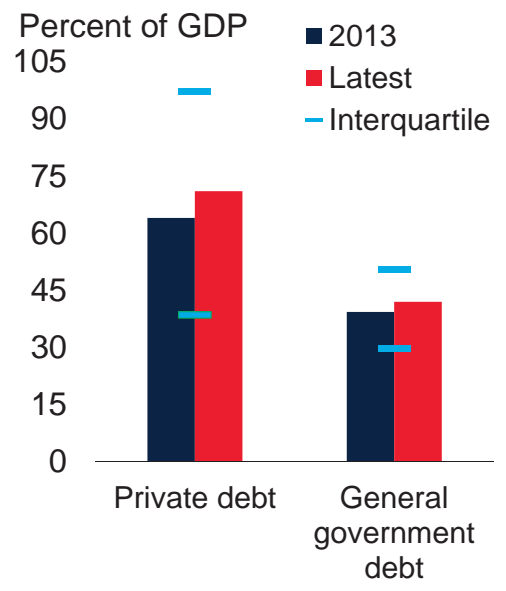

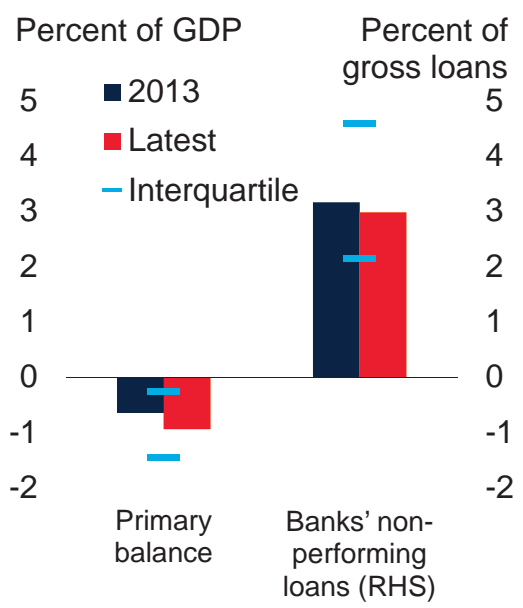

B. External and currency-related vulnerabilities

Percent of GDP Months of imports

Percent of GDP

Percent of
external debt

\section{Percent $\mathbf{\square} 2013 \quad$ Latest $2007 \quad 2013$}

$10-$ Interquartile

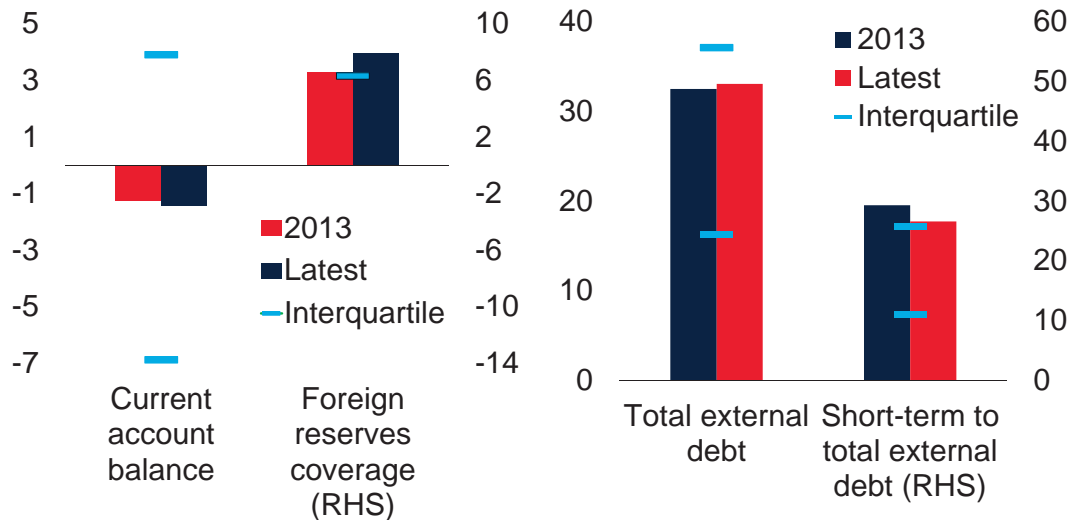

6
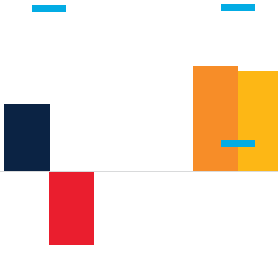

Real effective Foreign exchange rate currency exposure in EFEs (RHS)

Source: BIS, Haver Analytics, World Bank, IMF.

A.B.: The bars stands for the median value of the variables of interest among the selected group of countries listed in Figures 9 , 10, and $12 \mathrm{~A}$. Latest observation is $2014 \mathrm{H} 2$ for private debt and bank's non-performing loans, 2015 estimates for government debt, primary balance, and GDP, 2015 H1 for current account balances, foreign reserves, real effective exchange rate, and inflation, 2014 for total and short term external debt and 2013 for foreign currency exposure (measured as the ratio of total foreign currency deposits in the domestic banking system to total deposits in the domestic banking system). 
Figure 8. Evolution of domestic vulnerabilities in EFEs

Since 2013, GDP growth has slowed in most EFEs. Inflation remains elevated in several of countries. Private debt levels have edged up in EFEs, public debt has increased and primary balances have deteriorated, particularly among commodity exporters. Countries facing bank asset quality problems have seen very little improvement.

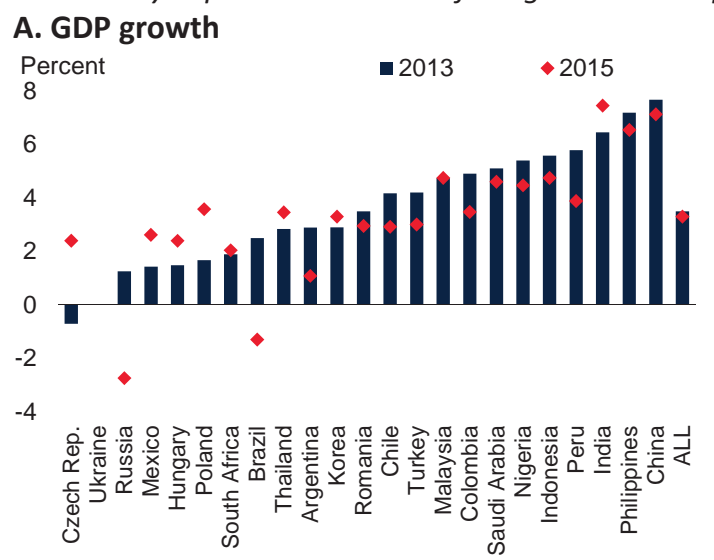

\section{Private debt}

Percent of GDP

200

- 2013H1 Latest 6 months

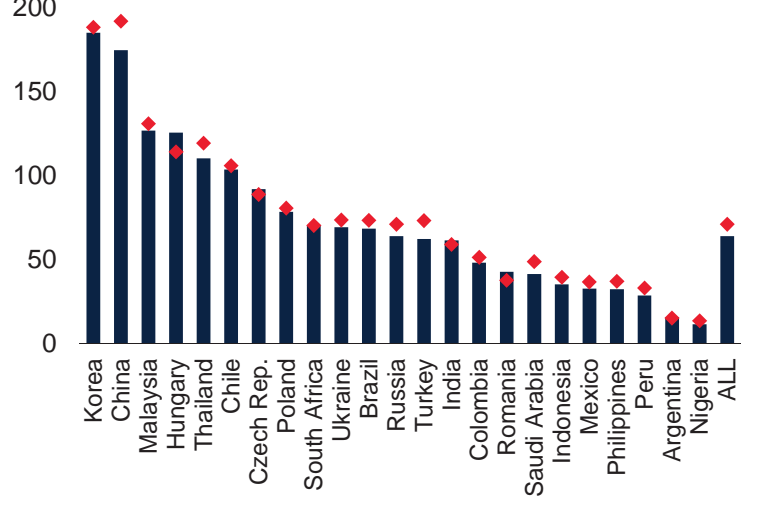

\section{E. Primary balance}

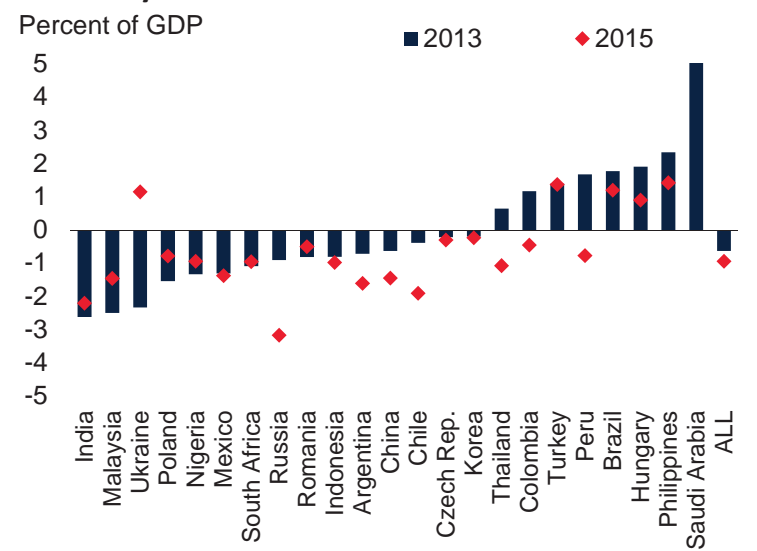

\section{B. Inflation}

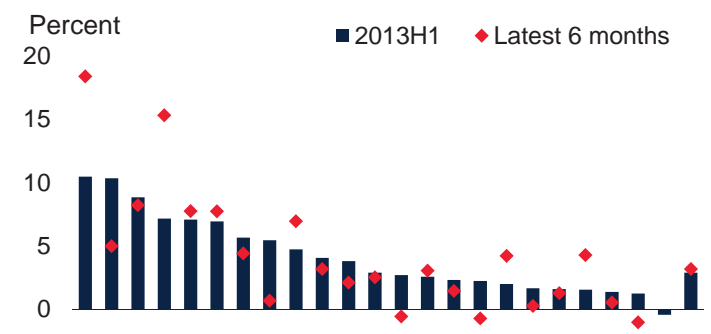

$-5$

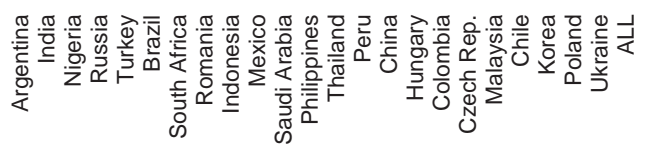

D. General government debt

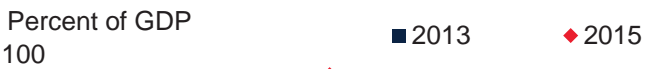

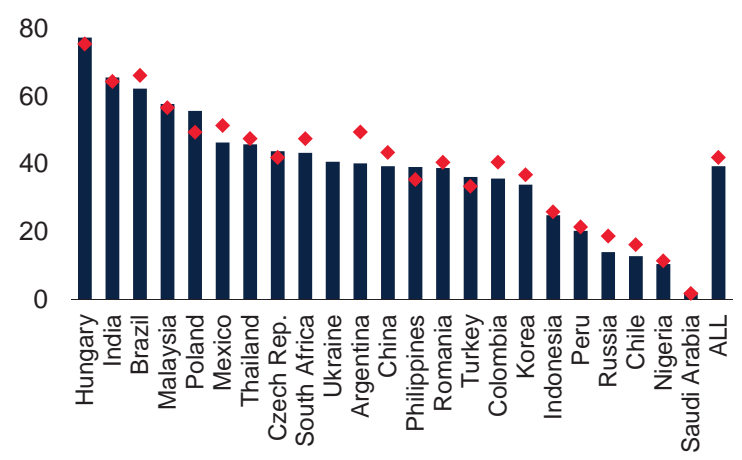

F. Banks' non-performing loans

Percent of total gross loans $-2013 \mathrm{H} 1$ • Lastest 6 months 30

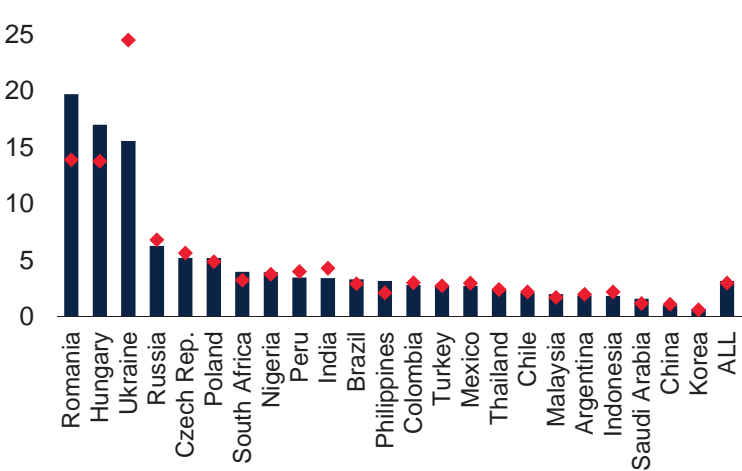

Source: BIS, Haver Analytics, World Bank, IMF. "All" refers to the un-weighted average among all listed countries.

A. Inflation is the 6-month average of the annual average consumer price inflation. Last data: May 2015 for most countries.

B. Private debt is defined as the sum of private non-financial sector debt and household debt. Last data: 2014 Q4.

D. Primary balance excludes net interest payments.

F. Last data: $2014 \mathrm{Q} 4$ for most countries. 
Figure 9. Evolution of external vulnerabilities in EFEs

Current account developments have diverged since 2013, with a few oil importers seeing some improvements, while their reserve coverage increased slightly but largely as a result of lower imports. Countries with high total external debt or short-term external debt have made limited progress in reducing those. Real exchange rate overvaluation has been brought down in several countries, partly due to recent nominal depreciation.

\section{A. Current account}

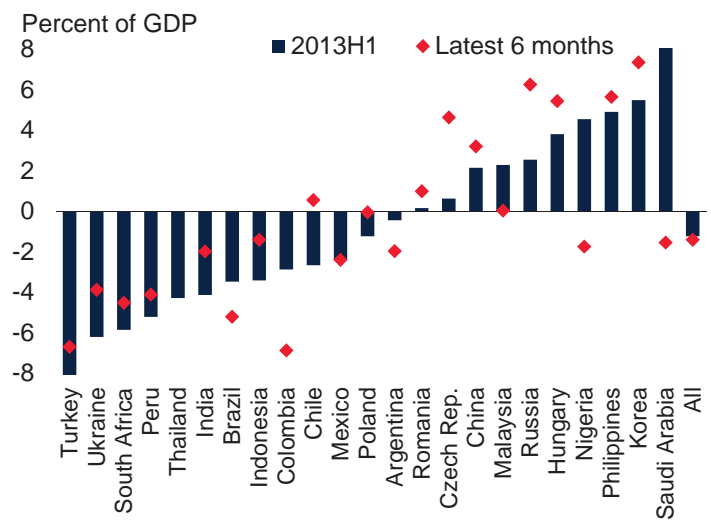

C. Total external debt

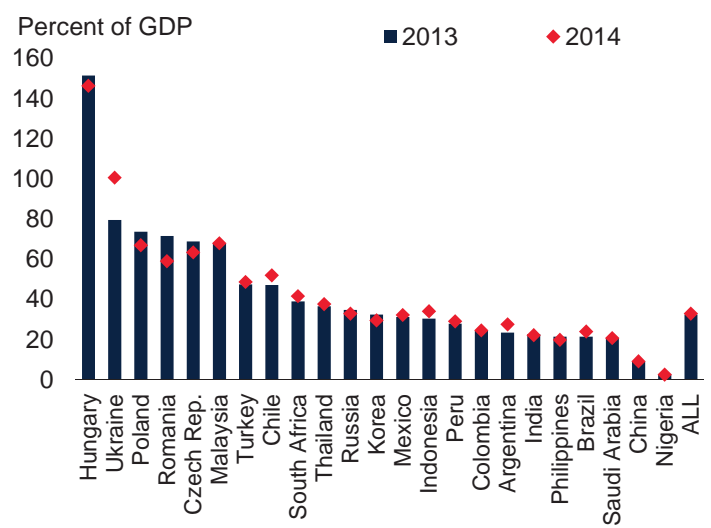

E. Real effective exchange rate

Deviation from 10-year average

Percent $\quad$-2013H1 Latest 6 months

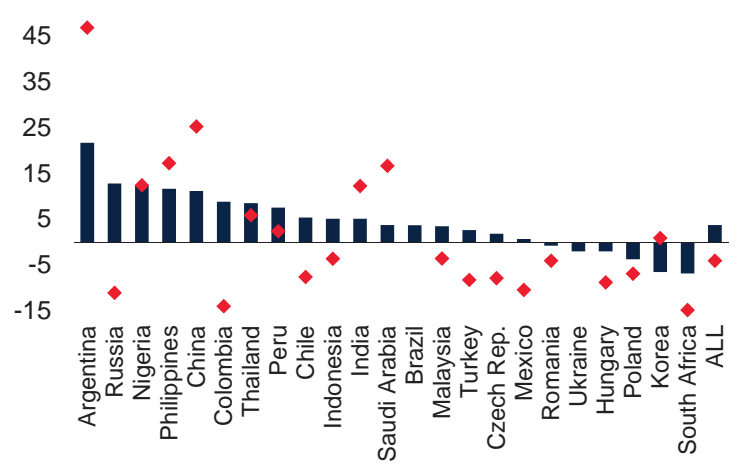

Source: BIS, Haver Analytics, World Bank, IMF.

A. "All" refers to the median among all listed countries. Last data: 2015Q1 for most countries.

B. Foreign reserves include gold. Last data: May 2015 for most countries.

E. Real effective exchange rate is trade-weighted exchange rates that have adjusted for inflation. Last data: August 2015. A decrease denotes a depreciation.

\section{B. Foreign reserve coverage}

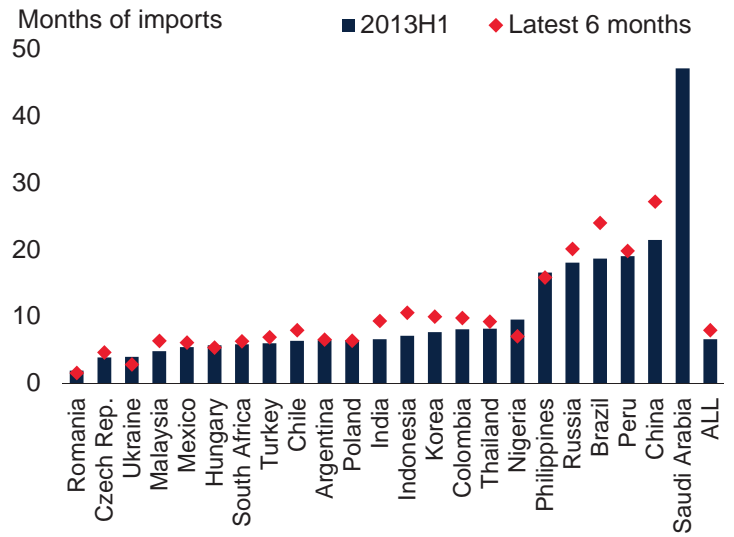

\section{Short-term debt}

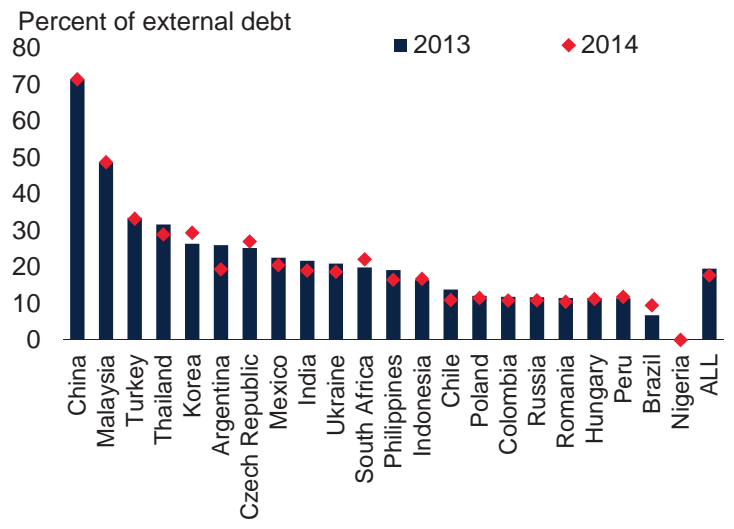


- External vulnerabilities (Figure 9). Relative to the taper tantrum episode, there has been some improvement in current account balances among a number of oil importing economies, although deficits remain elevated for several of them. In addition, foreign reserves have increased, albeit only modestly, for some EFEs; however, they came under pressure in some oilexporting countries in 2015. Some EFEs with elevated levels of total external debt as a percent of GDP or with a high share of short-term external debt have made only limited progress in reducing such burdens. The extent of real exchange rate overvaluation has been reduced in several countries, partly due to nominal depreciation, but still remains high in a few countries.

Despite the general lack of major progress, there are individual countries that have succeeded in reducing some of their vulnerabilities. For example, the Indian rupee and financial markets were severely affected during the taper tantrum, amid macroeconomic conditions that had weakened in prior years and had left them vulnerable to capital outflows (Basu, Eichengreen, and Gupta 2014). The Indian economy has since shown notable improvement, particularly in reducing its high current account deficit and inflation, and undertaking significant reforms.

\section{Implications of U.S. dollar strength for EFEs}

A broad-based appreciation of the U.S. dollar can add significant pressure on EFE currencies, contribute to the cost of debt refinancing and balance sheet pressures, and expose vulnerabilities in domestic banking sectors. Considering the negative correlation between commodity prices and the dollar, this effect could be reinforced by a negative income effect for some exporters (Druck, Magud and Mariscal 2015). In the past, periods of rapid dollar appreciations were sometimes associated with a greater incidence of financial crisis in EFEs, such as during the first half of 1980s in Latin America and second half of the 1990s in Asia (Figure 10). In the latter episode, countries with currencies tightly connected to the dollar experienced a greater proportion of sudden stops and sharper economic downturns (IMF 2015b).

Figure 10. U.S. dollar, financial crises, and recent currency developments in EFEs

Periods of rapid U.S. dollar appreciation were associated with a greater incidence of external crisis in EFEs during the mid-1980s and mid-1990s. A strengthening U.S. dollar since mid-2014 has been reflected in significant currency depreciations in a number of large commodity exporters and countries where uncertainty is elevated.

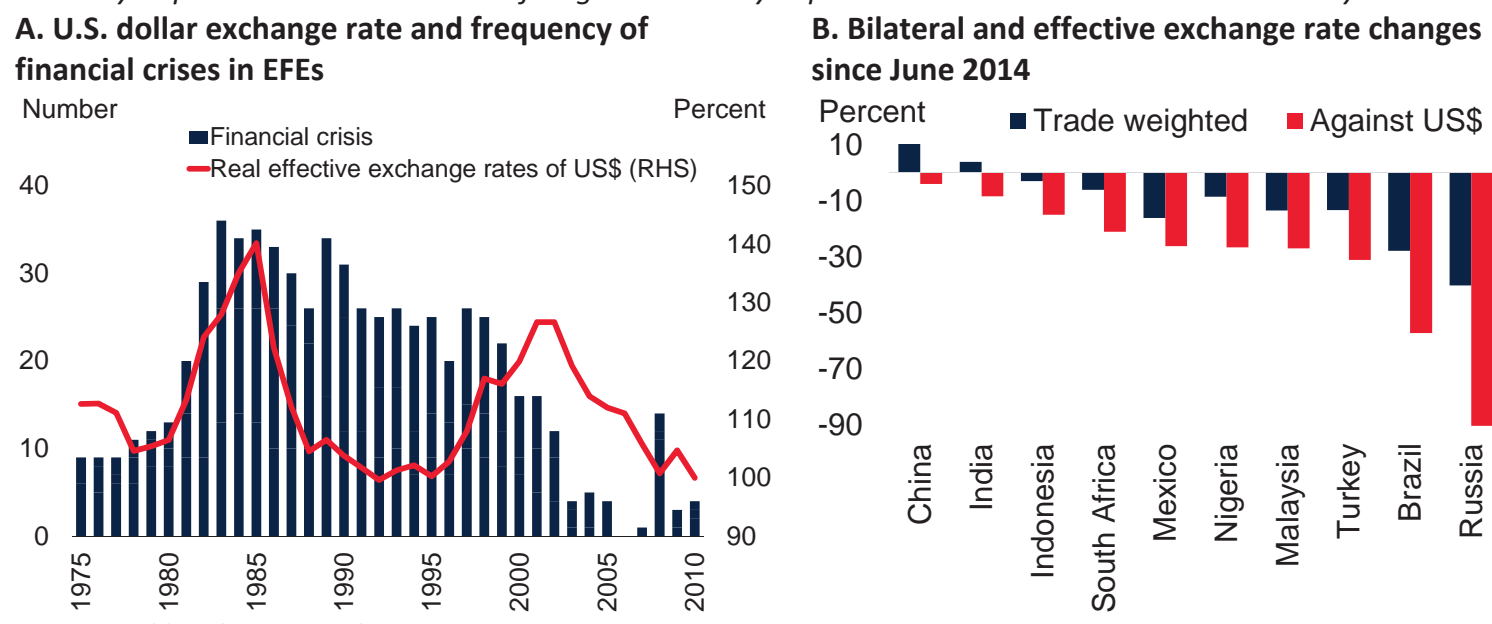

B. Bilateral and effective exchange rate changes since June 2014 financial crises in EFEs

Source: World Bank, Haver Analytics.

A. Frequency of crises refers to number of currency, sovereign debt (domestic or external), and banking crises identified by Escolano, Kolerus, and Ngouana (2014). 
Since the late 1990s, the share of debt denominated in foreign currency and the number of countries with currency regimes tightly linked to the U.S. dollar have declined. However, foreign currency exposures are still elevated in some countries, especially in several commodity exporters and EFEs that have received large capital inflows since the crisis (Figure 11). Given the pre-eminent role of the U.S. dollar as the currency denomination of cross-border debt, a dollar appreciation constitutes in itself a tightening of global financial conditions and could heighten risks associated with liability exposures and dollar shortages (Borio 2014). ${ }^{11}$ This is particularly true for some countries with significant short-term dollar denominated debt, making them more vulnerable to rollover and interest rate risks and a drying up of foreign exchange liquidity (IMF2015b).

\section{Figure 11. Foreign currency exposure and corporate debt in EFEs}

Foreign currency exposures in a number of EFEs and the share of foreign-currency-denominated external debt in some countries remain high, rendering them vulnerable to sharp movements in their currencies. Corporate debt has also increased in many countries.

\section{A. Foreign currency exposure in EFE banking systems}

Percent of banking system deposits

40

-2007-2013 Change 07-13

30

20

10

0

$-10$

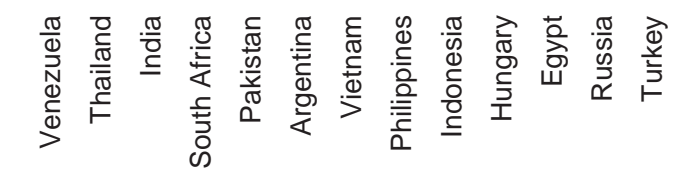

C. Corporate debt of emerging markets

Percent of GDP

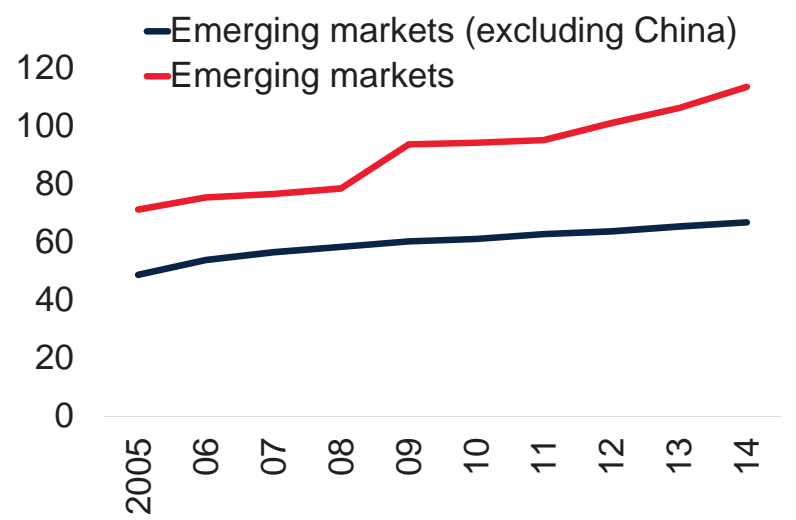

B. Share of foreign currency debt in external debt in EFEs

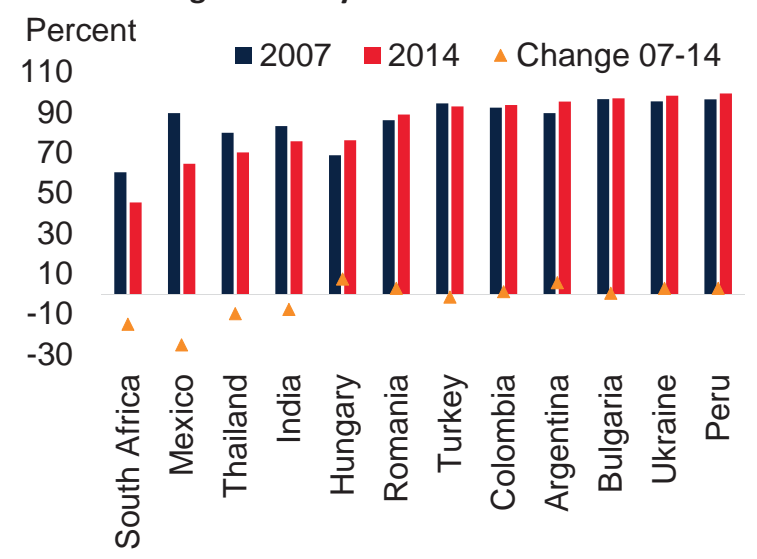

D. Corporate debt of selected emerging countries

Percent of GDP

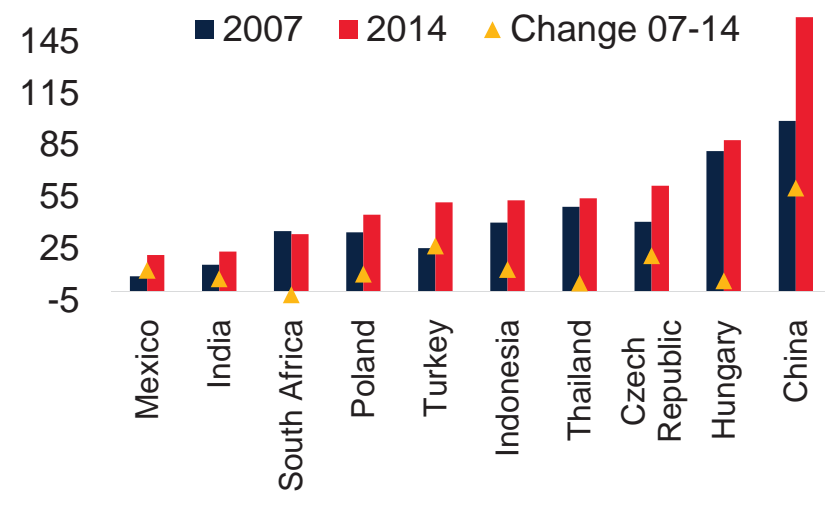

Source: BIS, Moody's, World Bank.

A. Foreign currency exposure is measured as the ratio of total foreign currency deposits in the domestic banking system to total deposits in the domestic banking system. Last available data for 2013.

C. GDP-weighted average. List of emerging markets includes China, Czech Republic, Hungary, India, Indonesia, Mexico, Poland, South Africa, Thailand, and Turkey.

D. The 2007 data of South Africa's corporate debt is not available and thus replaced by $2008 \mathrm{Q} 1$ data.

\footnotetext{
${ }^{11}$ Schularick and Taylor (2012) and Bruno and Shin (2013) highlight how currency developments interact with leverage in building financial vulnerabilities.
} 
Regarding corporate balance sheet exposures, record-low interest rates and access to abundant global liquidity in the post-crisis period have facilitated a significant increase in corporate bond issuance in international markets (Feyen et al. 2015, Lo Duca et al. 2014, McCauley et al. 2015). This has in turn led to a sizable increase in leverage in a growing number of EFEs (Figure 11). The corporate debt build-up is particularly marked in parts of East Asia and Latin America.

While a large number of corporates in some major EFEs, particularly in Asia, were able to issue debt denominated in their own currencies, the U.S. dollar still accounts for the bulk of corporate debt issuance in most countries (Gruić and Wooldridge 2013, Feyen et al. 2015). As a result, private external debt is sizable in several developing countries, especially in Europe and Central Asia. Much of this external debt has been accumulated by corporations exporting commodities or producing tradable goods, which may have foreign currency revenues providing a natural hedge to their external liabilities (BIS 2015). However, such hedging might not be as effective for commodity exporters, as some commodity prices are negatively (and tightly) correlated with the U.S. dollar. Furthermore, hedging in financial markets is effective only insofar as the counterparty selling protection is able to honor the contract-i.e. not vulnerable itself to large currency movements.

A further appreciation of the U.S. dollar could therefore amplify vulnerabilities in some countries, especially those with high levels of dollar-denominated debt as well as commodity exporters, as the effect would compound the impact of deteriorating terms of trade.

\section{HOPES AND RISKS ASSOCIATED WITH THE TIGHTENING CYCLE}

The challenging global environment, as well as weakening growth prospects and lingering vulnerabilities of EFEs suggest that the tightening cycle could lead to difficulties for some countries. However, amid a continued firming in U.S. economic conditions, there are multiple reasons to expect that U.S. monetary policy normalization will not have destabilizing effects in financial markets.

\section{A. A benign normalization scenario: smooth sailing}

If the timing of the liftoff and, more importantly, the subsequent path of policy rates are accurately reflected in market expectations, the normalization of U.S. policy rates amid robust growth prospects for the U.S. economy will be part of a smooth transition for global financial markets. ${ }^{12}$ Barring a sudden acceleration in inflation or an unexpected change in the Fed policy stance, U.S. long term yields should rise only modestly and the U.S. yield curve should flatten slightly. At present, markets predict that U.S. policy interest rates will reach 1.5 percent by the end of 2017, from a target rate of 0.0-0.25 percent before the liftoff, with long-term rates increasing from 2 percent in September 2015 to 2.4 percent over the same horizon.

The onset of previous monetary tightening cycles generally had mild initial repercussions (Figure 12). The U.S. yield curve usually flattened and term premia rose only modestly, if at all, during the first year of the tightening cycle (Adrian, Crump, and Moench 2013a). In 2004, term spreads even narrowed dramatically (dubbed the "conundrum"), partly reflecting ample global liquidity and declining mediumterm inflation expectations. This tightening episode-which, like the upcoming one, also started at very low U.S. policy interest rates-was fairly benign for EFE currencies and capital flows. Even during the

\footnotetext{
12 The Fed has laid out a set of plans that specify a gradualist approach to policy normalization above and beyond the liftoff of policy rates. (Board of Governors of the Federal Reserve System 2014; Williamson 2015).
} 
steep 1994 tightening cycle, term spreads declined, while they widened only temporarily in 1999, when the tightening cycle was accompanied by a particularly strong recovery. ${ }^{13}$

\section{Figure 12. Policy rates and bond yields around previous tightening cycles}

If the beginning of the tightening cycle proceeds smoothly, as expected, the yield curve could flatten and the term spread narrow further, as happened in some past episodes of first rate hikes in U.S. tightening cycles. In this context, U.S. long term interest rates would only rise slowly from currency low levels.

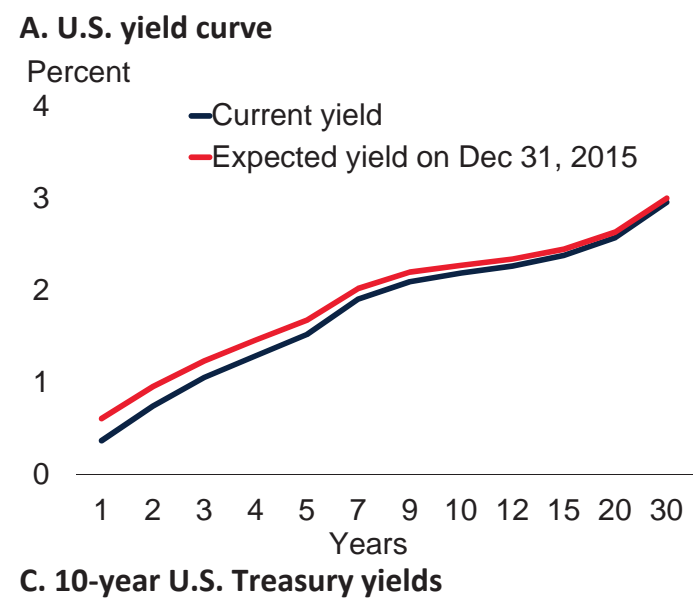

Percentage points; deviations from $\mathrm{t}=0$ )

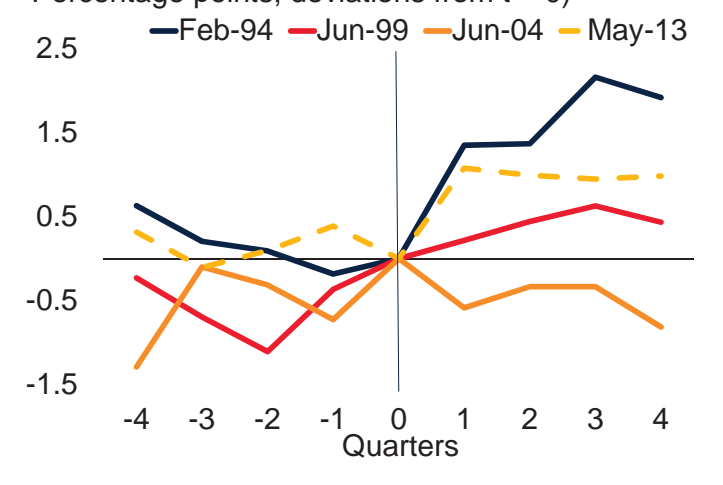

\section{B. Federal funds rate}

Percentage points; deviations from $\mathrm{t}=0$

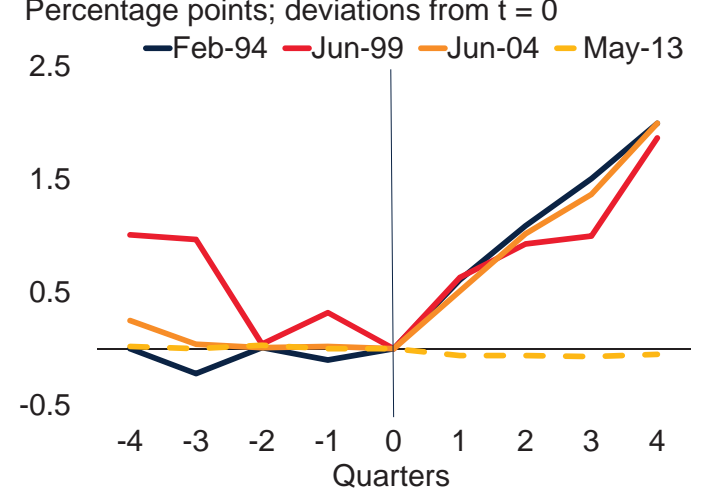

D. U.S. term spreads around previous U.S. tightening cycles

Basis points; deviations from $\mathrm{t}=0$

B.C.D. The $\mathrm{x}$-axis shows the number of quarters before and after the start of previous tightening cycles, $\mathrm{t}=0$ is February 1994 , June 1999 , June 2004, and May 2013

D. Term spread denotes the difference between 10-year U.S. Treasury and 6-month T-bill yields.

In principle, a fully anticipated normalization of U.S. policy rates should not trigger volatility in global financial markets, or lead to large depreciations in EFE currencies and sharp reversals in EFE capital flows. In particular, if the upcoming tightening cycle proceeds as in the 1999 and 2004 episodes, exchange rates in EFEs would depreciate mildly, EFE bond indexes would not face stress, and capital flows to EFEs would be impacted minimally (Figure 13).

\footnotetext{
13 More generally speaking, the assumption of a slight flattening of the yield curve is predicated on continued global demand for long-dated U.S. government bonds.
} 
The global bond market turmoil and reversal of EFE portfolio flows following an unexpectedly sharp tightening in 1994 stands as an exception in this regard. Unlike previous episodes, the 1994 episode was followed by a sharp sell-off in global financial markets. While the Fed had already been hinting at potential rate hikes for some time, the scale and pace of the monetary tightening caught markets offguard with bond investors taking large losses. In February 1994, the Fed started a tightening cycle, and it doubled the federal fund rates to 6 percent during the following 12 months in the course of seven consecutive rate hikes. Ten-year U.S. yields rose more than 250 basis points, peaking at 8 percent in November 1994, but declined thereafter as inflation expectations stabilized. The spillover effects of the 1994 episode was broad-based and caused a widening of emerging-market sovereign bond spreads from 405 basis points at end-1993 to 800 basis points by mid-December 1994, before the onset of the Mexican crisis.

\section{Figure 13. Adjustments in EFEs around previous tightening cycles}

Should the beginning of the tightening cycle proceed as during the 1999 and 2004 rate hikes, exchange rates in EFEs would experience mild depreciation, bond market conditions would loosen, and capital flows would be impacted minimally. A rapid tightening cycle, as in 1994, would lead to a more pronounced depreciation of EFE currencies, greater bond market stress, and capital flow declines. Adjustments similar to the taper tantrum could result in an even more abrupt fall in capital flows, particularly portfolio flows.

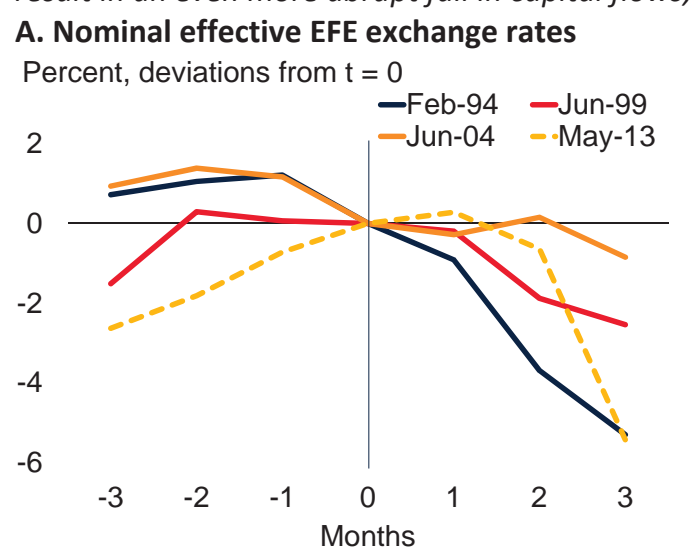

\section{Capital inflows to EFEs}

Net capital inflows to EFEs, excluding China ( $\$$ billion; deviations from $\mathrm{t}=0$ )
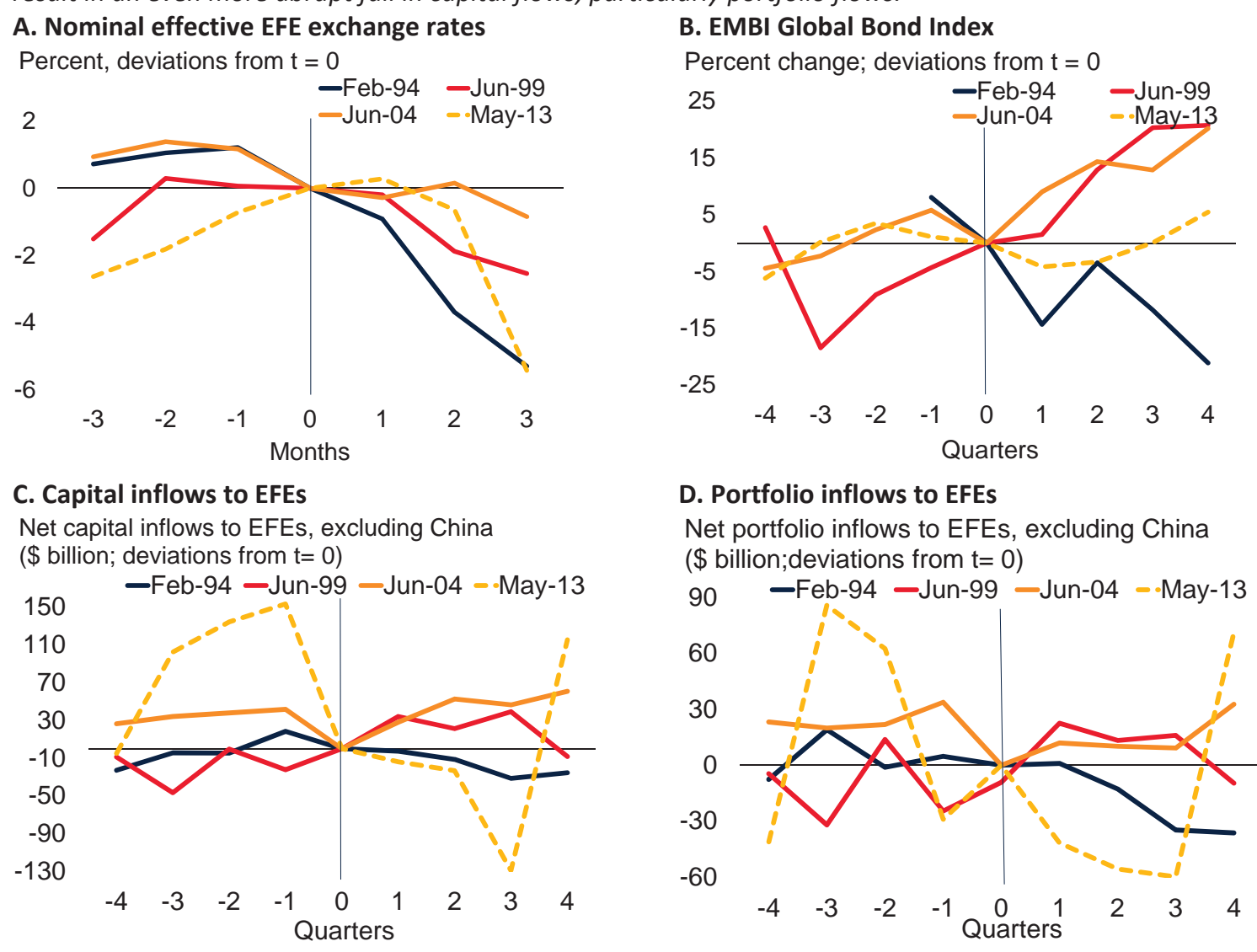

\section{Portfolio inflows to EFEs}

Net portfolio inflows to EFEs, excluding China ( $\$$ billion; deviations from $\mathrm{t}=0$ )

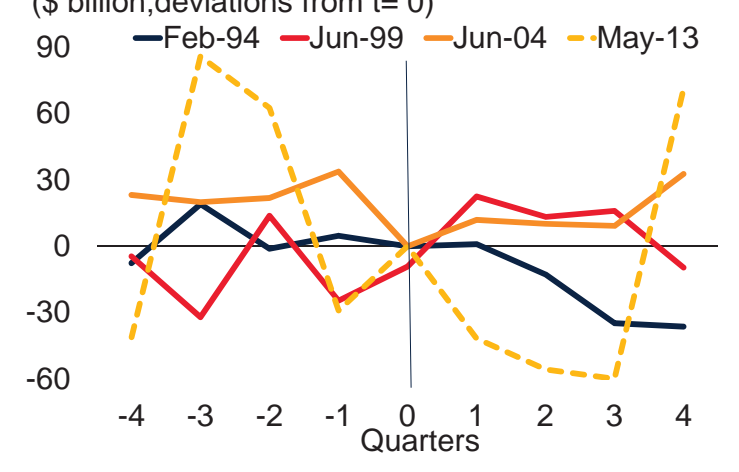

Source: IMF, Haver Analytics, Bloomberg, Federal Reserve Bank of New York, World Bank

A. A decline denotes a depreciation of the nominal effective exchange rate. The $x$-axis shows the number of monhts before and after $t=0$, where $t=0$ is February 1994, June 1999, June 2004, and May 2013.

B. An increase in the index indicates declining yields and easing financial conditions.

B.C.D. The $x$-axis shows the number of quarters before and after $t=0$, where $t=0$ is February 1994, June 1999, June 2004, and May 2013. 


\section{Figure 14. Global economic conditions around previous tightening cycles}

Compared with previous tightening cycles, nominal and real U.S. policy rates are starting from lower levels and growth is generally weaker. Core inflation and unemployment rates are broadly similar to those prevailing before the 2004 liftoff. In 1999, inflation was also low but growth stronger, labor market conditions tighter and real interest rates significantly higher than today. The 1994 tightening cycle stands out with rising inflation leading to steep interest rate hikes despite relatively modest growth. In other advanced economies, growth is currently weaker and inflation lower than during previous episodes, with the exception of 1994. EFE growth and inflation rates are also lower than in the past, barring 1999, which followed the Asian and Russia debt crisis.

\section{A. United States}

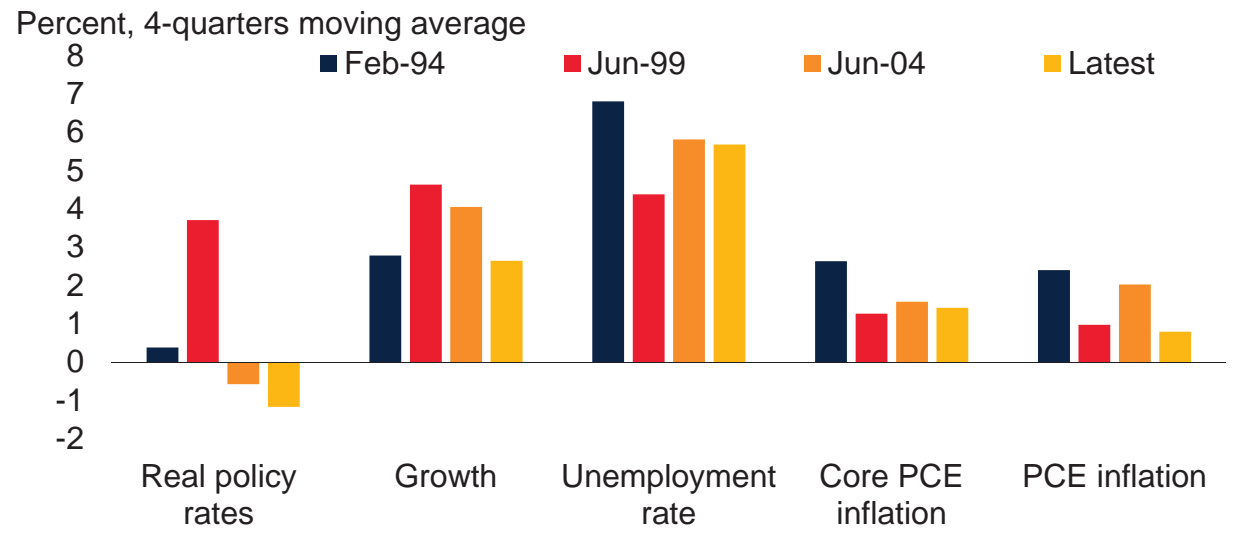

\section{B. Other advanced economies}

Percent, 4-quarters moving average

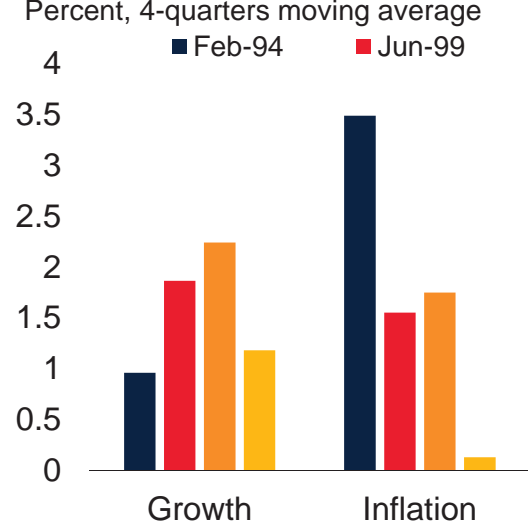

\section{Emerging and frontier market economies}

Percent, 4-quarters moving average

\section{World}

Percent, 4-quarters moving average

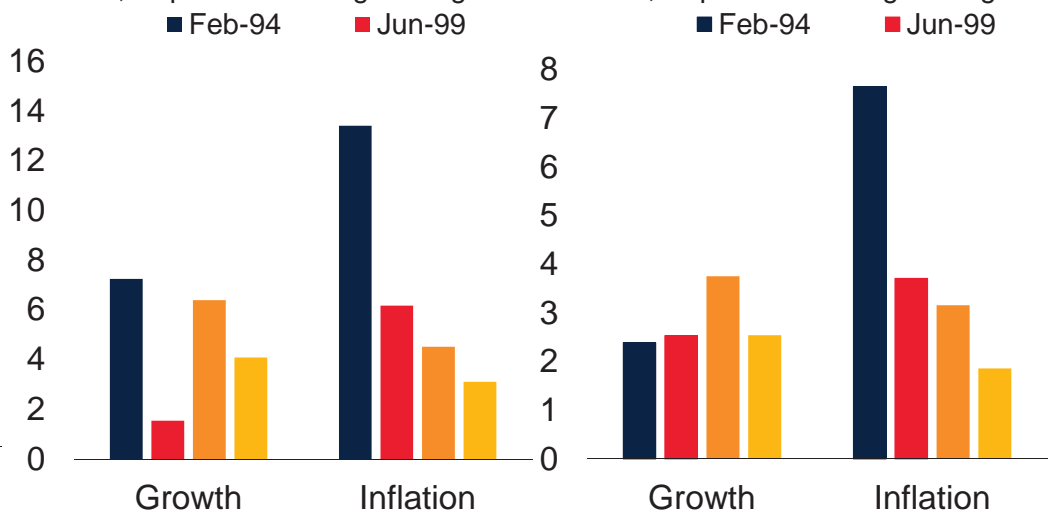

Source: World Bank and Haver Analytics

B. C. and D: inflation measured as median across countries.

While previous episodes suggest, in general, a largely benign baseline scenario for the upcoming tightening cycle, such episodes took place under different conditions in the United States, in other advanced economies, and in EFEs (Figure 14). This time, U.S. policy rates will begin to gradually raise from a much lower base than that of previous episodes. In addition, while U.S. growth is gathering momentum, it is nevertheless weaker than in previous episodes, while unemployment and core inflation are fairly similar, particularly to the 2004 episode. Again, the period leading up to the 1994 hikes stands out, as it was characterized by soft U.S. growth and somewhat higher unemployment, but rising inflation. In other advanced economies, inflation is significantly lower and growth is weaker than in 
previous episodes, with the exception of 1994. EFE inflation is also significantly lower and growth is weaker now than in 1994 and 2004, but stronger than in 1999, which followed the Asian and Russia debt crisis. In sum, even if past episodes suggest a benign scenario, conditions around these episodes are generally different from the current context, which suggest that the upcoming tightening cycle could have unanticipated consequences that may greatly differ from the historical record. Even if the pace of tightening is gradual amid low U.S. inflation, the challenging global environment could result in a less favorable outcome for EFEs than in the past. ${ }^{14}$

\section{B. Risks associated with the tightening cycle}

While a benign scenario remains likely, the upcoming tightening cycle carry significant risks, with potentially important implications for EFEs. The taper tantrum is a reminder that even an event long anticipated by markets can generate spikes in U.S. long-term yields, significant financial market volatility, and shifts in capital flows to EFEs. Current low U.S. long-term interest rates may be vulnerable to a sharp increase around the liftoff or subsequent tightening cycle. This could be triggered by changing market expectations regarding the state of the economy or the course of Fed policies.

Given the perception that the cost of hiking too soon could potentially surpass that of hiking too late (IMF 2015c), markets have so far taken the view that the interest rates will increase slowly in the short term and stabilize at a lower level over the medium term. However, new data, or unanticipated changes in Fed communication, could shift expectations. For instance, signs of accelerating wage growth, amid sluggish productivity and a continued decline in labor force participation, may lead market participants to anticipate a faster normalization of policy rates in the short term and to request higher compensation for inflation risks over the medium-term (Abrahams et al 2015).

Even incremental changes in the data could lead to significant increases in long-term interest rates, considering in particular that: (i) there remains significant uncertainty about the strength of the U.S. recovery; (ii) the U.S. term premium is exceptionally low; (iii) expectations about the future path policy rates diverge between market participants and Federal Open Market Committee (FOMC) members; and (iv) market liquidity conditions are fragile.

- Uncertainty about the strength of the U.S. economy. There is notable uncertainty about the underlying strength of the U.S. economy and the amount of slack still remaining in the labor market. This creates ambiguity about how far the Fed actually is from achieving its dual objectives of maximum employment and 2 percent inflation, and where policy interest rates are likely to stabilize over the medium term. In particular, the underlying pace of productivity growth (Gordon 2014, Hall 2014, Fernald and Wang 2015) and labor participation (Aaronson et al. 2014, Council of Economic Advisers 2014) remains unusually low (Figure 15). Whether these trends will partially reverse as economic conditions improve, or become entrenched, will have important implications for the assessment of potential output and for the trajectory of the tightening cycle (Reifschneider, Wascher and Wilcox 2015). The prevailing uncertainty is illustrated by the significant dispersion of output gap estimates derived from different methods (Figure 15). Thus, there is an upside risk that actual growth performance is consistent with the greater role of positive real shocks discussed earlier, suggesting continued strength. There is also a downside risks that the amount of slack is lower than expected, leading to inflation pressures and a faster-than-expected pace of tightening.

\footnotetext{
14 The fact that some previous tightening episodes took place after some major EME financial crises (e.g. in Asia or Russia) further clouds direct comparisons with the current context.
} 


\section{Figure 15. Slack in the U.S. economy}

There is considerable uncertainty on supply-side constraints to U.S. growth and the amount of slack still remaining in the labor market, even if it has declined. In particular, the underlying pace of productivity growth and labor participation remains unusually low. The prevailing uncertainty is illustrated by the significant dispersion in output gap estimates derived from different methods.

\section{A. Labor force participation and productivity \\ B. Output gap estimates \\ growth}

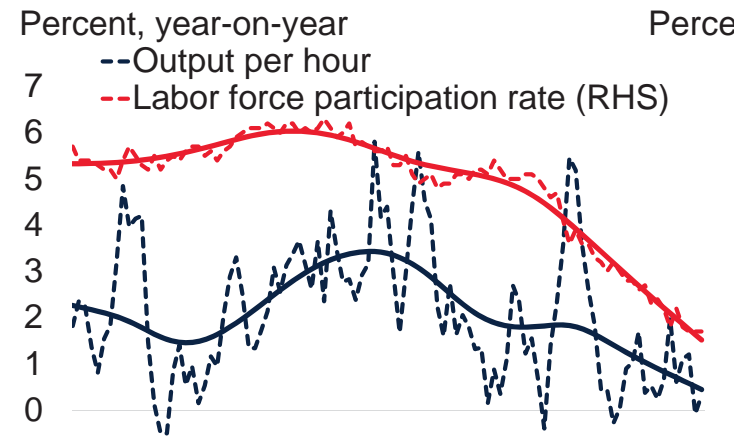

$-1$

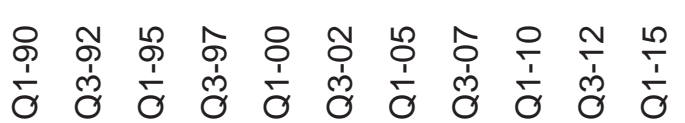

$\begin{array}{ll} & \text { Percentage point } \\ 68 & 3 \\ 67 & 2 \\ 66 & 1 \\ 65 & 0 \\ 64 & 0 \\ 63 & -1 \\ 62 & -2 \\ 61 & -3\end{array}$

- Range $\bullet$ Median 60

Source: Haver Analytics, Federal Reserve Bank of San Francisco, World Bank, Weidner and Williams (2015)

A. Productivity growth is measured as annual change in real output per hour worked of all persons in the non-farm business sector. The civilian labor force participation rate is the ratio of people either employed or actively looking for work to the active age population. The thick lines show the trend measured by a Hodrick-Prescott filter.

B. Range of U.S. output gap estimates compiled by Weidner and Williams (2015), including two Congressional Budget Office estimates (output and unemployment-based), business, household and labor market survey-based estimates and Phillips curve estimates.

- Low term premium. Long-term interest rates can be broken down into expectations about the future path of real policy interest rates, inflation expectations, and a term premium. The term premium is the extra return required by investors to hold a longer-term bond instead of reinvesting in successive short-term securities, and is positive under normal circumstances. The term premium generally reflects compensation for perceived macroeconomic and financial risks, which could increase, for instance, when the level of disagreement about future inflation among forecasters rises or when implied volatility in U.S. Treasury markets increases (Abrahams et al. 2015). Previous monetary policy surprises and the Fed's large-scale asset purchases have been important drivers of U.S. term premia in recent years. Currently, the term premium in the United States is exceptionally compressed (Figure 16). The compression partly reflects a modest assessment of inflation risks and strong global demand for U.S. Treasuries as safe assets. ${ }^{15}$ This has been reinforced by low interest rates for assets denominated in other reserve currencies, which in part resulted from quantitative easing programs by other major central banks (Bernanke 2015). Inherent in the current low term premium is the risk of a sudden widening, with greater uncertainty potentially leading to a surge in long-term yields (Yellen 2015c).

- Gap between market and FOMC expectations. Since 2014, expectations for the path of future policy rates among market participants have been considerably below those of members of the FOMC (Figure 16). The gap currently exceeds 100 basis points in 2017 and beyond. This reflects in particular the uncertainty surrounding the so-called natural rate of interest, that is, the level of the real federal funds rate expected to prevail after all transitory shocks have played out and

\footnotetext{
15 See Williams (2015); Abrahams et al. (2015); Blanchard, Furceri, and Pescatori (2014); and Caballero and Farhi (2014) for details on these observations.
} 
the economy stabilize at its potential (Williams 2015; Hamilton et al. 2015; Dupor 2015). At present, market participants appear to expect this equilibrium rate to remain low for a considerable period of time while FOMC members foresee a gradual rise in coming years, as post-crisis legacies and uncertainties unwind (Yellen 2015a). This gap in medium-term expectations could suddenly close, should markets conclude that the underlying performance of the U.S. economy is improving as anticipated by the FOMC. New data might also lead the FOMC to revise downwards its projections, more in line with current market expectations.

- Fragile market liquidity. Several factors make liquidity conditions more fragile than before the global financial crisis, even in deep sovereign bond markets in advanced countries. The volume of primary dealer trading - which typically smoothes liquidity over fluctuations in other market participants' demand and supply-has fallen since mid-2014 relative to outstanding treasury bonds (Figure 17). Banks' dealer inventories and market-making activities have declined due to changing business models, diminished bank risk appetite, and tighter regulatory requirements for liquidity and other buffers (IMF 2015; Committee on the Global Financial System 2014). In particular, non-risk-based leverage and liquidity rules, while making banks safer, have reduced their propensity to trade in low risk/low return areas such as secured financing, or to provide liquidity to clients. As a result, the role of less-regulated, non-bank market intermediaries has increased since the global financial crisis (Blume and Keim 2012; Fender and Lewrick 2015). Traditionally less volatile, long-term focused institutional investors such as pension and insurance funds may also have become more procyclical in their behavior. ${ }^{16}$ While the composition and behavior of sovereign debt holders has changed, their overall share in total debt holdings has declined from pre-crisis levels as central banks' holdings of sovereign bonds increased with quantitative easing programs. During episodes of financial stress, fragile liquidity conditions could be accompanied by larger and longer price dislocations. This could amplify the impact of the initial shock on prices and facilitate its propagation to other market segments.

Apart from the possibility of broad-based market volatility, the risks around the upcoming rate increases differ in their specifics from those that materialized during the taper tantrum. In particular, taper talk signaled a tightening that directly affected long term rates, because it related to Fed purchases of longterm debt securities. In contrast, the initial phase of the upcoming tightening would be a move affecting current and expected policy rates, with indirect upward pressure on long-term yields.

Another key difference is that the mid-2013 taper talk was unexpected (even if eventual tapering was not). In contrast, the intention by the Fed to begin to tighten policy rates soon has been signaled well in advance, even though there is uncertainty about the particular FOMC meeting when policy rates will first be increased. The main risk for EFEs does not stem from the first rate increase; instead, it is the pace of subsequent rate increases, which is currently expected to be very gradual, but could be faster than anticipated for the reasons outlined above. In other words, the timing of the liftoff is less important that the contour of the upcoming monetary policy tightening. ${ }^{17}$

\footnotetext{
16 During the taper tantrum, market liquidity deteriorated quickly in U.S. Treasury markets, as primary dealers reduced their inventories at a time when interest rate risks were re-priced more generally (Adrian et al. 2013). Liquidity strains spread rapidly across markets, leading to particularly large adjustments in emerging market asset prices (García-Luna and van Rixtel 2013). Portfolio outflows were concentrated in the most liquid emerging markets (Eichengreen and Gupta 2014) and were largely driven by retail investors. In 2013, institutional investors generally maintained their exposures (World Bank 2014b). However, institutional investors have begun to act less countercyclically and, under acute and persistent market stress, could contribute to a "rush to the exit" (IMF 2014a; Bank of England and Procyclicality Working Group 2014; Opazo, Raddatz and Schmukler 2014; Raddatz and Schmukler 2012). Through their hedging activities, they can also add to exchange rate pressures (IMF 2013). 17 Should EFE financial stress ensue during the tightening cycle, there is evidence suggesting that lower uncertainty and greater anticipation by investors may also lead to less pronounced contagion effects among EFEs (Didier, Mauro, and Schmukler 2008).
} 


\section{Figure 16. Term premia and policy rate expectations}

There is a risk of a spike in long-term interest rates, especially since term premia are well below their historical average and market expectations of future interest rates are below those of members of the Federal Open Market Committee (FOMC). The gap in policy rate expectations, which remains significant over the medium-term, reflects uncertainty surrounding the equilibrium level of policy interest rates in the post-crisis period. FOMC projections appear consistent with a gradual rise in this equilibrium rate from current low levels, while markets expect it to stay low for a considerable period of time. This expectation gap combined with low term premia imply the risk of sudden adjustments in long term yields.

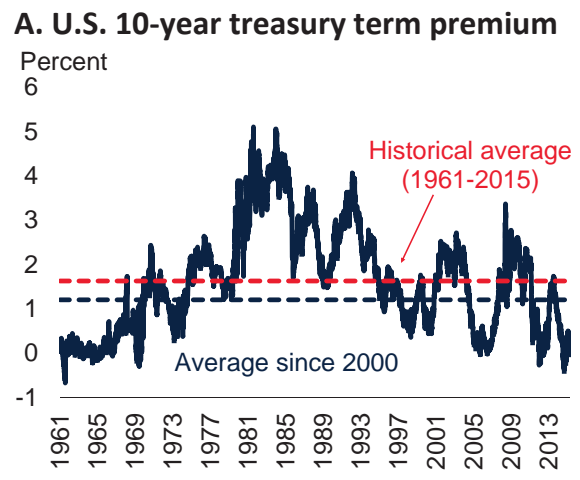

C. Gap between FOMC and market expectations over time

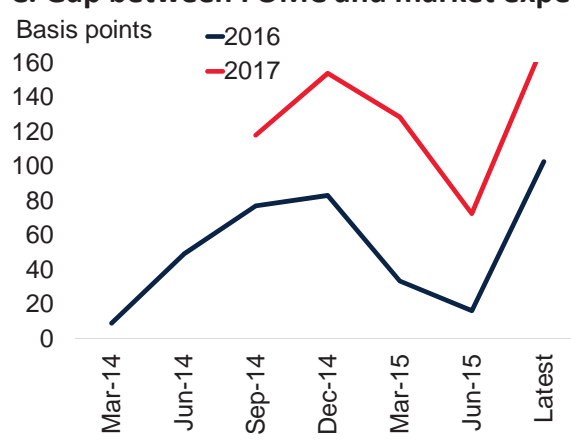

E. Different measures of the natural rate of interest Percent, 2014Q4

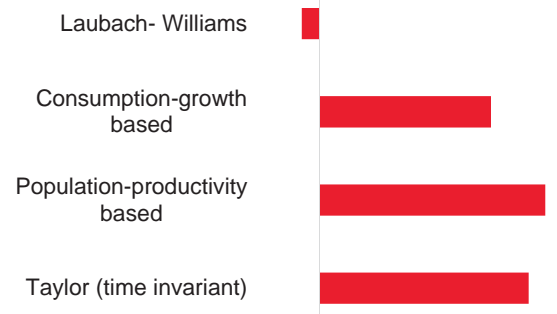

$\begin{array}{lllllll}-0.5 & 0 & 0.5 & 1 & 1.5 & 2 & 2.5\end{array}$

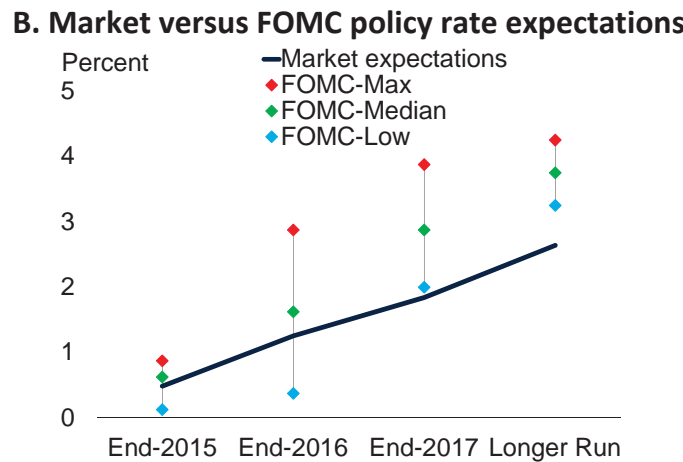

D. U.S. natural rate of interest

Percent
7
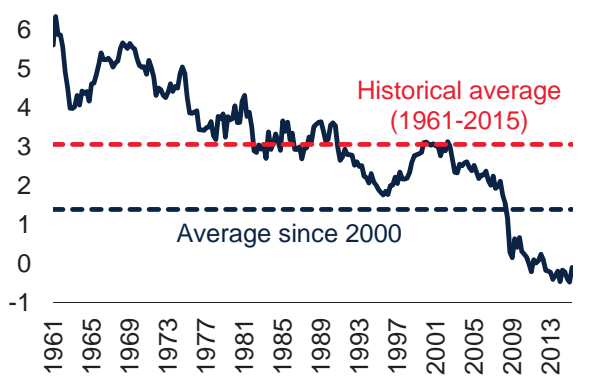

F. Decomposition of FOMC policy rate expectations

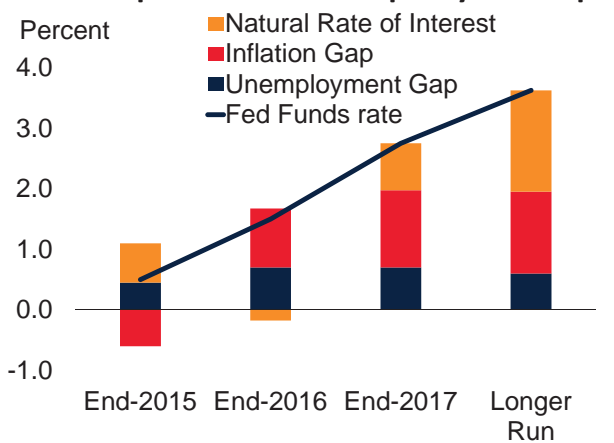

Source: Haver Analytics, Bloomberg, Laubach and Williams (2003), U.S. Fed FOMC, Yellen (2015b), Dupor (2015).

A.Term premium estimates are obtained from the model described in Adrian, Crump, and Moench (2013b). This model characterizes yields as linear functions of a set of pricing factors. It imposes no-arbitrage restrictions which ensure that the time series and cross-section of bond yields are consistent with one another. Last observation: August 202015.

D. The natural rate of interest is the real federal funds rate level which should stabilzie activity around potential output over the medium term. Estimates are derived from the baseline model described in Laubach and Williams (2003).

F. Using the Taylor rule described in Yellen (2015b) and the central tendency of FOMC forecasts for unemployment and inflation, FOMC projections for the federal funds rate path can be decomposed into the expected contribution from future labor market improvements, rising inflation and the natural rate of interest. More specifically, the Taylor Rule is defined as $R=R R^{*}+p+0.5(p-2)-\left(U-U^{*}\right)$, where $R$ denotes the Taylor Rule federal funds rate, $R R^{*}$ is the estimated value of the natural rate of interest, $p$ is the current inflation rate (measured as PCE inflation), $\mathrm{U}$ is the unemployment rate and $\mathrm{U}^{*}$ is the natural rate of unemployment (considered to be the long run FOMC forecast for the unemployment rate). 


\section{Figure 17. Market liquidity conditions}

With shrinking primary dealer transactions, U.S. Treasury market liquidity conditions have become more fragile since 2013. Shocks can hence trigger sharp volatility, especially in "illiquid" markets. At the height of the Euro Area crisis and during the taper tantrum, liquidity in some emerging bond markets dropped off sharply, as reflected in rising bid-ask spreads.

\section{A. Primary dealer Treasury transactions}

US\$, billions/unit

10

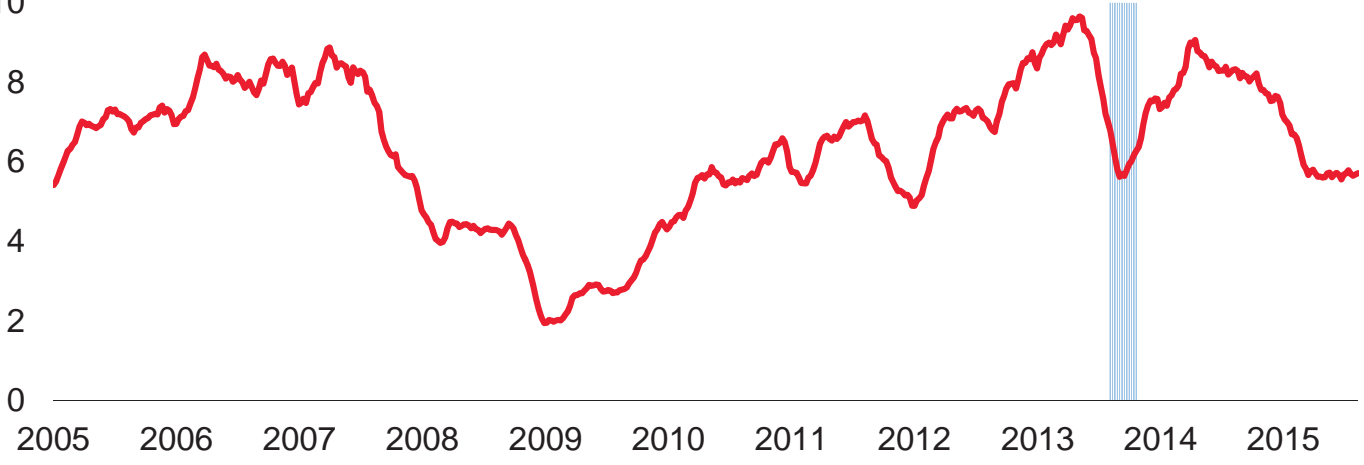

\section{B. Bid-ask spread on emerging market foreign currency bonds}

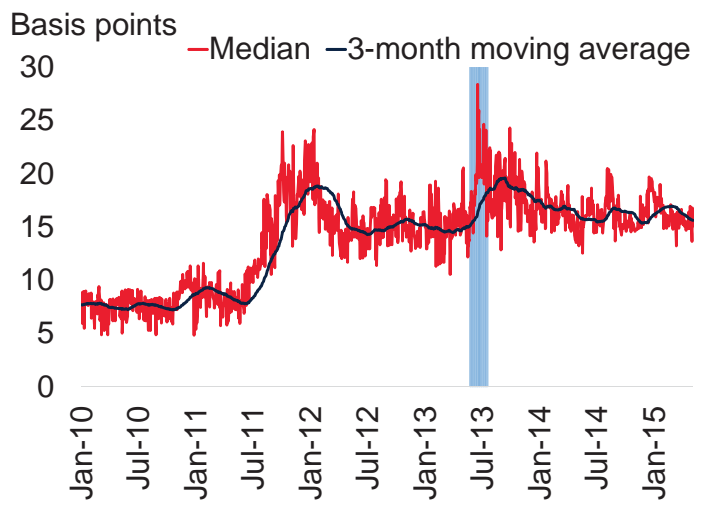

\section{Bid-ask spread on emerging market local currency bonds}

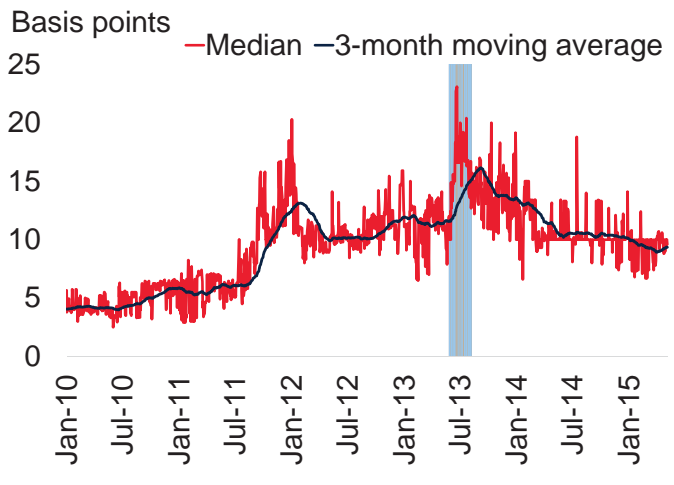

Source: Federal Reserve Bank of New York, Bloomberg, World Bank. Note: Blue bars show the taper tantrum of May-June 2013.

A. Line shows primary dealer Treasury transactions divided by the Merrill Option Volatility Estimate (MOVE index) (12-week moving average). Merrill Option Volatility Estimate (MOVE) is a yield curve weighted index of the normalized implied volatility on 1-month Treasury options. Last observation: July 2015.

B. C. List of countries included Brazil, Chile, Colombia, Hungary, Indonesia, Korea, Rep., Lithuania, Philippines, Poland, Romania, Turkey, and South Africa. Median bid-ask spreads on 10-year government bonds. Last observation: May 2015.

\section{Impact on EFE real and financial activity}

The impact of increasing U.S. yields on EFEs depends on the trigger of the increase. Rising U.S. yields that reflect a strengthening U.S. economy would likely be associated with stronger growth in EFEs, as the positive growth spillovers would offset the effects of higher borrowing costs. In contrast, rising U.S. yields that purely reflect a perception of accelerated monetary tightening would likely be accompanied 
by deteriorating activity and tighter financial conditions and, hence, with financial market volatility in, and capital outflows from, EFEs.

A panel VAR model was estimated to examine the diverging impacts of different types of U.S. shocks on activity and financial markets in EFEs (see Box 1 for technical details). Activity indicators (industrial production) and financial market indicators (stock prices, nominal effective exchange rates, long-term bond yields) for EFEs are regressed on the monetary and real shocks identified in the econometric exercise in Section II. As expected, the results suggest that a U.S. yield increase triggered by a favorable real shock has a considerably more benign impact on EFEs than one resulting from an adverse monetary shock (Figure 18).

An adverse U.S. monetary shock that leads to an immediate change in EFE long term yields by 100 basis points also results in a decline in EFE industrial production by 0.1 percent over a 12 -month horizon. In

\section{Figure 18. Impact of U.S. shocks on activity and financial markets in EFEs}

U.S. bond yield hikes caused by favorable U.S. real shocks should have more benign effects on EFEs than those caused by adverse U.S. monetary shocks. U.S. bond yield jumps associated with benign real shocks tend to raise EFE equity prices and production and appreciate their currencies. Those caused by adverse U.S. monetary shocks tend to raise EFE bond yields, reduce equity prices, and depreciate their currencies.
A. EFE Bond Yield

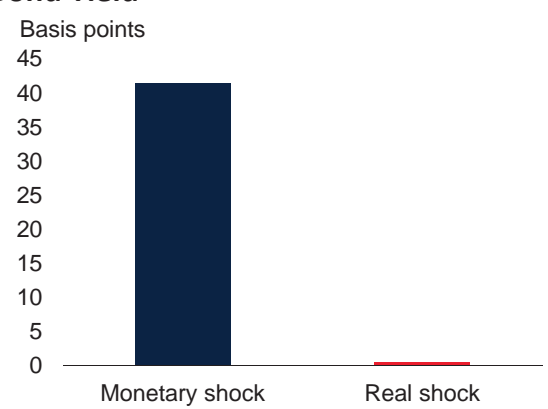
B. EFE Stock Price
Percent change
4.0

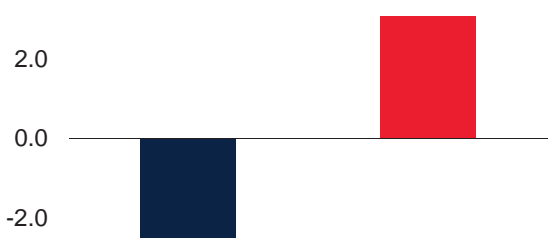
$-4.0$
Monetary shock Real shock
C. EFE Nominal Effective Exchange Rate
Percent change
0.8
D. EFE Industrial Production
Percent change
1.2

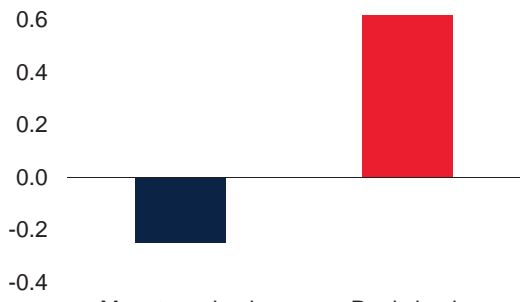
1.0
0.8
0.6
0.4
0.2
0.0
$-0.2$
Monetary shock Real shock
Monetary shock Real shock

Source: Haver, Bloomberg, World Bank estimates.

Note: Impulse responses after 12 months from a panel VAR model including EFE industrial production, long-term bond yields, stock prices, nominal effective exchange rates and bilateral exchange rates against the U.S. dollar, and inflation, with monetary and real shocks (estimated as in the previous section) as exogenous regressors. All data are monthly or monthly averages of daily data, for January 2013-Sep 2015 for 23 EFEs. For comparability, the size of the U.S. real and monetary shocks is normalized such that each shock raises EFE bond yields by 100 basis points on impact. List of countries is: Brazil, Chile, China, Colombia, Czech Republic, Egypt, Arab Rep., Hungary, India, Indonesia, Korea, Malaysia, Mexico, Pakistan, Peru, Philippines, Poland, Romania, Russian Federation, South Africa, Thailand, Turkey, Ukraine, and Venezuela, RB.

A. Bond yields refer to the yields on 10-year (or nearest equivalent) government treasury bonds.

C. An increase denotes an appreciation. GDP-weighted average of EFE exchange rates. 


\section{Box 1. Econometric analysis of U.S. yields and spillovers}

This box briefly describes the main features of the three econometric models used to analyze the role of monetary and real shocks in explaining movements in U.S. yields, the spillovers of such shocks for emerging and frontier market economies (EFES), and the impact of a sudden increase in U.S. yields on capital flows to EFEs.

\section{Contribution of monetary and real shocks to U.S. long-term yields}

To analyze the drivers of moves in U.S. yields, the first econometric model uses a structural vector autoregression (SVAR) framework with sign restrictions to decompose daily movements in yields during January 2013-September 2015 into two components: one reflecting real U.S. growth shocks and another reflecting U.S. monetary shocks. Daily (rather than monthly) data is used to ensure that U.S. shocks, in particular monetary shocks that reflect Fed announcements, and their near immediate effects on stock prices, are well identified.

The SVAR follows a similar approach as Matheson and Stavrev (2014) and IMF (2014b) based on three U.S. variables: long-term interest rates, stock prices, and the nominal effective exchange rate. The nominal effective exchange rate is added on technical grounds, to ensure that the two identified shocks are orthogonal while also ensuring that the sign restrictions are satisfied. Due to data availability, other variables (e.g. inflation expectations) that may also be important drivers of the long-term interest rate are excluded from the model. The sign restrictions assume that an adverse "monetary" shock (such as an unexpected real or perceived policy tightening) increases yields and reduces stock prices in the United States, while a favorable "real" shock (such as reflecting better growth prospects) increases both yields and stock prices. The shocks identified using these restrictions naturally reflect market perceptions of monetary policy and growth.

\section{Spillovers from U.S. monetary and real shocks to activity and financial markets in EFEs}

To assess the spillovers from the shocks driving U.S. yields to EFEs, a panel VAR model is estimated for EFE variables, with monetary and real shocks (estimated as in the above model) as exogenous regressors. The panel VAR includes six variables for EFEs: long-term bond yields, stock prices, nominal effective exchange rates, bilateral exchange rate with the dollar, industrial production, and inflation.

The list of countries is: Brazil, Chile, China, Colombia, Czech Republic, the Arab Republic of Egypt, Hungary, India, Indonesia, the Republic of Korea, Malaysia, Mexico, Pakistan, Peru, the Philippines, Poland, Romania, the Russian Federation, South Africa, Thailand, Turkey, Ukraine, and República Bolivariana de Venezuela. The sample is restricted to emerging market economies and the largest frontier market economies that are highly integrated into global financial markets. All data are monthly or monthly averages of daily data for January 2013-June 2015. Spillovers are then evaluated by tracing out the impulse responses of these variables due to adverse monetary U.S. shocks and favorable U.S. real shocks. The size of the U.S. shocks is normalized such that EFE bond yields change by 100 basis points on impact. 


\section{Spillovers from U.S. financial conditions to capital flows}

The effects of movements in U.S. yields on aggregate capital inflows to EFEs are modeled using a VAR model, based on Burns et al. (2014). This model links quarterly aggregate capital inflows (including foreign direct investment, portfolio investment, and other investment) to 58 EFEs (from BPM6 balance of payment data, expressed in percent of gross domestic product [GDP]) to real GDP growth both in EFEs and in G4 countries (the United States, the Euro Area, Japan, and the United Kingdom), real G4 short-term interest rates (GDP-weighted average of three-month money market rates for G4 countries), G4 term spreads (GDP-weighted average of 10-year government bond yields for G4 countries minus G4 short-term rates), and the VIX index of implied volatility of S\&P 500 options. This captures the response of capital flows to external shocks, and their propagation through global uncertainty and growth effects. The feedback between global interest rates and investors' risk appetite is captured by incorporating in the model the VIX index of implied stock market volatility, which is often used as proxy of risk aversion and deleveraging pressures (Adrian and Shin 2010 and 2012), with significant repercussions for capital flows to emerging markets and developing countries (Rey 2013; Bruno and Shin 2013; Forbes and Warnock 2012).

To compute impulse responses, the covariance matrix is derived from a Cholesky decomposition. The Cholesky decomposition is based on the following order of variables (from least to most "endogenous"): G4 GDP growth, real G4 short-term rates, G4 term spreads, VIX, EFE GDP growth, and capital inflows to EFEs. The impact of a 100 basis points shock in long-term interest rate across $\mathrm{G} 4$ economies is estimated to reduce aggregate capital flows to EFEs by 2 percent of their combined GDP (45 percent drop in flows), with the impact peaking after 4 quarters and remaining significant at a 90 percent confidence interval up to 6 quarters. A similar VAR model was computed for portfolio flows (balance of payment data), with the impact of an interest rate shock estimated to be of similar magnitude, but peaking earlier and with wider confidence intervals given greater volatility in quarterly portfolio flows. For robustness, a Panel VAR model for $35 \mathrm{EFEs}$ was estimated as well, yielding comparable average response of capital flows to interest rate shocks (a peak effect of 1.80 percent of GDP for a 100 basis-point shock after 4 quarters) with slightly narrower confidence bands reflecting higher degrees of freedom. The magnitude of these effects is in consistent with the estimated impact of a 100 basis-point real U.S. yield shock found by Adler, Djigbenou, and Sosa (2014) and a 120 basis-point shock in U.S. yields on portfolio flows found by Dahlhaus and Vasishtha (2014).

A 100 basis-point shock to the U.S. term spread is applied to the model, assuming a range of passthrough effects on Euro Area, U.K., and Japanese long-term yields (from zero to 100 percent). In the median case, global bond yields increase by 70 basis points on impact, roughly comparable to the passthrough rate observed during the taper tantrum. 
contrast, a favorable U.S. real shock of similar magnitude leads to an increase in EFE industrial production of 1.1 percent. Similarly, EFE stock prices decline by 2.5 percent over the 12 -month horizon after an adverse U.S. monetary shock, whereas they increase 3.1 percent after a favorable U.S. real shock. EFE nominal effective exchange rates depreciate 0.2 percent after an adverse U.S. monetary shock, while they appreciate 0.6 percent after a favorable U.S. real shock.

\section{Impact on EFE capital flows}

Even if "telegraphed" by the Fed and expected in principle for some time, there is a risk that the liftoff or the subsequent tightening cycle take investors aback, leading to bouts of financial market volatility and sudden increases in U.S. long-term yields. This would likely disrupt capital flows to EFEs, with important repercussions in terms of growth prospects and policy choices.

A VAR model of capital flows and financial conditions was estimated to examine the potential role of rising U.S. bond yields (Burns et al. 2014). Quarterly capital flows, including foreign direct investment, portfolio, and bank flows, are regressed on global interest rates, financial market volatility, and growth in major advanced economies and in EFEs (see Box 1 for technical details).

The results indicate that about one-fifth of quarterly fluctuations in aggregate capital inflows to EFEs since the early 2000 s can be ascribed to changes in global financial conditions, while about a third of them are due to changes in growth (Figure 19). Rising long-term interest rates in major economies tend to dampen capital flows to EFEs, with the effect amplified in the short term by market volatility. In fact, a steepening yield curve is often associated with a period of heightened uncertainty and risk aversion which, in turn, further reduces capital flows to EFEs. ${ }^{18}$ The role of market volatility in amplifying global interest rate shocks appears particularly noticeable in the case of portfolio inflows to EFEs.

Should market expectations for medium-term interest rates suddenly adjust upwards during the upcoming tightening cycle, U.S. yields could increase abruptly as seen during the taper tantrum. Significant co-movement between long-term interest rates across major advanced countries could contribute to the propagation of the initial shock. ${ }^{19}$ Depending on the pass-through to other advanced countries' interest rates, capital flows to EFEs could slow sharply over the following year. If U.S. term spreads increase by 100 basis points, the fall in capital flows to EFEs could peak after four quarters, in the range of 1.0-2.2 percentage points of their combined GDP, which translates in a decline of between 20 and 45 percent in the level of capital flows (Figure 19).

- Full pass-through. A 100 basis-point increase in U.S. yields that is accompanied by a similarly sharp increase in yields in the Euro Area, Japan, and the United Kingdom would trigger a sudden increase in market volatility and a temporary drop in capital inflows to EFEs, with the decline peaking after four quarters at 2.2 percentage points of GDP (corresponding to a 45 percent dip in aggregate capital flows). The effect would unwind after two years, with capital flows in percent of GDP returning close to pre-shock levels.

\footnotetext{
18 Higher U.S. term premia and a steepening yield curve are often associated with larger financial market volatility and greater risk aversion (Abrahams et al. 2015; Adrian, Crump, and Moench 2013b; Borio and Zhu 2012; Adrian and Shin 2011; Dell'Ariccia, Laeven, and Suárez 2013). Greater risk aversion and volatility, in turn, reduce capital flows to EMEs further (Fratzscher 2012; Forbes and Warnock 2012; Bruno and Shin 2015; Lo Duca 2012; Ahmed and Zlate 2013; Bluedorn et al. 2013; Rey 2013).

19 Diebold and Yilmaz (2015) find that long-term interest rates among non-U.S. major advanced economies co-move (with some lag) with U.S. long-term interest rates. Hunter and Simon (2005) report that bond market returns and volatility in the United States lead those of German and Japanese bond markets.
} 


\section{Figure 19. U.S. yields and capital inflows to EFEs}

Global financial conditions-especially changes in U.S. yields and measures of market risk aversion-account for a significant part of movements in capital flows to EFEs, although growth conditions in both EFE and advanced countries matter most. Portfolio flows appear more sensitive than overall capital flows to global push factors such as market volatility and growth conditions in advanced economies. A 100 basis point rise in U.S. 10-year yields could trigger a drop in capital inflows amounting to 1-2 percentage points of GDP in EFEs after one year. Emerging economies appear to be, on average, less affected than frontier markets. However, this owes in large part to China, where capital inflows appear least responsive to global financing conditions.

\section{A. Financial drivers of capital flows to EFEs}

Percent of variance, explained

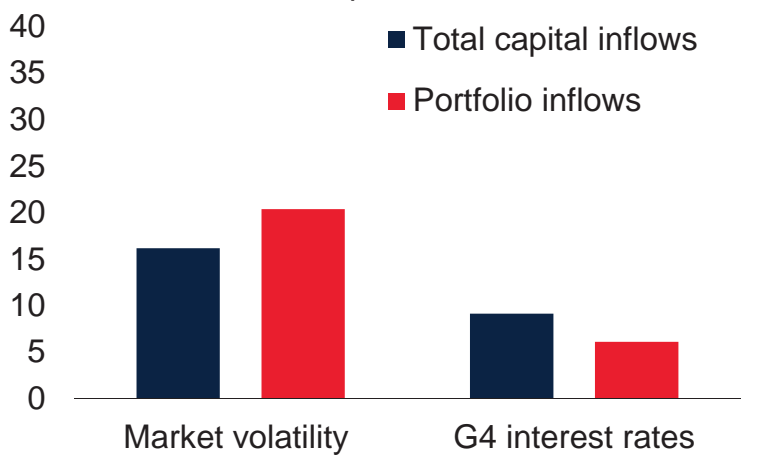

\section{Impact of G4 interest rate shock on EFE capital inflows}

Deviation from baseline, percentage points - G4 long-term yields -Capital inflows (percentage points of GDP)

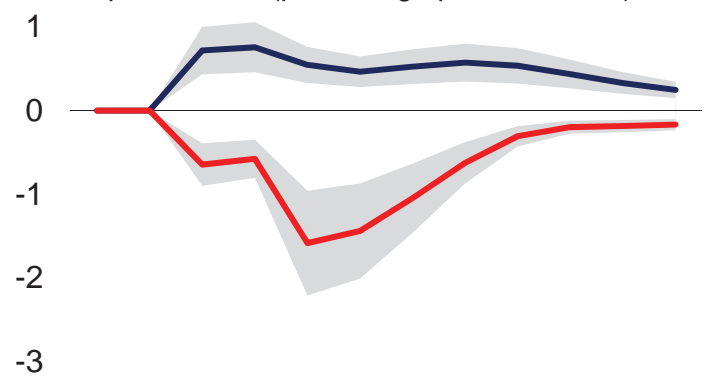

\section{B. Growth drivers of capital flows to EFEs}

Percent of variance, explained 40

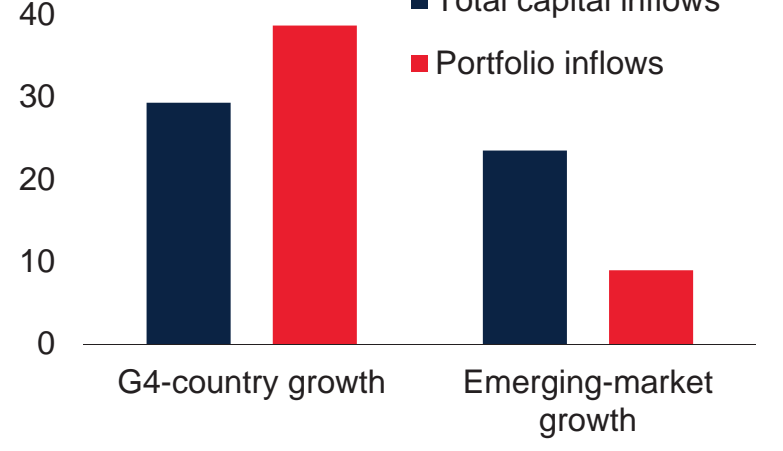

\section{Impact of G4 interest rates shock on EFE capital flows after 1 year, by region}

Percent of GDP
$2 \quad$ Confidence bands • Scaled response

1

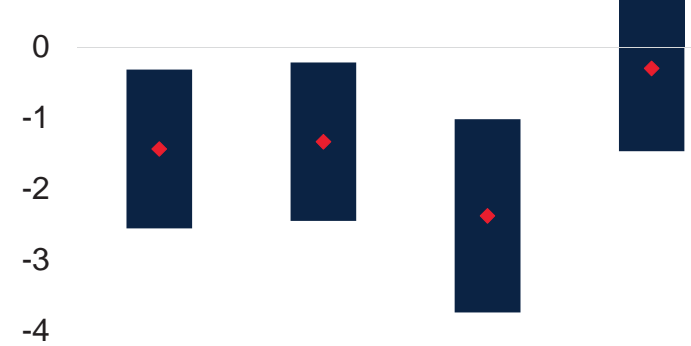

EFE $\quad$ EME $\quad \mathrm{FME} \quad \mathrm{CHN}$

Source: World Bank, Bloomberg.

A.B. Figure shows the variance decomposition of capital inflows to EFEs after eight quarters, according to a six-dimensional VAR model estimated over the period 2001Q1 to 2014Q4. The model links capital inflows (including foreign direct investment, portfolio investment and other investment as a share of GDP), to quarterly real GDP growth in both EFE and G4 countries (United States, Euro Area, Japan and the United Kingdom), real G4 short-term interest rates (three-month money market rates minus annual inflation measured as changes in GDP deflator), G4 term spread (10-year government bond yields minus three month money market rates), and the VIX index of implied volatility of S\&P 500 options. To compute the variance decomposition, a structural identification was derived from a Cholesky decomposition on the covariance matrix, using the following order of variables: G4 GDP growth, G4 real short-term rates, VIX, G4 term spread, EFE GDP growth and capital inflows. Impulse responses show that a shock in $\mathrm{G} 4$ long-term rates has a peak effect on capital flows after four quarters, while the impact remains significant at a 90 percent confidence interval up to six quarters.

C. The 100 basis point shock on the U.S. term spread was applied to the VAR model assuming a range of pass-through rates to Euro Area, U.K. and Japanese bond yields, from zero to 100 percent. Grey area shows the range of estimated effects on capital inflows depending on passthrough rates (the lower bound corresponds to a zero pass-through rate implying a 40 basis points shock to global bond yields, while the upper bound corresponds to a 100 percent pass-through rates, or a 100 basis points shock to global bond yields). In the median case, global bond yields increase initially by 70 basis points, which corresponds to the observed pass-through rate during the taper tantrum.

D. DEV, EFE, EME, and FME stands for all developing countries, all emerging and frontier markets, all emerging markets, and all frontier markets, respectively. 
- Partial pass-through (as in taper tantrum). If other major economies' yields adjust in a manner similar to the taper tantrum (when global yields increased by 70 basis points following an increase in U.S. yields of 100 basis points), the decline in capital flows would peak at about 33 percent, or 1.6 percentage points of GDP, after four quarters.

- No pass-through. Should long-term yields in other major economies remain broadly unaffected, capital flows to EFEs would fall considerably less, peaking at about 20 percent or 1 percentage point of GDP after four quarters. Quantitative easing or other forms of monetary policy accommodation by other major central banks could insulate their markets from pass-through and reduce the impact of rising U.S. bond yields on EFEs.

These effects vary somewhat depending on country groupings and regions (Figure 19). For instance, in the partial pass-through scenario, the impact of a 100 basis point increase in U.S. yields would have smaller effects for emerging markets than frontier markets. A lower average sensitivity of capital flows to emerging markets is in part explained by China, which is estimated to be least responsive among large emerging markets to changing U.S. yields.

The magnitude of the potential decline in capital flows reported here is consistent with those presented in Adler, Djigbenou, and Sosa (2014) and Dahlhaus and Vasishtha (2014). Our results are both statistically and economically significant, implying considerable challenges for those EFEs facing more acute vulnerabilities. However, the overall effect for EFEs remains modest in view of the historical volatility of capital flows. A decline in capital flows amounting to 1.6 percentage points of GDP would be broadly equivalent to a decline of one standard deviation in quarterly flows since the start of the 2000s (compared with the typical sudden stop definition in the literature as a two-standard deviation shock).

\section{E. Multiple sudden stops in EFEs: a perfect storm?}

A decline in capital flows to EFEs on the back of surging U.S. yields could be manageable on average, but would increase the likelihood of damaging sudden stops at the country level. This likelihood is accentuated by the weak fundamentals and lingering vulnerabilities documented above, which, along with the challenging global context and recent spikes in global financial market volatility, could set the stage for a "perfect storm" for the most fragile economies. As observed in the past, periods of heightened global financial market volatility tend to be conducive to such episodes. For example, the number of EFEs experiencing sudden stops surged during the global financial crisis (Figure 20). During the taper tantrum, around 12 percent of EFEs experienced sustained declines in capital inflows, especially portfolio inflows (measured as a one standard deviation drop in quarterly flows).

These external shocks may result in more severe "systemic" sudden stops, defined here as significant reversals in capital flows associated with a period of global financial volatility. ${ }^{20}$ These systemic sudden stops generally hit countries that are highly integrated in international capital markets, and may occur even if the affected countries have limited domestic vulnerabilities (Calvo and Reinhart 1996; Kaminsky 2008). The short-run costs of such "systemic" sudden stops appear substantial. Average GDP growth in EFEs declines, on average, almost 7 percentage points in the two years following a systemic sudden stop (Figure 20). Similarly, average investment growth in EFEs declines more than 21 percentage points in the two years around these events. And the bilateral exchange rate with respect to the U.S. dollar depreciates on average about 14 percentage points the year following the onset of an episode. ${ }^{21}$

\footnotetext{
20 More precisely, systemic sudden stops are defined in this note as periods during which total capital inflows decline by at least two standard deviations from their historical mean (following Forbes and Warnock 2012) and, at the same time, the VIX index of implied stock volatility increases by more than two standard deviation from its historical mean.

${ }^{21}$ This exercise is not extended further back into the past, encompassing, for instance, the early 1980s tightening, since U.S. conditions were fundamentally different and a sizable share of our EFE sample did not have the same degree of market access.
} 


\section{Figure 20. Sudden stops and EFE financial crises}

A number of EFEs experienced sudden stops during the taper tantrum, but significantly fewer than that during the global financial crisis, or the Asian crisis in the late 1990s. In past episodes, growth in EFEs declined considerably and currencies depreciated sharply following systemic sudden stops. The frequency of financial crisis in EFE is only loosely associated with U.S. monetary policy cycles, although the combination of rising policy rates and term premia have seen greater incidence in the 1980s and 1990s.

\section{A. Sudden stops: total EFE capital inflows} Percent of countries

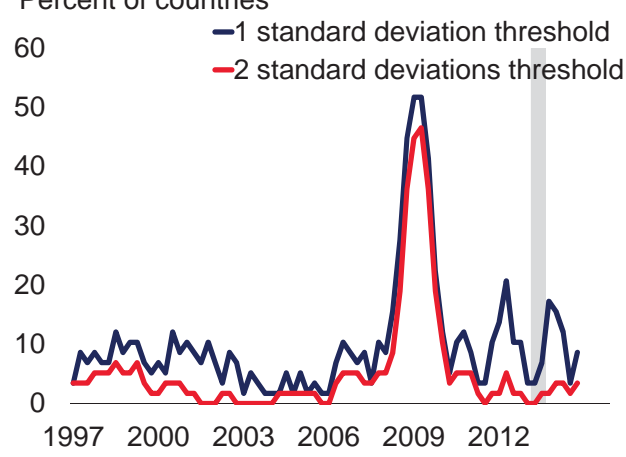

C. Sudden stops and EFE GDP growth

Percentage point, deviations from $\mathrm{t}=0$

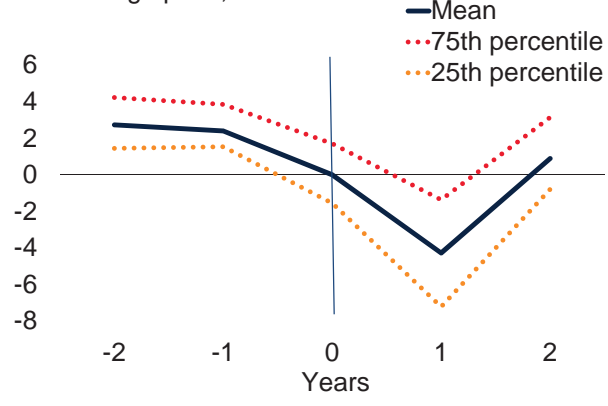

\section{E. Sudden stops and EFE currency depreciation}

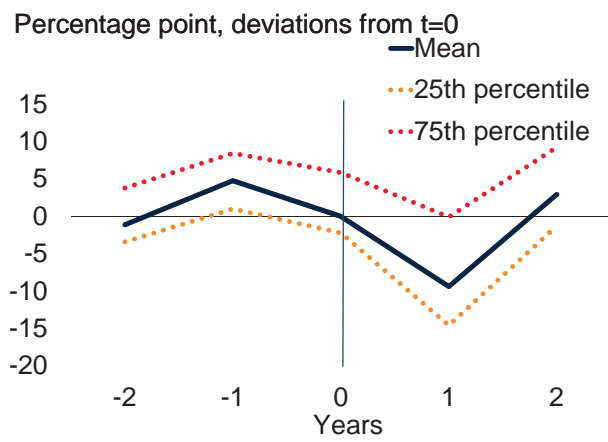

\section{B. Sudden stops: EFE portfolio inflows} Percent of countries

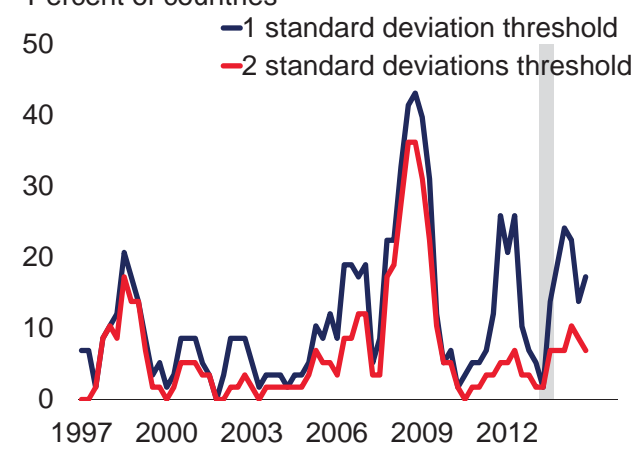

D. Sudden stops and EFE investment growth Percentage point, deviations from $\mathrm{t}=0$

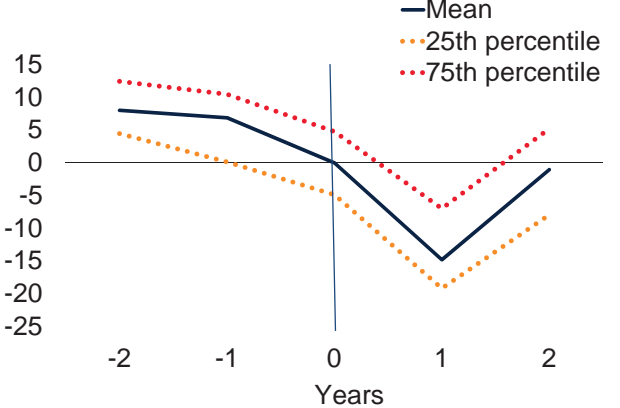

F. U.S. interest rates and frequency of financial crises in EFEs

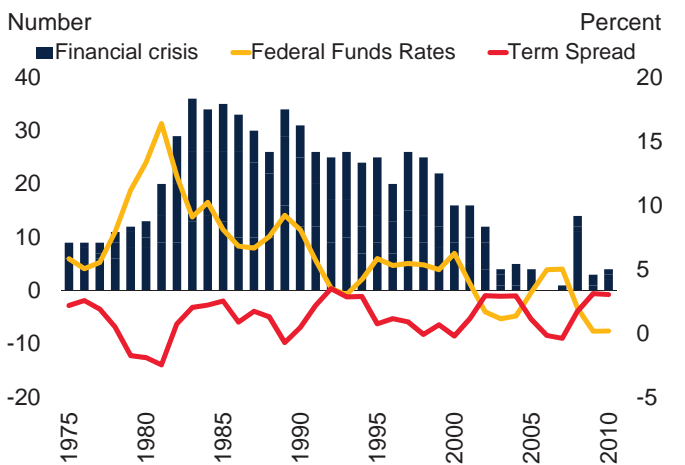

Source: World Bank and Escolano, Kolerus, and Ngouana (2014).

A.B. Figures show the fraction of 58 EFEs that experienced a sudden stop. The methodology used to identify sudden stop episodes at the country level is based on Forbes and Warnock (2012), with the threshold for sudden stops being defined as a decline in flows larger than one (or two) standard deviation(s) around a five-year rolling mean. Grey bars show the taper tantrum period of May-June 2013. Last observation: 201404.

C.D.E. Blue line denotes averages for EFEs that experienced systemic sudden stops. Grey shades denote 75 th and 25 th percentiles. A systemic sudden stop is a period when capital flows fall one standard deviation below their historical mean and, at the same time, the VIX index surpasses by one standard deviation its historical mean. The calculations include 21 nonconsecutive systemic sudden stop episodes for 58 EFEs in $1995-2014$.

E. A decline denotes a depreciation.

F. Frequency of financial crises refers to number of currency, sovereign debt (domestic or external), and banking crises identified by Escolano, Kolerus, and Ngouana (2014) 
The economic costs of sudden stops have been widely documented (Claessens and Kose, 2014; Appendix Table 2). For example, about two-thirds of 33 sudden stop episodes through the 1990s and early 2000s were associated with output collapses-contractions in GDP of 4.4 percent from peak to trough (Calvo, Izquierdo, and Talvi 2006). ${ }^{22}$ The negative effects on activity are generally larger in countries with a greater share of foreign-currency-denominated liabilities, among other factors. ${ }^{23}$ Sudden shifts in capital flows are sometimes associated with heightened financial stress. A third of banking crises in EFEs occur within two years after a period of strong capital inflows and are strongly correlated with a sudden retrenchment in the year of the crisis (World Bank 2014a). There is some tentative evidence that U.S. monetary tightening may affect the incidence of financial stress in EFEs (Figure 20). For example, the frequency of sovereign debt crisis among EFEs tends to be somewhat higher at the beginning of U.S. tightening cycles and when term spreads are rising (Escolano, Kolerus, and Ngouana 2015). However, the change in the frequency of debt crises is less perceptible when the term spread remains close to historical averages.

Even countries that are not directly exposed to global financial market shocks could be affected through intraregional spillovers from their larger, financially more integrated neighbors. Whereas within-regional financial exposures often tend to be limited, trade, remittance, and direct investment links are strong in some regions. For example, Brazil could transmit shocks to neighboring countries through trade and confidence channels (World Bank 2015b). Economic and financial stress in Russia, amid recession and international sanctions, would spill over to other countries in Central Asia and the South Caucasus through trade, remittances, and FDI. India is the single largest trading partner for some of the smaller South Asian economies, suggesting potential spillover effects in that region. ${ }^{24}$

\section{POLICY OPTIONS TO PREPARE FOR RISKS}

Policy makers in EFEs have several options to prepare for the risks associated with the coming tightening cycle. As discussed below, foremost among them is the adoption of policies that reduce vulnerabilities and the proactive pursuit of structural reform agendas that improve growth prospects.

\section{A. Major lessons for EFEs from the taper tantrum}

Before discussing policy options for EFEs, it is useful to review the major lessons that can be drawn from the taper tantrum episode. As mentioned above, many EFEs experienced sustained declines in capital

\footnotetext{
22 Cardarelli, Elekdag and Kose (2010), examining 109 episodes of large net private capital inflows to 52 countries over 19872007, report that the typical post-inflow impact on GDP growth for episodes that end abruptly is about 3 percentage points lower than during the episode, and about 1 percentage point lower than during the two years before the episode. Claessens et al. (2014) provide a comprehensive review of the literature on financial crises, including sudden stops, in light of recent evidence.

23 In addition, some sectors are particularly vulnerable to output losses as a result of sudden stops due to their reliance on debt finance, including construction, wholesale and retail trade, transport, and communications (Craighead and Hineline 2013). Also, contractions and job losses during sudden stops in less financially-developed countries appear to be larger in sectors and industries that exhibit greater liquidity needs, that depend on external finance, or that produce durable goods (Gallego and Tessada 2012; Cowan and Raddatz 2013).

${ }^{24}$ The size of regional spillovers from these major emerging markets have notable variations. For example, a 1 percentage point growth slowdown in Brazil could reduce growth in Uruguay and Paraguay by 0.5-0.9 of a percentage point and in Argentina and Bolivia by almost 0.3 of a percentage point (IMF 2014b). A 1 percentage point decline in Russian growth could reduce growth in the Baltics, Belarus, Kazakhstan, and Tajikistan by 0.6-2.0 percent (Alturki, Espinosa-Bowen, and Ilahi 2009). And a 1 percentage point decline in India's per capita growth would be associated with a 0.4 percentage point decline in growth in the rest of the region (Ding and Masha 2012).
} 
inflows during that episode. EFE currencies depreciated, liquidity tightened, bond spreads jumped, foreign portfolio inflows to EFE bond and equity funds fell sharply, and EFE bond market and capital flows volatility increased markedly (Figure 21 ). ${ }^{25}$

\section{Figure 21. U.S. bond yields and EFE capital flows during the taper tantrum}

The sharp rise in U.S. yields during the taper tantrum in May-June 2013 was accompanied by a spike in EFE sovereign yields and a marked fall in capital inflows to EFEs. The volatility in U.S. bond markets coincided with greater volatility of EFE bond yields and capital inflows.

\section{A. Bond yields \\ Percent}

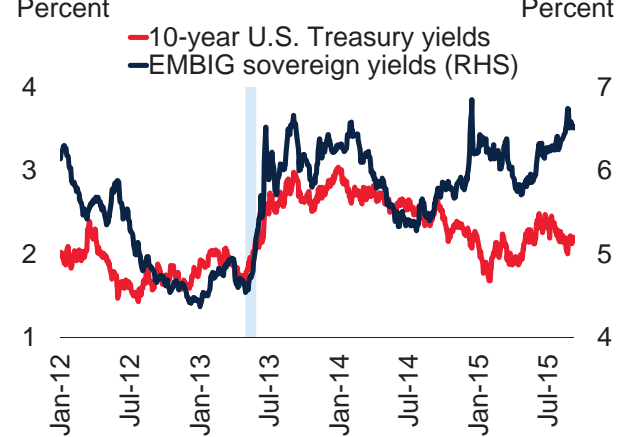

C. Bond market volatility

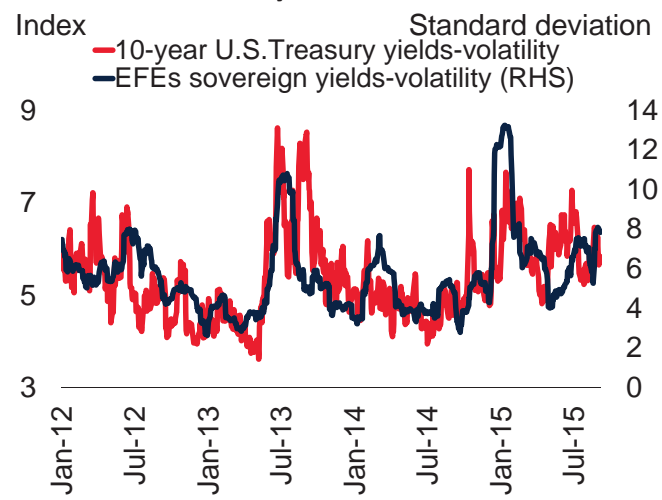

\section{B. Bond yields and portfolio flows}

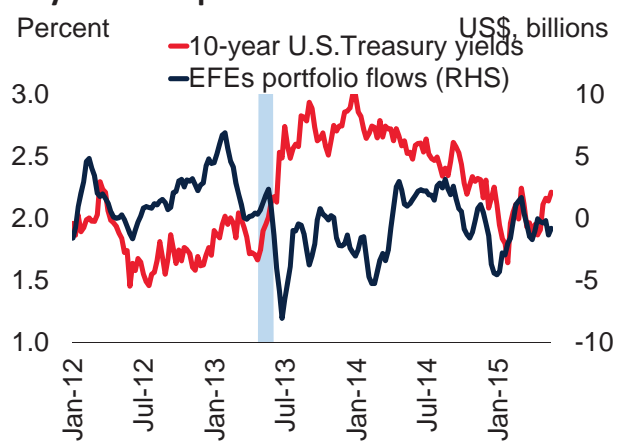

D. Volatility of bond yields and portfolio inflows

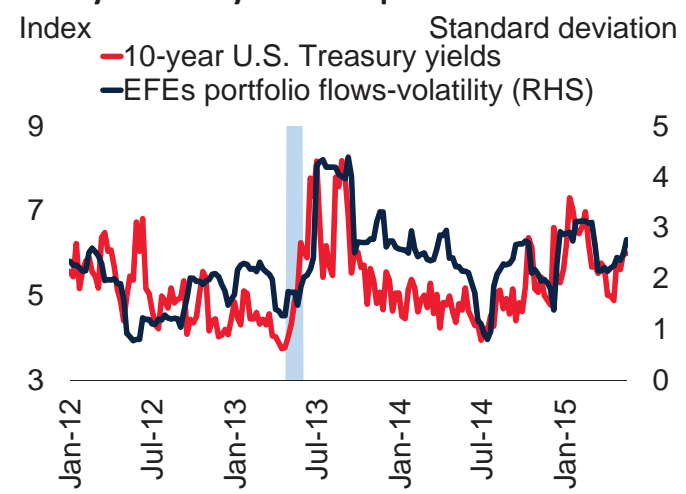

Source: Bloomberg, Emerging Portfolio Fund Research, JPMorgan Chase, CBOE, and World Bank.

Note: Blue bars show the taper tantrum period of May-June 2013.

A. Based on JPMorgan EMBIG sovereign bond yield index that includes 49 EFEs. Last observation: August 2015.

B. 4-week moving average of net inflows to EFE bond and equity funds in the EPFR database. Last observation: May 2015.

C. Volatility index for U.S. Treasury yields refers to the expected volatility of the price of 10-year U.S. Treasury note futures (CBOE's TYVIX index). Volatility of EFE bond yields refers to 30-day rolling standard deviation of JPMorgan EMBIG sovereign bond yield index. Last observation: August 2015.

D. Volatility of EFE portfolio flows refers to 12-week rolling standard deviation of net inflows to EFE bond and equity funds. Last observation: May 2015.

\footnotetext{
25 Dahlhaus and Vasishta (2014) document the modest shock to portfolio capital flows to emerging markets during the taper tantrum that, nevertheless, triggered significant financial market adjustment in some emerging markets. Díez (2014) examines the exchange rate adjustment in emerging markets during the taper tantrum and finds that current account deficits and previous real exchange rate appreciations were key factors in explaining the observed cross-country differences. Lim, Mohapatra and Stocker (2014) estimate the impact of prior U.S. quantitative easing policies on capital flows to EFEs and find that most of the estimated effect unwound around the taper tantrum.
} 
An extensive literature has identified the following key factors and policy responses characterizing the impact of the taper tantrum (Appendix Table 3).

- Initial impact versus longer-term impact. The taper talk initially triggered indiscriminate capital outflows from EFEs. Over time, greater country differentiation emerged as capital flows returned to some countries but not to others (Sahay et al., 2014; Lavigne, Sarker, and Vasishtha 2014).

- Differentiation depending on country characteristics. Financial market disruptions during the taper tantrum period were particularly sizable in countries with weaker macroeconomic fundamentals, larger financial markets, and less robust policy responses. Large current account deficits following a period of rapid real appreciation, modest international reserves, and weaker growth prospects were associated with sharper drops in capital inflows and disruptions in financial markets. Larger and more liquid financial markets-including as a result of past capital inflows - also experienced greater exchange rate pressures, foreign reserve losses, and equity price drops. ${ }^{26}$

- Differentiation depending on asset classes. The differentiation by fundamentals, financial market size, and policies was particularly pronounced for certain types of capital outflows. For example, cross-border bank flows to a number of EFEs-especially in Latin America-with sizable U.S. dollar-denominated liabilities fell especially sharply during the taper tantrum (Avdijev and Takats 2014; García-Luna and van Rixtel 2013). In contrast, FDI flows were broadly stable (Basu, Eichengreen, and Gupta 2014), and drops in equity market valuations were more uniform across countries (Mishra et al. 2014; Rai and Suchanek 2014). Finally, the composition of the foreign investor base appears to have an important role in shaping the response of capital flows, with countries relying more on international funds and global banks exhibiting a greater sensitivity to global push factors, such as higher interest rates in advanced economies (Cerutti, Claessens, and Puy 2015).

In a number of countries, the impact of the taper tantrum was mitigated by proactive policy responses (Sahay et al. 2014). Some countries - particularly those most affected by the taper tantrum, such as Brazil, India, Indonesia, South Africa, and Turkey-hiked policy interest rates. A few of these countries (Brazil, India, Indonesia, Turkey) also implemented liquidity provisions to ensure proper market functioning. Removal of restrictions on capital inflows (Brazil, India, Indonesia) and foreign exchange interventions (Brazil, India, Indonesia, Russia, Turkey, Poland) were also pursued. To varying degrees, these actions helped stem depreciations, stock market declines, and bond yield jumps. Fiscal policy announcements were least used (Brazil, India) and appear to have been less significant in mitigating the impact of short-term financial stress.

Lessons from the taper tantrum episode are consistent with those from the broader literature on sudden stops in capital inflows. Country-specific vulnerabilities not only increase the probability of a sudden stop, but also intensify its severity in terms of currency depreciation and declines in GDP growth, as well as lengthen the time it takes for growth to revert to its long-term trend (see also Appendix Table 2). A greater reliance on FDI and equity flows instead of debt flows and cross-border bank loans may reduce the severity of sudden stop episodes (Levchenko and Mauro 2007).

\footnotetext{
26 See Ahmed, Coulibaly, and Zlate (2015); Aizenman, Binici, and Hutchison (2014); chapter 3 of IMF (2014c); Avdiejv and Takats (2014); Basu, Eichengreen and Gupta (2014); Collyns and Koepke (2015); Díez (2014); Mishra et al. (2014); Rai and Suchanek (2014) and Eichengreen and Gupta (2014).
} 


\section{B. Monetary policy}

The optimal monetary policy response to preparing for the risks associated with the upcoming tightening cycle is contingent on the outlook for domestic inflation and growth, the existence of external vulnerabilities as well as the exchange rate regime, and whether a given country is an importer or exporter of commodities.

For oil and other commodity-importing countries, declining prices have eased constraints on monetary policy by slowing inflation and reducing current account deficits (Figure 22). This has allowed a number of commodity-importing countries with flexible exchange rates and below-target inflation to cut policy rates in support of growth. By doing so, these economies are also creating space to tighten policy in response to the Fed tightening cycle once it occurs. For oil-importing countries where inflation is running at or near the top of formal or informal target bands, buttressing monetary policy credibility remains an immediate priority.

Among oil-exporting countries, central banks need to implement policies to strike a delicate balance between competing objectives of stimulating growth and maintaining stable inflation and investor confidence in the face of significant currency pressures. In oil- exporting countries with flexible exchange rates, an orderly depreciation can help them adjust to a negative terms-of-trade shock and limit the effect on aggregate demand. However, disorderly currency movements can put significant strain on balance sheets and lead to a challenging combination of above-target inflation, declining activity and rising financial pressures.

For the limited number of countries with currency regimes tightly pegged to the U.S. dollar and open capital accounts, space for autonomous monetary policy is limited. Policy might need to be contractionary in response to the Fed tightening cycle, even if growth moderates and inflation slows.

EFE central banks risk will likely face increasingly challenging policy tradeoffs during the upcoming tightening cycle. Financial globalization and the rising influence of global interest rates in determining domestic financing conditions complicate some of these trade-offs and make domestic policy objectives more difficult to achieve (Obstfelt 2015, Sobrun and Turner 2015). However, monetary policy authorities should primarily focus on credible commitments to price stability over the medium term and, where appropriate, institutional reforms aimed at limiting the risk of pro-cyclical policies associated with capital flows.

\section{Macroprudential and financial policy}

The upcoming tightening cycle may exert downward pressure on both exchange rates and short-term capital flows. Accordingly, banks and non-financial corporates in EFEs with elevated foreign currency mismatches and/or significant reliance on short-term debt from abroad are more vulnerable to the potential negative effects of the Fed tightening. Even if corporates can hedge some of their foreign currency-denominated liabilities, such hedging may be subject to counterparty risk and be limited in the face of large currency movements. Banks' matching foreign-currency-denominated liabilities with foreign currency-denominated credit to the private sector may limit currency risks but at the cost of higher probability of default on their loans. Banks also have direct credit exposures to corporates through counterparty risk from any derivative positions (Chui, Fender, and Sushko 2014). Therefore, both banks and corporates in countries with these vulnerabilities may merit close monitoring, improved supervision, and where appropriate, tighter prudential requirements. 


\section{Figure 22. Current account positions and policy space in EFEs}

Current account positions have improved for some oil importers, but generally not for exporters. Fiscal positions in EFEs have deteriorated since the crisis, but debt and deficits remain, on average, moderate. Median inflation rates have declined among oil-importing countries, but have increased among oil-exporters, partly reflecting the impact of significant currency depreciations. Inflation has remained above central bank targets in a number of countries.

A. Current account balance of oil exporters and importers

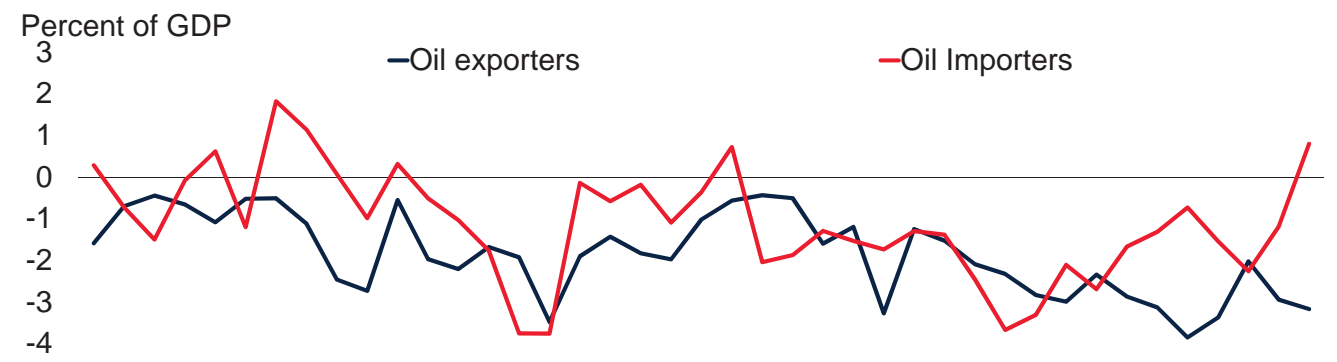

$-5$

B. General government debt and balance

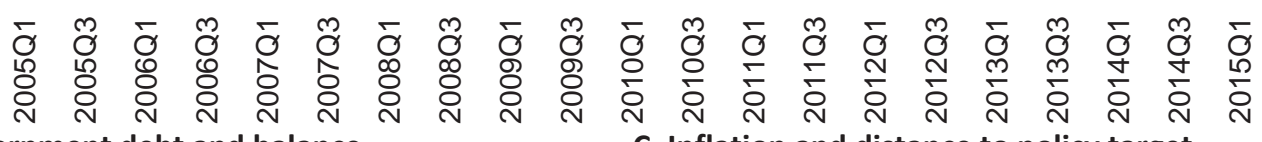

C. Inflation and distance to policy target
Percent of GDP

80 Government debt

= Government primary 15 balance (RHS)

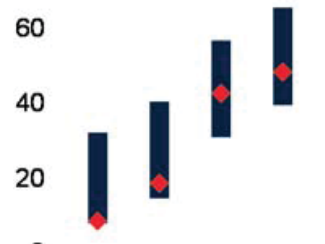

0

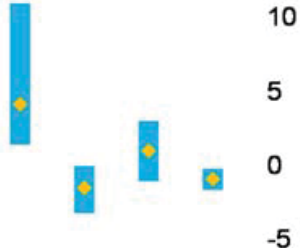
Percent 16 - Distance from inflation target 16

응 유유 유

Oil Ex. Oil Im.

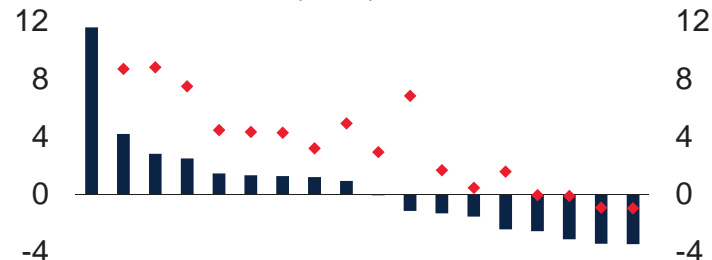

Source: World Bank, Centralbanking.com, International Monetary Fund, Haver Analytics.

A. Current account is the median value of country groups. Oil exporters are Colombia, Mexico, Malaysia, Russia, Nigeria, Saudi Arabia. Oil Importers are Turkey, Ukraine, South Africa, Peru, Thailand, India, Brazil, Indonesia, Chile, Poland, Argentina, Romania, Czech Republic, China, Hungary, Philippines, Korea.

B. Bar illustrates interquartile range for EFEs. Dot shows median for EFEs.

B.C. For EFE countries. Hydrocarbon exporters (as proxy for oil exporters) are Azerbaijan, Côte d'Ivoire, Colombia, Ecuador, Gabon, Indonesia, Kazakhstan, Mexico, Malaysia, Nigeria, Venezuela, RB. List of oil importers are Bangladesh, Bulgaria, Bolivia, Brazil, Botswana, China, Costa Rica, Egypt, Arab Rep., Georgia, Guatemala, Honduras, Hungary, India, Jamaica, Jordan, Kenya, Lebanon, Sri Lanka, Morocco, Mauritius, Namibia, Pakistan, Panama, Peru, Philippines, Paraguay, Romania, Senegal, El Salvador, Serbia, Thailand, Tunisia, Turkey, Ukraine, South Africa, Zambia.

C. Inflation is the average for the last 6 months.

Macroprudential policies should also be reinforced to mitigate systemic risks and reduce the procyclicality of domestic financial sectors. Beyond the implementation of counter-cyclical capital buffers under Basel III requirements, macro-prudential frameworks can be reinforced through a range of instruments, including caps on loan-to-value or debt-to-income ratios, dynamic provisioning, and credible stress tests. 


\section{Fiscal policy}

Since the management of capital flows associated with the upcoming Fed tightening cycle can constrain monetary policy, the availability of fiscal policy as a countercyclical tool becomes particularly important. However, in order for fiscal policy to be implemented and be effective, economies need to have the necessary fiscal space to employ countercyclical measures. Space affects the effectiveness of fiscal policy through two channels:

- Interest rate channel. When fiscal space is narrow, expansionary policy can increase lenders' perceptions of sovereign credit risk. This raises sovereign bond yields and hence, borrowing costs across the whole economy (Corsetti et al., 2013; Bi, Shen, and Yang, 2014). This, in turn, crowds out private investment and consumption, and constrains monetary policy. If the crowding out is sufficiently strong, the net effect of expansionary fiscal policy on output, that is, the size of the fiscal multiplier, may be negligible or even negative.

- Ricardian channel. When a government with narrow fiscal space conducts a fiscal expansion, households expect tax increases sooner than in an economy with wide fiscal space (Perotti, 1999; Sutherland, 1997). The perceived negative wealth effect encourages households to cut consumption and save, thereby weakening the impact of the policy on output.

Fiscal space among EFEs generally narrowed in recent years. Although EFE sovereign debt is significantly less than in the early 2000s, fiscal deficits widened rapidly in the aftermath of the global financial crisis and have yet to return to pre-crisis levels (Figure 22). Over the medium term, several EFEs need to improve their fiscal positions to regain policy space for effective fiscal stimulus that may be needed during the upcoming tightening cycle (World Bank 2015a). These countries need to rebuild buffers at a pace appropriate to their specific cyclical circumstances and specificities. Current soft oil prices provide a window of opportunity for many countries to implement subsidy reforms that could help build fiscal space while, at the same time, removing long-standing distortions. Over the medium-term, credible and well-designed institutional arrangements, such as fiscal rules, stabilization funds, and medium-term expenditure frameworks, can help build fiscal space and strengthen policy outcomes. For oil exporters, policy options are constrained by persistently low oil prices. In light of the drop in government revenues, some countries have already started tightening fiscal policy, even as growth slows. ${ }^{27}$

\section{E. Structural reforms}

The upcoming increase in U.S. interest rates is unlikely to be transient in nature. Coupled with fiscal and monetary policy adjustments aimed at reducing vulnerabilities, policymakers need to seek ways to upgrade country fundamentals in order to continue attracting capital flows and investment. Even with adequate policy space, an optimal fiscal-monetary policy mix will not be effective in curbing persistent capital outflows or boosting long-term growth. Therefore, the proactive pursuit of structural reforms to improve total factor productivity and strengthen long-term growth prospects is an integral part of preparing for the Fed tightening cycle.

Although the benefits of reforms take time to materialize, their implementation signals to investors the commitment of policy makers to prepare their economies for the new era of tighter monetary conditions

\footnotetext{
27 This is particularly the case in countries where fiscal deficits were already large before commodity price declines (Angola, Brazil, Cameroon, Ghana, Mongolia, Venezuela, Zambia), or debt levels were elevated (Ghana, Mongolia), or "rainy day" savings or stabilization funds were of limited size (Mongolia, Nigeria). Concerned about possible credit rating downgrades, policymakers pursued consolidation budgets in several oil-exporting countries (Malaysia, Nigeria).
} 
and to enhance long-term growth prospects despite short-term adjustments. This signaling effect could in turn temper capital flow volatility in the medium-term (Kose et al. 2010). In addition to signaling effects, some reforms-especially those requiring investment in infrastructure projects-can support cyclically weak demand if sufficient fiscal space is available. Others, such as tax and subsidy reforms, as noted above, can also help create more fiscal space.

For commodity exporters, the ongoing orderly slowdown in China and lower commodity prices, both of which are expected to be sustained at least in the medium-term, mean that it is especially important to accelerate the diversification of their economies and to find new sources of growth less reliant on commodity exports.

While reform needs are necessarily country-specific, they typically fall into a few categories (World Bank 2014c). These include easing infrastructure bottlenecks, especially in energy and transportation; improving education; reforming labor markets and increasing female participation; enhancing competition and easing administrative burdens; improving access to private and multilateral financing; reducing barriers to trade and facilitating regional integration; and reforming energy subsidies. In addition to raising long-term growth, some reforms-especially those requiring investment in infrastructure projects-can support cyclically weak demand. Others such as tax and subsidy reforms, as noted above, can create also more fiscal space.

Among some of the major emerging-market countries, the pace of reform has generally picked up in recent years. However, there is significant room for improvement. Reducing growth impediments and reforming markets could spur productivity and increase resilience to external shocks, such as those potentially associated with the Fed tightening cycle.

\section{F. Priorities if risks materialize}

Should risks around the Fed tightening materialize, EFEs need to resort to policy measures to alleviate short-term financial stress. These include, most importantly, exchange rate flexibility, targeted monetary and prudential measures to ensure market functioning, and policies aimed at restoring confidence (Figure 23). As discussed earlier, many of these measures appeared to help countries effectively respond to the taper tantrum (Sahay et al. 2014, World Bank 2014a). ${ }^{28}$

- Exchange rate flexibility. In contrast to the 1990s, most EFEs now maintain flexible exchange rate regimes. Allowing exchange rates to adjust will be an important buffer to external shocks, including shocks emanating from rising U.S. yields, in many EFEs - as long as they have manageable currency mismatches on corporate and household balance sheets and credible macroeconomic policies (Davies et al. 2014).

- Interest rate increases. EFEs concerned about the balance sheet effects of sizable depreciations may opt to raise monetary policy interest rates to stem depreciations. This has been done, to varying degrees, in past U.S. tightening episodes. However, the effectiveness of an interest rate hike in stemming depreciation pressures rests on the credibility of the monetary policy framework (Eichengreen and Rose 2003).

- Use of available fiscal space. In some countries,_depleted fiscal buffers may become a contributor to further financial stress. For these, credible commitments to rebuild fiscal space

\footnotetext{
28 A rich literature examines policy responses to financial stress and emphasizes various tradeoffs (Frankel and Wei 2004; Claessens et. al. 2014; Forbes and Klein 2015).
} 
would be a priority. For countries with wider space and credible medium-term objectives, the use of counter-cyclical fiscal policies and stimulus measures could be a feasible option when most needed (World Bank 2015a).

- Targeted support measures. If financial stress threatens financial stability-for example because of large foreign currency liabilities-intervention in foreign currency markets through the use of international reserve or swap market operations may be necessary. Liquidity provision in local capital markets may be required to preserve orderly market conditions. The removal of capital inflow restrictions-or the imposition of temporary controls on certain outflows, but only as a complement to sound macroeconomic policies, financial supervision and regulation, and strong institutions-might temper net outflows (IMF 2014d). Erecting trade barriers to solve financial and economic headwinds would be counterproductive and should be resisted.

- Measures to restore confidence. Reforms to improve the credibility of monetary, fiscal, and regulatory policies through changes in the governance of associated policy institutions may help convince investors of a commitment to sustainable macroeconomic and financial policies. As discussed above, credible commitments to structural reforms could enhance investors' perceptions of long-term growth prospects.

\section{G. International policy coordination}

The global financial crisis, the advent of large-scale unconventional monetary policies and the associated with spillovers have led to intensive debates on international coordination of monetary policies. ${ }^{29}$ When monetary policy authorities are viewed as deviating from transparent rule-based policies, some form of coordination may lead to less volatility and higher welfare gains for the global economy (Taylor 2013, Bullard 2014, Bullard and Singh 2008). This has been argued by some as depicting the post-crisis period where unconventional measures were undertaken by major central banks, while others were forced to deviate from traditional policies to manage excessive exchange rate and capital flow movements (Rajan 2014, Mohan and Kapur 2014).

International policy coordination could hence be viewed as a potential tool to help limit the risks of financial turmoil around the Fed tightening cycle. If risks materialize, coordination could help EFE countries mitigate them and avoid spillbacks to advanced countries (Sahay et al. 2014). Policy coordination could range from heightened efforts by advanced-country central banks to engage in clear and effective communication to the internalization by central banks of the spillover effects of their policies, although the latter may be difficult to operationalize. ${ }^{30}$ First, quantifying the magnitude (or even the sign) of these spillovers might be difficult in practice (Bean 2013). Second, issues of neutrality and credibility relating to the institution in charge of providing recommendations might create additional hurdles to formal coordination (Ostry and Ghosh 2013).

\footnotetext{
${ }^{29}$ Gains from international coordination of monetary policy were generally seen in the pre-crisis period as being relatively small (Obstfeld and Rogoff 2002, Taylor 2013). In fact, traditional (New Keynesian) models used in modern macroeconomics predict that if all central banks follow monetary policy rules that are optimal for the sake of stabilizing domestic output and inflation, there would be little additional gain from them optimizing their policies jointly. Such predictions fitted the period of great moderation from the mid-1980s to the global financial crisis, when the move of many central banks towards more transparent rules-based monetary policies (inflation-targeting or flexible inflation targeting) led to improved outcomes in terms of reduced fluctuations in output and inflation. In this environment, the international monetary system was viewed as operating near an internationally cooperative equilibrium.

${ }^{30}$ An example of coordination is the introduction of liquidity swap lines by the Fed to other (mostly advanced country) central banks in the 2008-09 global financial crisis (Fischer 2014). Dudley (2014) presents a discussion of the impact of U.S. monetary policies on emerging economies and summary of policy lessons from the taper tantrum.)
} 
Advanced-country central bankers need to employ clear and effective communication strategies to minimize the risks associated with their policies. Policymakers in EFEs need to concentrate on domestic policies minimizing the risk of large movements in capital inflows during the upcoming Fed tightening cycle. More broadly speaking, there may be scope for enhanced global and regional safety nets, including through multilateral institutions and regional risk-sharing arrangements, to support EFEs during periods of financial stress (Carstens 2015a).

\section{Figure 23. Policy options to cope with tightening cycle risks}

EFEs should prioritize monetary and fiscal policies that reduce vulnerabilities and strengthen policy credibility in advance of the liftoff and subsequent tightening cycle. In the event that risks surrounding the tightening cycle materialize, exchange rate flexibility could buffer shocks in some countries but may need to be complemented by monetary policy and prudential measures to support orderly market functioning. Although the benefits of structural reforms take time to materialize, decisive moves to implement ambitious reform agendas signal improving growth prospects to investors.

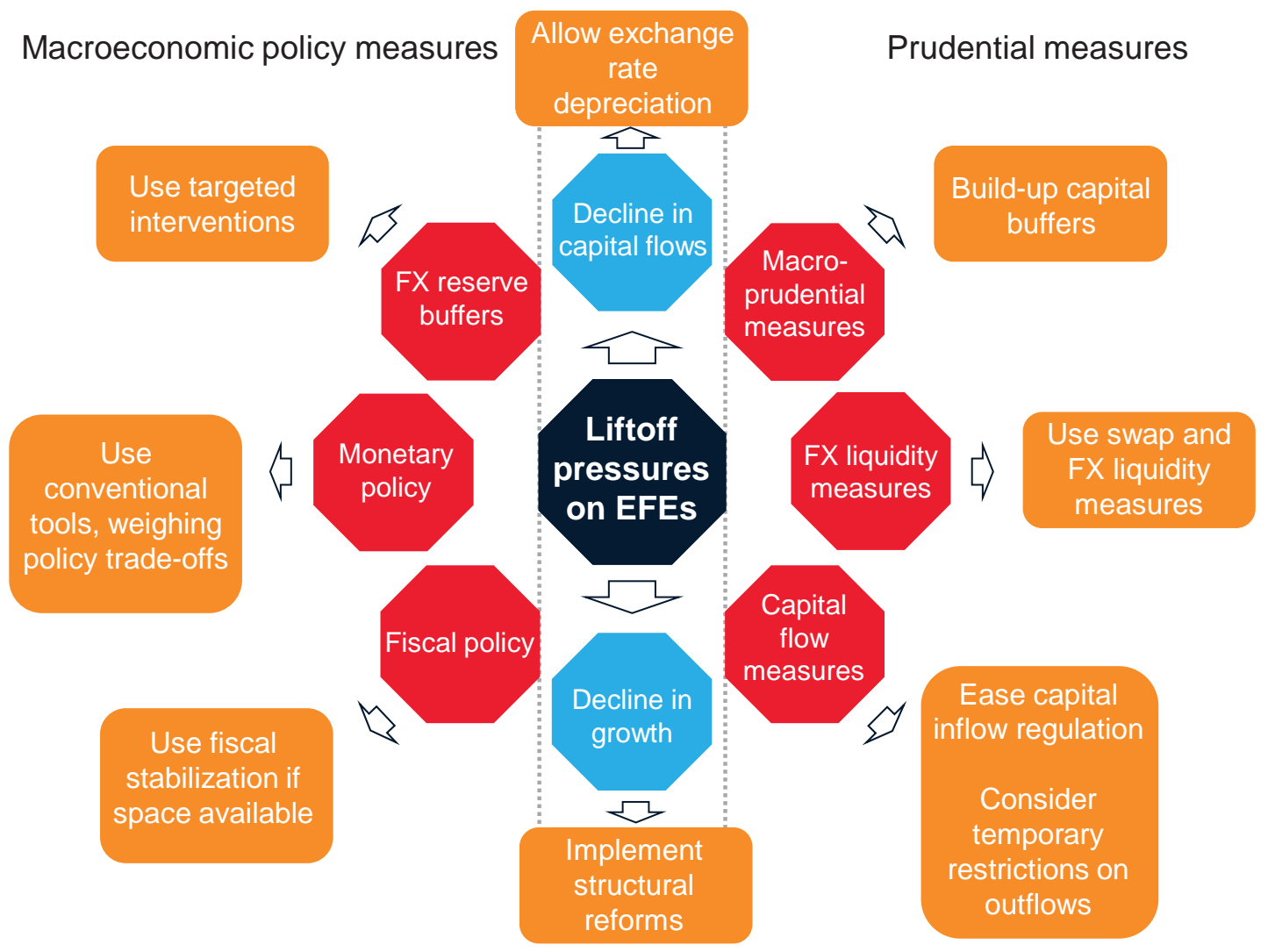

Source: World Bank 


\section{CONCLUSION}

Financial conditions are on the cusp of becoming more challenging for EFEs as the Fed will soon embark on its first tightening cycle in almost a decade. This will take place in a difficult global context for EFEs: global growth remains subdued, world trade is weak, and commodity prices remain low. Moreover, many EFEs are struggling with weakening growth prospects and lingering vulnerabilities that constrain their policy options.

The taper tantrum episode of May-June 2013 is a reminder that even a long-anticipated change in Fed policies can surprise markets and trigger substantial volatility in capital flows to EFEs. During the taper tantrum episode, a jump in U.S. long-term interest rates initially led to significant financial stress across the entire spectrum of EFE assets. Over time, greater differentiation among countries increased based on country-specific vulnerabilities, policies, and growth prospects. This paper addressed four major questions:

\section{How have growth prospects and policies in advanced countries changed since the taper tantrum?} Conditions in advanced economies are an important factor in driving capital inflows to EFEs. Since mid2013, interest rates in advanced economies have remained exceptionally low amid continued monetary policy accommodation by other major central banks. The U.S. economy and labor markets have further strengthened. Activity in other advanced economies is firming, although it remains fragile.

How have growth prospects and vulnerabilities changed in EFEs since the taper tantrum? EFEs have become more resilient since the 1990s. Fewer have fixed exchange rates, most have sounder fiscal positions and better monetary policy frameworks, and the extent of liability dollarization has declined (Kose and Prasad 2010; Davies et al. 2014). However, since mid-2013, EFE growth prospects and credit worthiness have deteriorated. Furthermore, many EFEs have made little progress in reducing domestic and external vulnerabilities, such as elevated debt levels, current account deficits, and sizable foreign currency exposures.

What are the major risks associated with the tightening cycle for EFEs? The tightening cycle is expected to proceed smoothly since it has long been anticipated and it will most likely evolve very gradually. If it takes place in line with market expectations, U.S. long-term yields will likely remain low and the term premium will be narrow. Global interest rates are also expected to remain low as the ECB and Bank of Japan will likely continue pursuing exceptionally accommodative policies. It is therefore likely that the impact of the coming tightening cycle on capital flows to EFEs will be modest.

However, as during the taper tantrum, there is a risk that market expectations adjust in a disorderly fashion during the tightening cycle. Specifically, low U.S. term premia, diverging views between markets and Fed policy makers about the future path of interest rates, fragile market liquidity, and an increasingly challenging external environment for EFEs all heighten financial market risks.

In a context of soft global growth, weak trade flows and low commodity prices, the sudden realization of risks during the tightening cycle could lead to a significant decline in capital flows to EFEs (up to 2.2 percentage points of GDP after a year). Global financial market volatility could combine with underlying weakness into a "perfect storm" in some EFEs, in particular those that need to adjust to the prospects of persistently low commodity prices and tighter financial conditions, or that face domestic policy uncertainty against the backdrop of lingering vulnerabilities and weaker growth. 
What policy options are available for EFEs to cope with the potentially adverse effects of the tightening cycle? In anticipation of the risks surrounding the tightening cycle, EFEs should prioritize monetary and fiscal policies that reduce vulnerabilities and undertake structural policy measures that improve growth prospects. In the event that risks materialize, the priority should be on policy measures to alleviate short-term financial stress. Exchange rate flexibility could buffer shocks in some countries but may need to be complemented by monetary policy measures and targeted interventions to support orderly market functioning. Accelerated implementation of long-standing structural reforms could signal improved long-term growth prospects to risk-averse investors.

While emerging and frontier market economies may hope for the best during the upcoming tightening cycle, given the substantial risks involved, they need to prepare for the worst. 


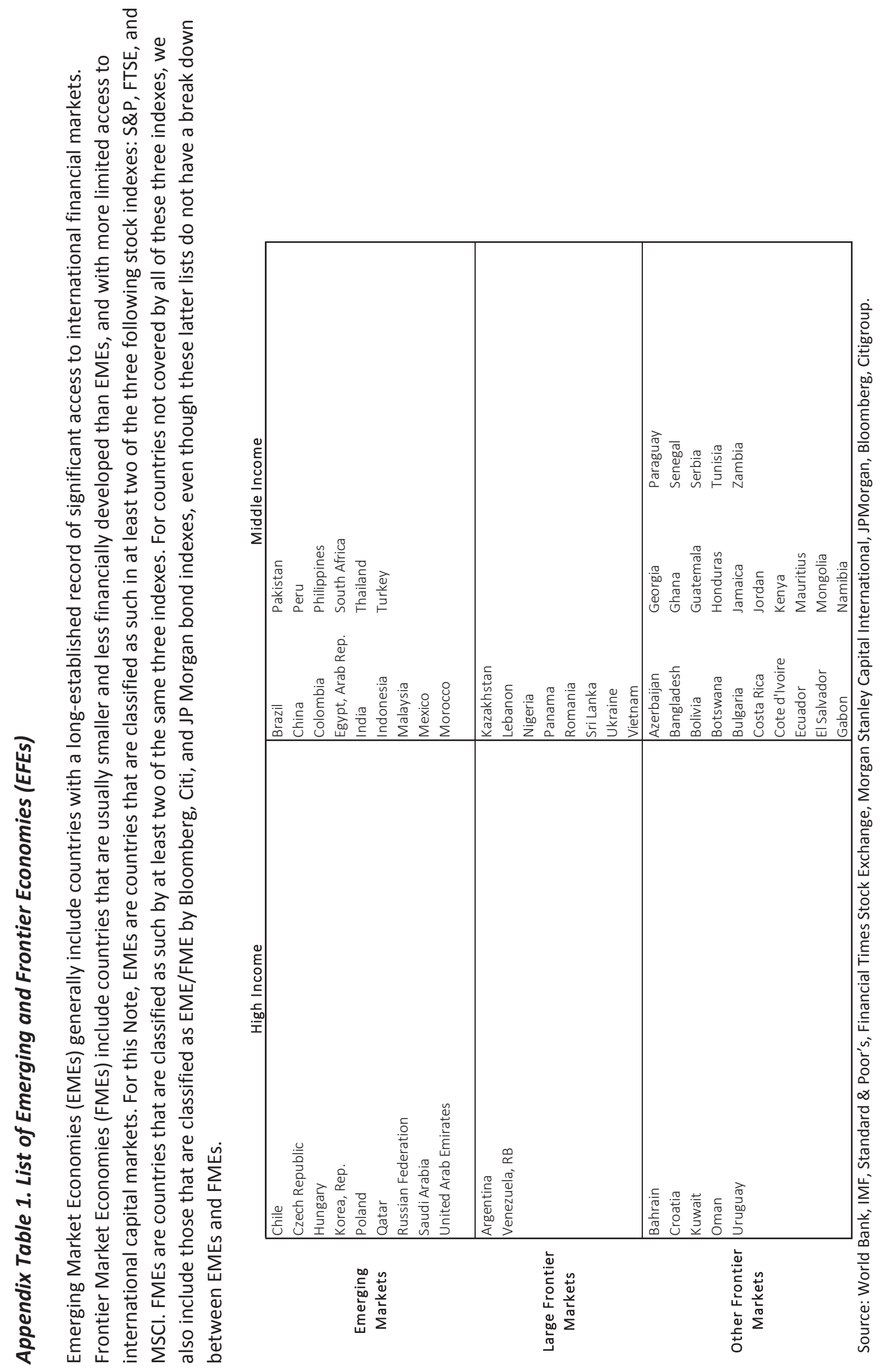




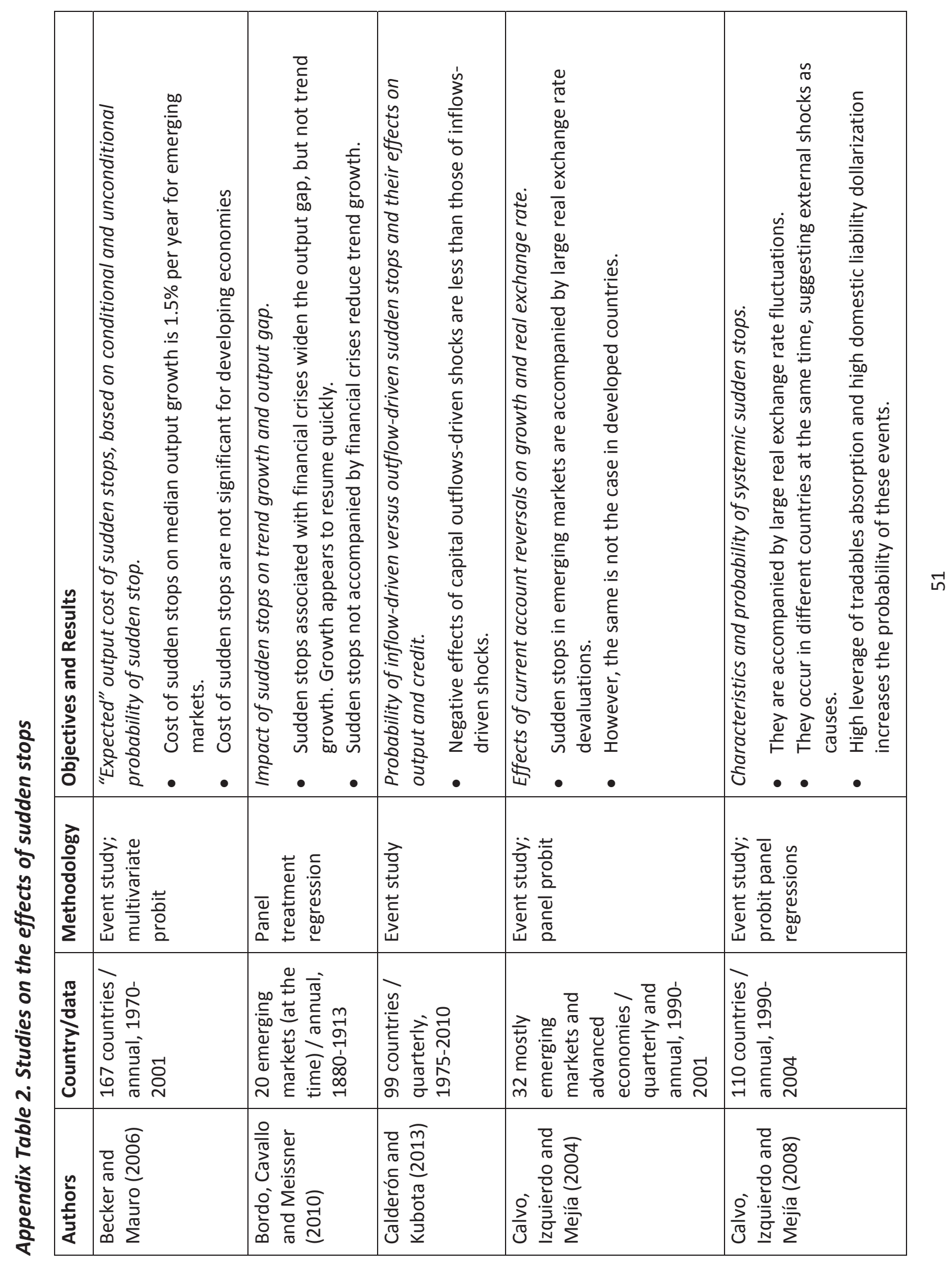




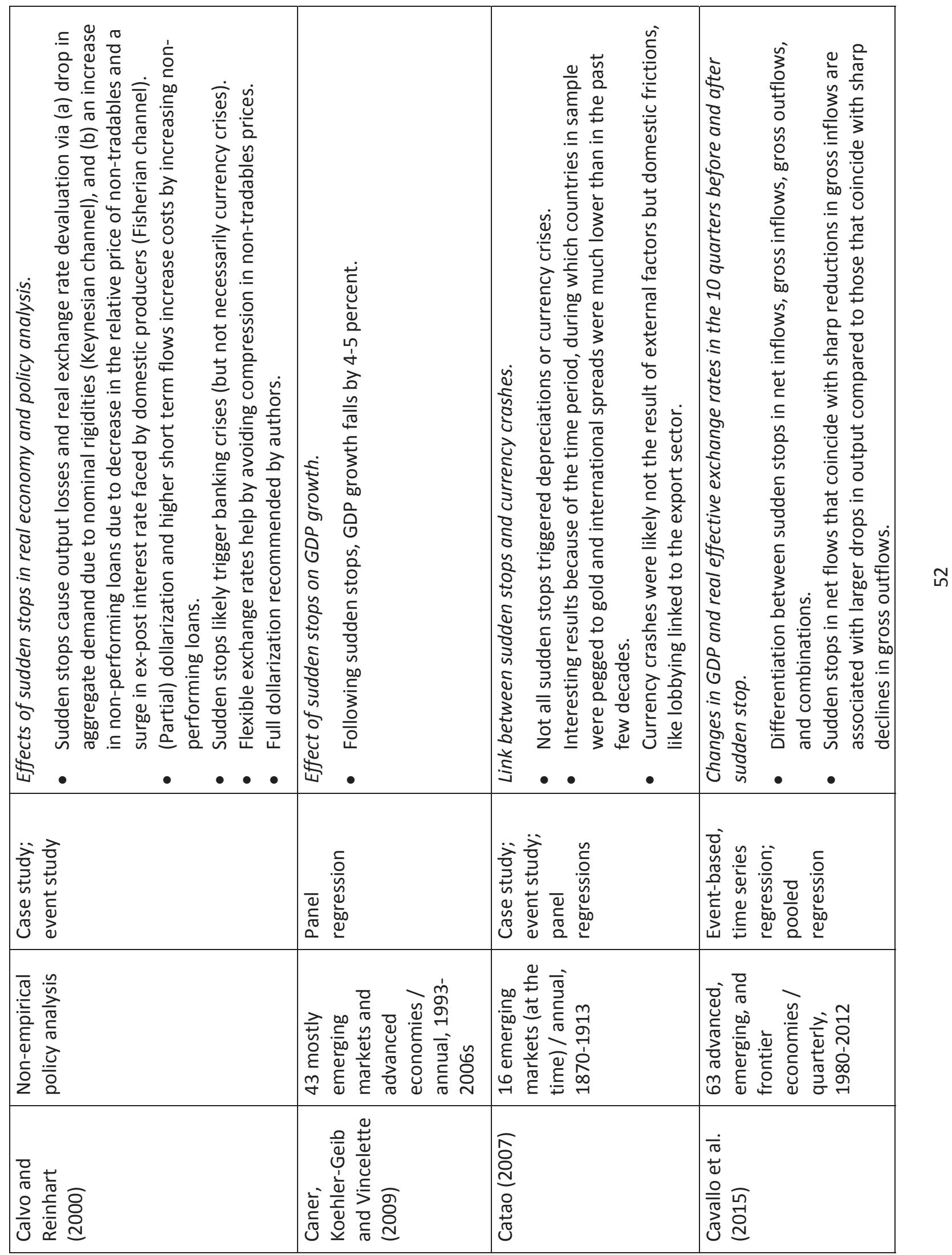




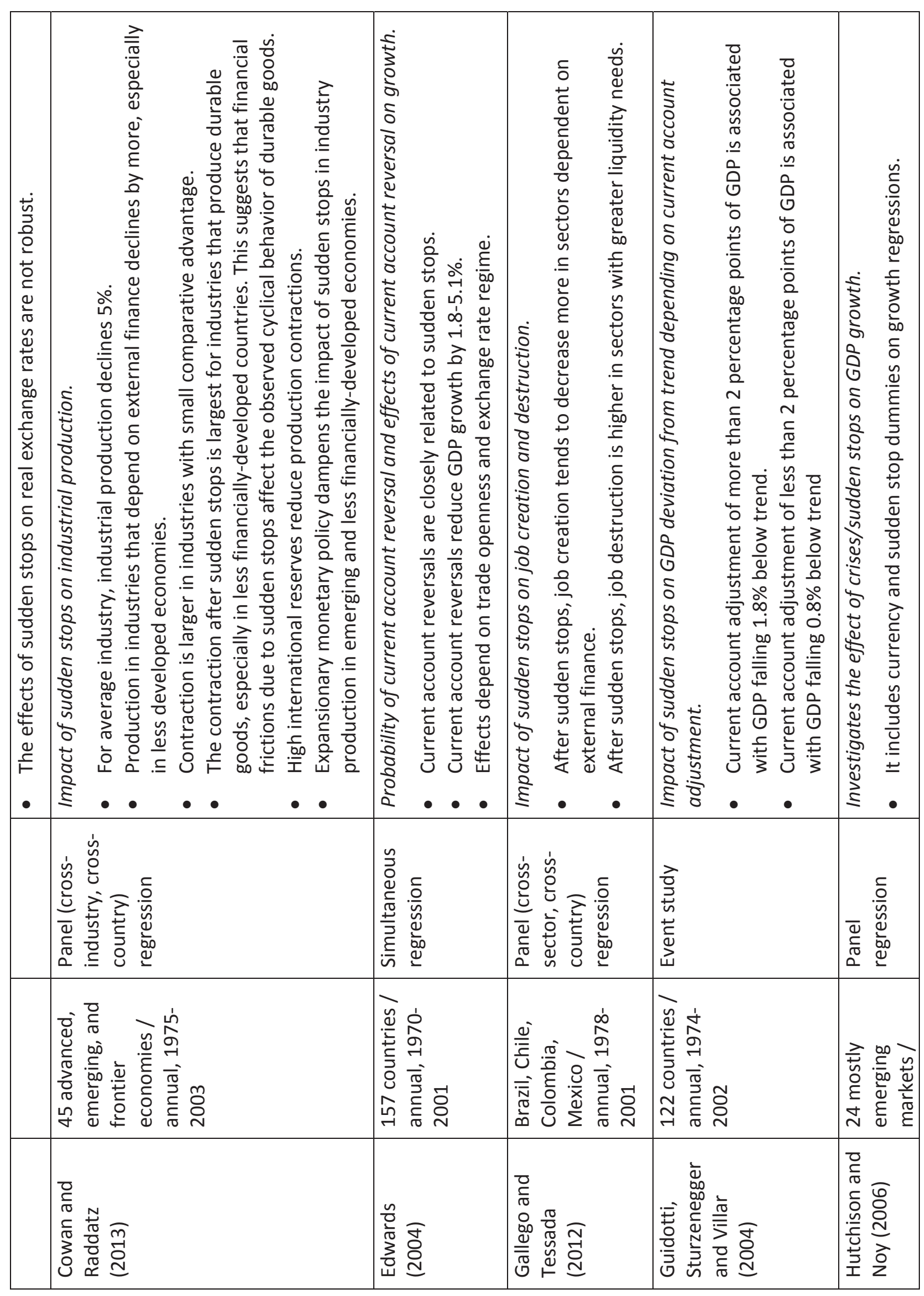




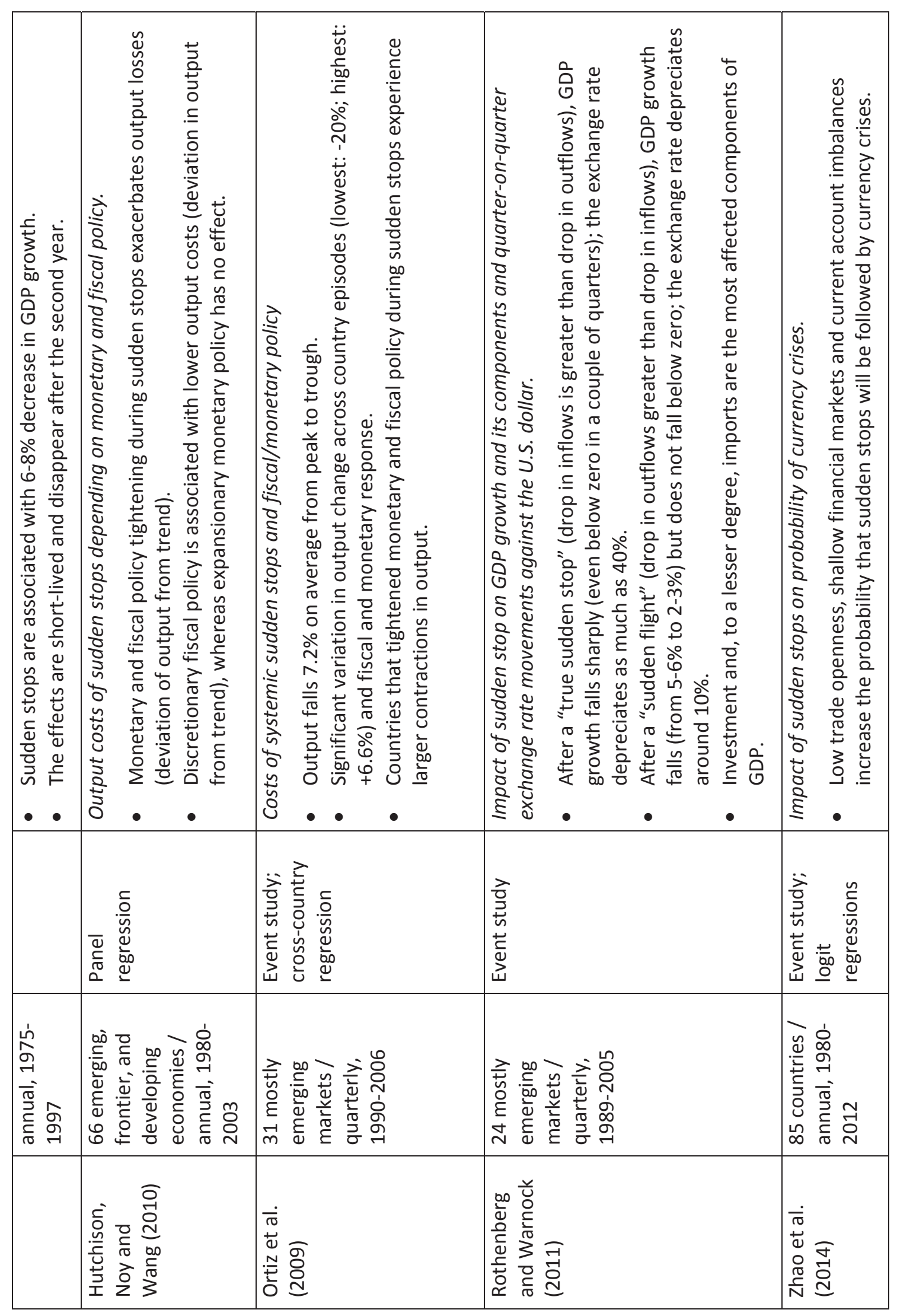




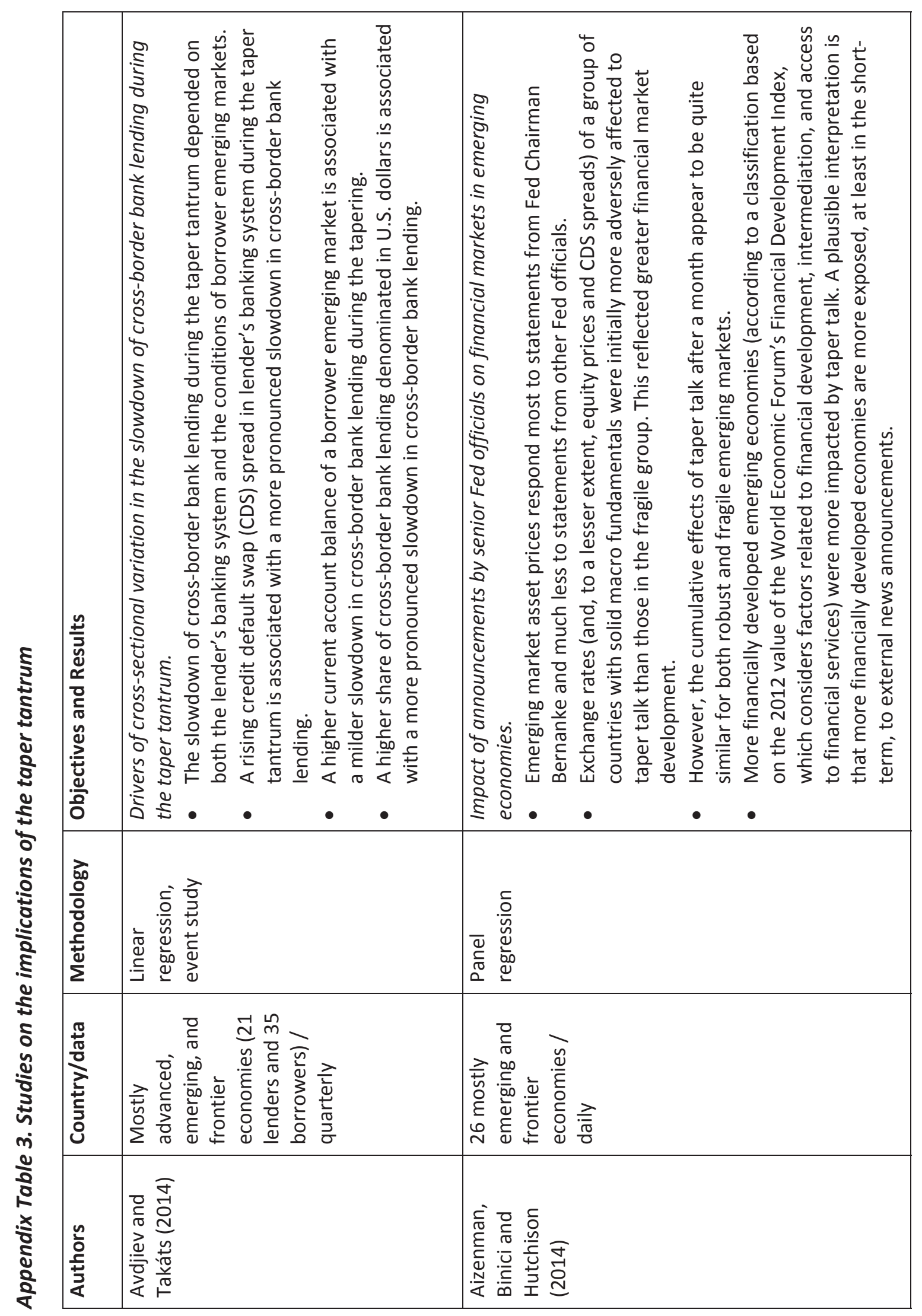




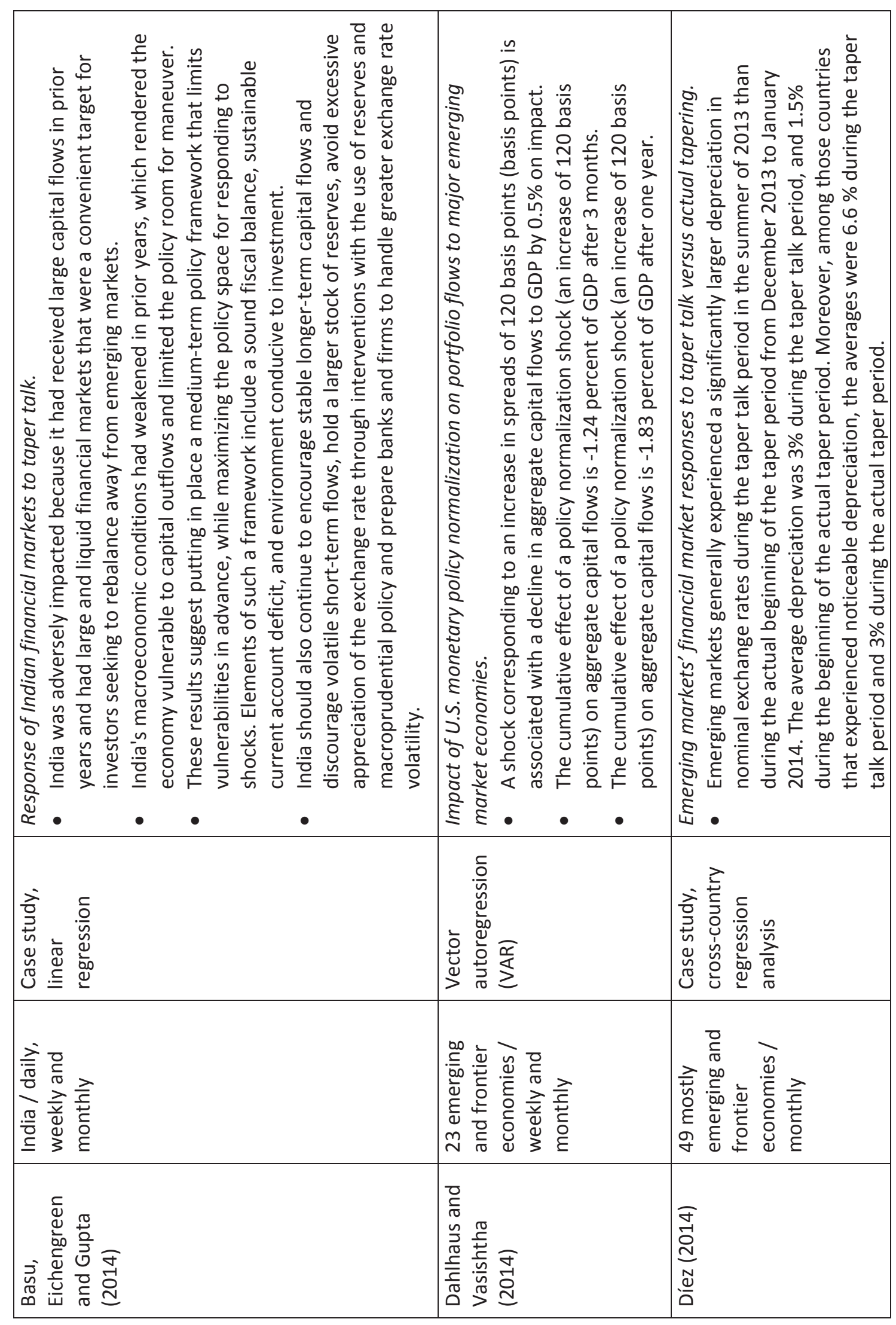




\begin{tabular}{|c|c|c|c|}
\hline 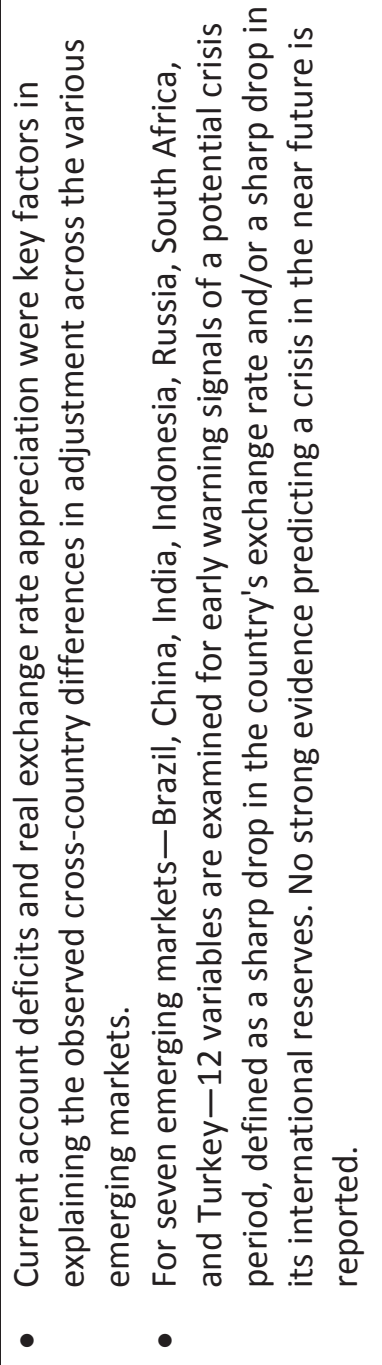 & 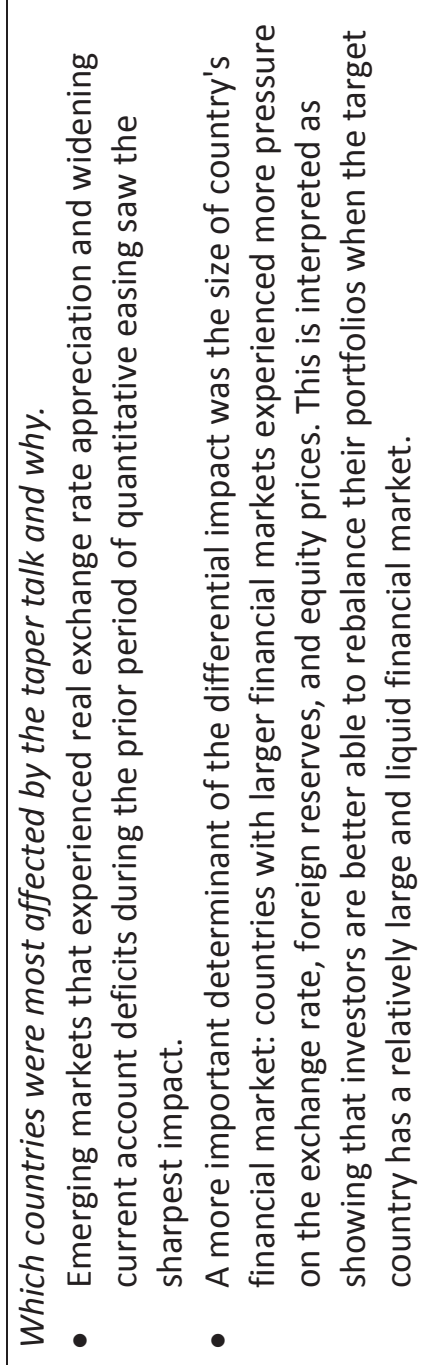 & 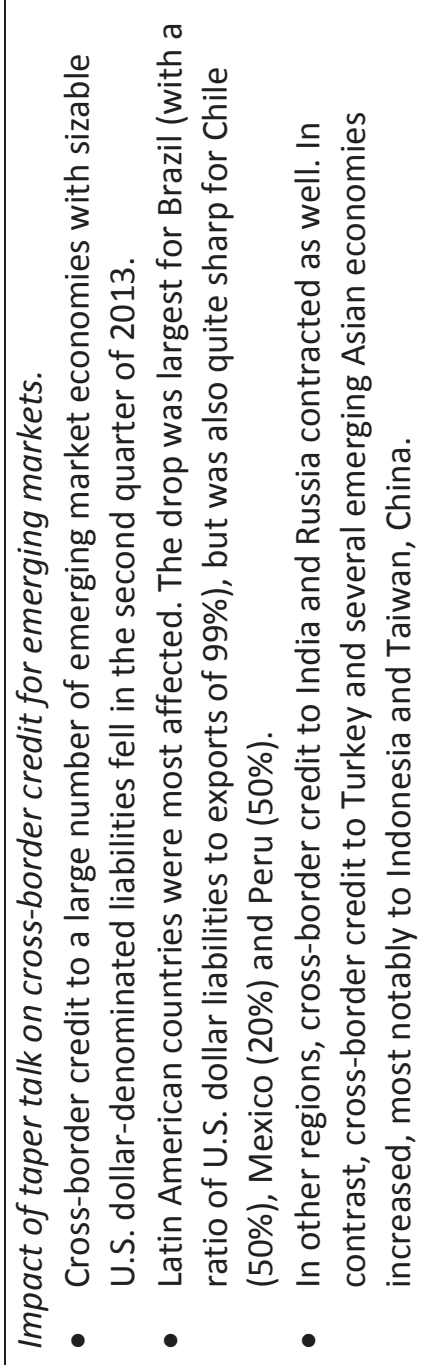 & 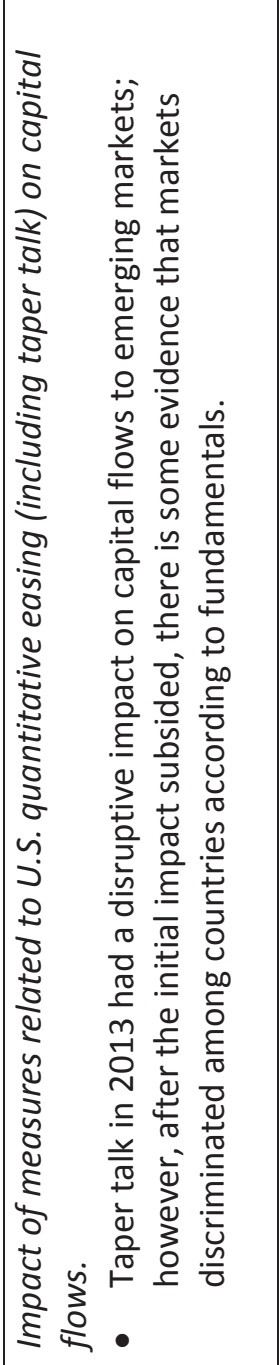 \\
\hline & 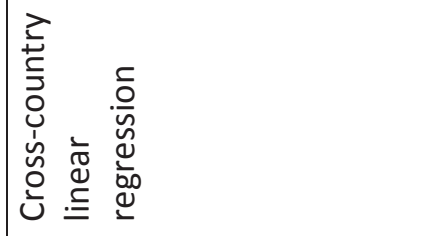 & 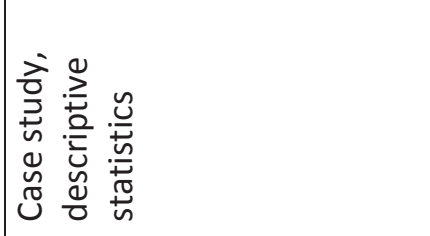 & 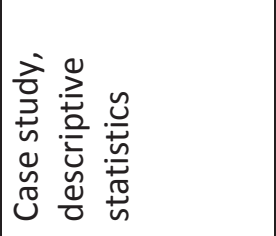 \\
\hline & 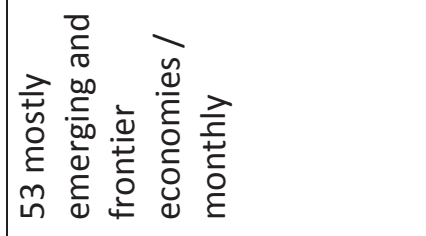 & 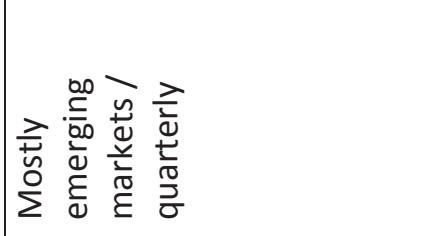 & 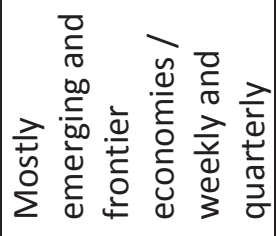 \\
\hline & 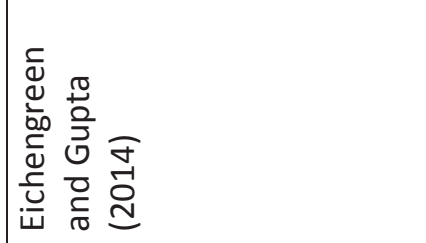 & 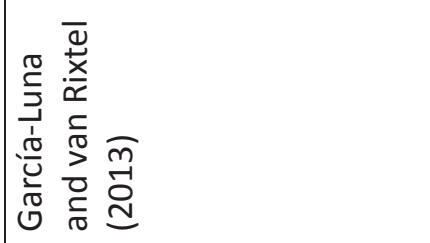 & 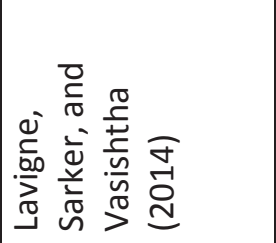 \\
\hline
\end{tabular}




\begin{tabular}{|c|c|c|c|}
\hline 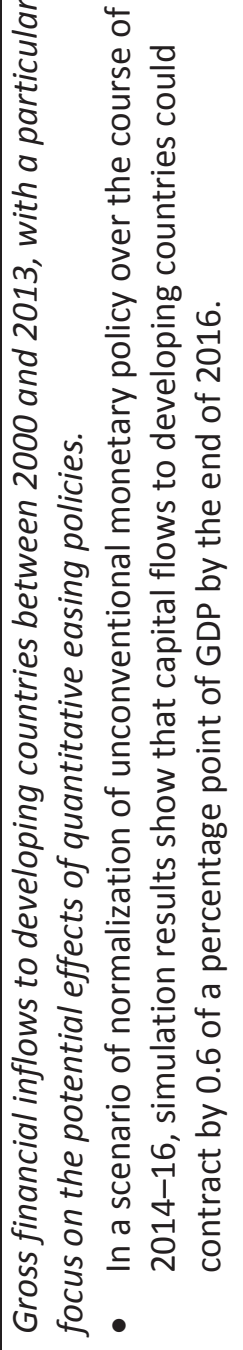 & 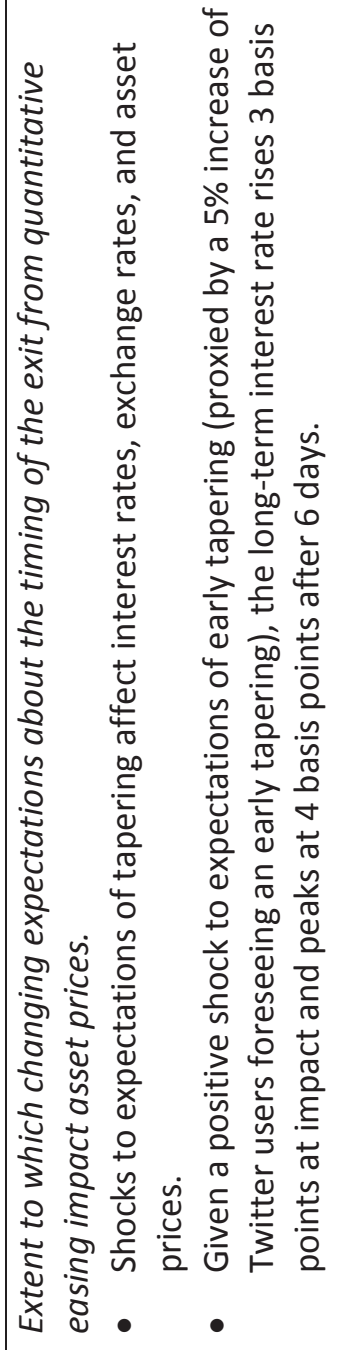 & 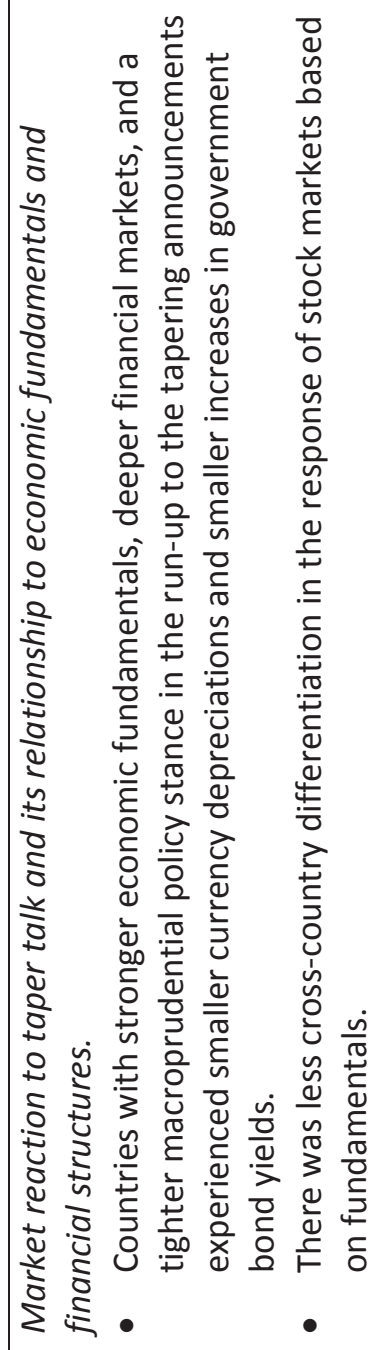 & 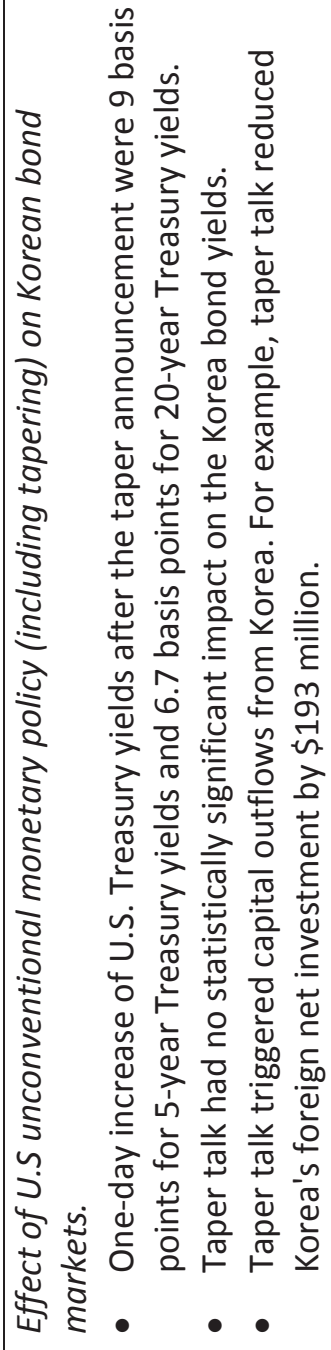 \\
\hline 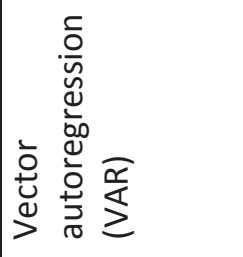 & 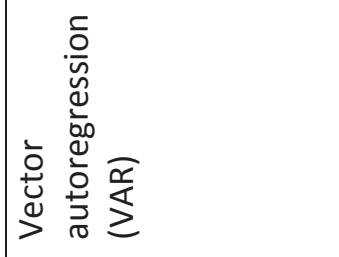 & 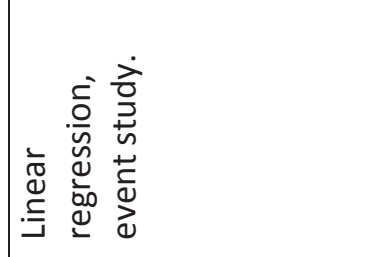 & 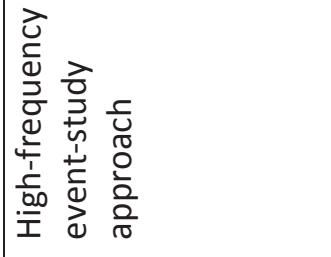 \\
\hline 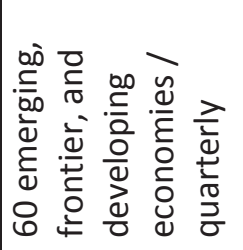 & 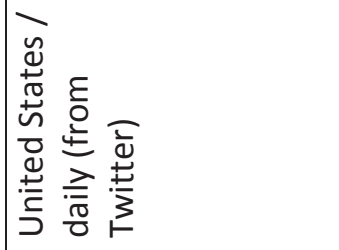 & 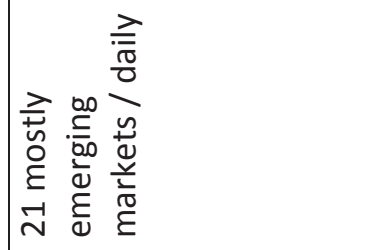 & 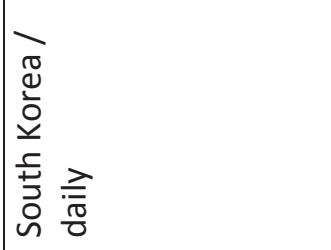 \\
\hline 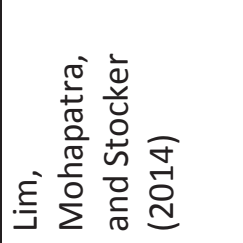 & 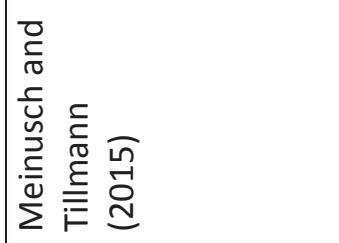 & 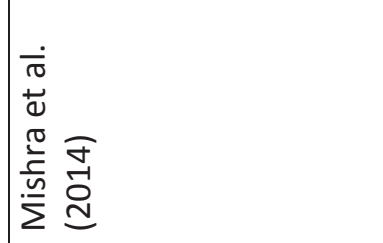 & 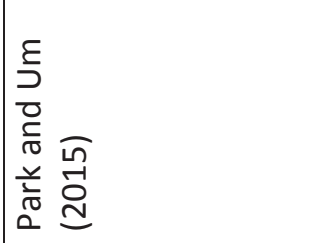 \\
\hline
\end{tabular}




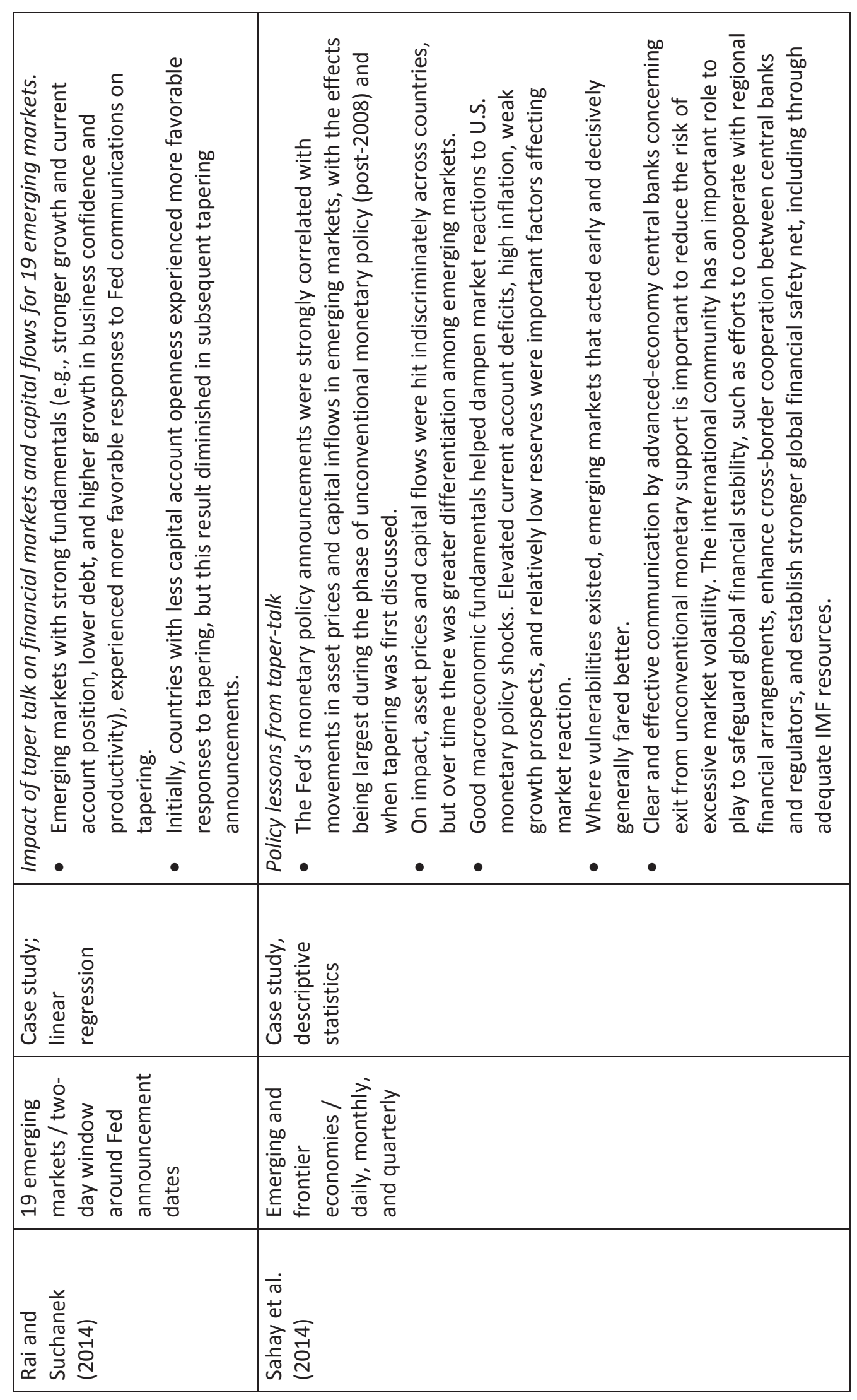




\section{REFERENCES}

Aaronson, S., T. Cajner, B. Fallick, F. Galbis-Reig, C. Smith, and W. Wascher. 2014. "Labor Force Participation: Recent Developments and Future Prospects." Brookings Papers on Economic Activity. Brookings Institution, Washington, DC.

Abrahams, M., T. Adrian, R. K. Crump, and E. Moench. 2015. “Decomposing Real and Nominal Yield Curves." Staff Reports No. 570. Federal Reserve Bank of New York.

Adler, G., M.-L. Djigbenou, and S. Sosa. 2014. "Global Financial Shocks and Foreign Asset Repatriation: Do Local Investors Play a Stabilizing Role?" IMF Working Paper 14/60. International Monetary Fund, Washington, DC.

Adrian, T., R. Crump, and E. Moench. 2013a. "Do Treasury Term Premia Rise around Monetary Tightenings?" Liberty Street Economics Blog. April 15. http://libertystreeteconomics.newyorkfed.org/.

2013b. "Pricing the Term Structure with Linear Regressions." Journal of Financial Economics 110 (1): 110-38.

Adrian, T., M. Fleming, J. Goldberg, M. Lewis, F. Natalucci, and J. Wu. 2013. "Dealer Balance Sheet Capacity and Market Liquidity during the 2013 Selloff in Fixed-Income Markets." Liberty Street Economics Blog. October 16.

http://libertystreeteconomics.newyorkfed.org/.

Adrian, T., and H. S. Shin. 2010. "Liquidity and Leverage." Journal of Financial Intermediation 19:418-37.

2011. "Financial Intermediaries and Monetary Economics." Handbook of Monetary Economics, Vol. 3, 601-50. San Diego, CA: Elsevier.

2012. "Pro-cyclical Leverage and Value-at-Risk." Staff Reports No. 338. Federal Reserve Bank of New York.

Ahmed, S. and A. Zlate. 2013. "Capital Flows to Emerging Market Economies: A Brave New World?" International Finance Discussion Papers 1081. Board of Governors of the Federal Reserve System, Washington, DC.

Ahmed S., B. Coulibaly, and A. Zlate. 2015. "International Financial Spillovers to Emerging Market Economies: How Important Are Economic Fundamentals?" International Finance Discussion Papers 1135. Board of Governors of the Federal Reserve System, Washington, DC.

Aizenman, J., M. Binici, and M. M. Hutchison. 2014. "The Transmission of Federal Reserve Tapering News to Emerging Financial Markets." NBER Working Paper No. 19980. National Bureau of Economic Research, Cambridge, MA.

Alturki, F., J. Espinosa-Bowen, and N. Ilahi. 2009. "How Russia Affects the Neighbourhood: Trade, Financial and Remittance Channels." IMF Working Paper 09/277. International Monetary Fund, Washington, DC.

Avdijev, S., and E. Takáts. 2014. "Cross-Border Bank Lending During the Taper Tantrum: The Role of Emerging Market Fundamentals." BIS Quarterly Review (September): 49-60. 
Aziz, Z.A. 2015. Comments after a presentation at a "Master Class in Financial Crises" organized by Yale University's School of Management. August 7. http://www.wsj.com/articles/mexico-and-malaysiacentral-bankers-ready-for-liftoff-1438965131

Bakanova, M., and R. Sobirzoda. 2014. Tajikistan: Moderated growth, heightened risks. Tajikistan Economic Report, No.6. Washington, DC: World Bank Group.

Bank of England and the Procyclicality Working Group. 2014. "Procyclicality and Structural Trends in Investment Allocation by Insurance Companies and Pension Funds." Bank of England and Procyclicality Working Group Discussion Paper. London.

Bank of International Settlements. 2015. 85th Annual Report, 2014/15. Basel, June.

Basu, K., B. Eichengreen, and P. Gupta. 2014. "From Tapering to Tightening: The Impact of the Fed's Exit on India." Policy Research Working Paper 7071. World Bank, Washington, DC.

Bean, C. 2013. "Global Aspects of Unconventional Monetary Policies." Bank of England, August.

Becker, T. I., and P. Mauro. 2006. "Output Drops and the Shocks That Matter." Working Paper 06/172. International Monetary Fund, Washington, DC.

Bernanke, B. 2013a. Comments after "The Economic Outlook," testimony before the Joint Economic Committee, U.S. Congress, Washington, DC, May 22. http://www.gpo.gov/fdsys/pkg/CHRG-113shrg81472/pdf/CHRG-113shrg81472.pdf.

2013b. "Long-Term Interest Rates." Speech at the Annual Monetary/Macroeconomics Conference, "The Past and Future of Monetary Policy," sponsored by the Federal Reserve Bank of San Francisco, San Francisco, March 1.

. 2015. "Why Are Interest Rates so Low, Part 4: Term Premiums?" Ben Bernanke's Blog. http://www.brookings.edu/blogs/ben-bernanke.

Bi, H., W. Shen, and S. Yang. 2014. "Fiscal Limits, External Debt, and Fiscal Policy in Developing Countries." Working Paper 14/49. International Monetary Fund, Washington, DC.

Blanchard, O., D. Furceri, and A. Pescatori. 2014. "A Prolonged Period of Low Real Interest Rates?" In Secular Stagnation: Facts, Causes and Cures, edited by C. Teulings and R. Baldwin. London: Centre for Economic Policy Research.

Bluedorn, J. C., R. Duttagupta, J. Guajardo, and P. Topalova. 2013. “Capital Flows Are Fickle: Anytime, Anywhere." IMF Working Paper No. 13/183. International Monetary Fund, Washington, DC.

Blume, M. E., and D. B. Keim. 2012. "Institutional Investors and Stock Market Liquidity: Trends and Relationships." Working Paper. The Wharton School, University of Pennsylvania, Philadelphia, PA.

Board of Governors of the Federal Reserve System. 2014. "Policy Normalization Principles and Plans." Monetary Policy Releases, September 17.

http://www.federalreserve.gov/newsevents/press/monetary/20140917c.htm

Bordo, M. D., A. F. Cavallo, and C. F. Meissner. 2010. "Sudden Stops: Determinants and Output Effects in the First Era of Globalization, 1880-1913." Journal of Development Economics 91 (2): 227-41.

Borio, C. 2014. "The International Monetary and Financial System: Its Achilles Heel and What to Do about It." BIS Working Papers No. 456. Bank for International Settlements, Basel.

Borio, C., and H. Zhu. 2012. "Capital Regulation, Risk-taking and Monetary Policy: A Missing Link in the Transmission Mechanism?" Journal of Financial Stability 8(1): 236-51. 
Bruno, V., and H. S. Shin. 2013. "Capital Flows, Cross-Border Banking and Global Liquidity." NBER Working Paper No. 19038. National Bureau of Economic Research, Cambridge, MA.

2015. "Capital Flows and the Risk-Taking Channel of Monetary Policy." Journal of Monetary Economics 71 (1): 119-32.

Burns, A., Kida, M., Lim, J., Mohapatra, S and Stocker, M. 2014. "Unconventional monetary policy normalization in high-income countries: implications for emerging market capital flows and crisis risks." Policy Research Working Paper Series 6830. World Bank, Washington, DC.

Bullard, J. 2014. "Two Views of International Monetary Policy Coordination." Speech at 27th Asia/Pacific Business Outlook Conference USC Marshall School of Business-CIBER, 7 April 2014, Los Angeles.

Bullard, J. and A. Singh. 2008. "Worldwide Macroeconomic Stability and Monetary Policy Rules." Journal of Monetary Economics 55 (Supplement): S34-S47.

Caballero, R. J., and E. Farhi. 2014. "On the Role of Safe Asset Shortages in Secular Stagnation." In Secular Stagnation: Facts, Causes and Cures, edited by C. Teulings and R. Baldwin. London: Centre for Economic Policy Research.

Calderón, C., and M. Kubota. 2013. "Sudden Stops: Are Global and Local Investors Alike?” Journal of International Economics 89 (1): 122-42.

Calvo, G., A. Izquierdo, and L. F. Mejía. 2004. "On the Empirics of Sudden Stops: the Relevance of Balance-sheet Effects." NBER Working Paper No. 10520. National Bureau of Economic Research, Cambridge, MA.

. 2008. "Systemic Sudden Stops: The Relevance of Balance-Sheet Effects and Financial Integration." NBER Working Paper No. 14026. National Bureau of Economic Research, Cambridge, MA.

Calvo, G. A., A. Izquierdo, and E. Talvi. 2006. "Sudden Stops and Phoenix Miracles in Emerging Markets." American Economic Review 96 (2): 405-10.

Calvo, S., and C. Reinhart. 1996. "Capital Flows to Latin America: Is There Evidence of Contagion Effects?" Policy Research Working Paper 1619. World Bank, Washington, DC.

2000. "When Capital Inflows Come to a Sudden Stop: Consequences and Policy Options." In Reforming the International Monetary and Financial System, edited by P. Kenen and A. Swoboda. Washington, DC: International Monetary Fund.

Caner, M., F. Koehler-Geib, and G. A. Vincelette. 2009. “When Do Sudden Stops Really Hurt?” Policy Research Working Paper 5021. World Bank, Washington, DC.

Cardarelli, R., S. Elekdag, and M. A. Kose. 2010. “Capital Inflows: Macroeconomic Implications and Policy Responses." Economic Systems 34 (4): 333-56.

Carstens, A. 2015a. Comments after a presentation at a "Master Class in Financial Crises" organized by Yale University's School of Management. August 7. http://www.wsj.com/articles/mexico-andmalaysia-central-bankers-ready-for-liftoff-1438965131

2015b. "Challenges for Emerging Economies in the Face of Unconventional Monetary Policies in Advanced Economies." Stavros Niarchos Foundation Lecture, Peterson Institute for International Economics, April 20. 
Catao, L. A. V. 2007. "Sudden Stops and Currency Drops: A Historical Look." In The Decline of Latin American Economies: Growth, Institutions and Crises, edited by S. Edwards, G. Esquivel, and G. Marquez. Chicago, IL: University of Chicago Press.

Cavallo, E., A. Powell, M. Pedemonte, and P. Tavella. 2015. "A New Taxonomy of Sudden Stops: Which Sudden Stops should Countries be Most Concerned About?" Journal of International Money and Finance 51: 47-70.

Cerutti, E., S. Claessens, and D. Puy. 2015. "Push Factors and Capital Flows to Emerging Markets: Why Knowing Your Lender Matters More Than Fundamentals." IMF Working Paper No. 15/127. International Monetary Fund, Washington, DC.

Chui, M., I. Fender and V. Sushko. 2014. "Risks Related to EME Corporate Balance Sheets: the Role of Leverage and Currency Mismatch", BIS Quarterly Review (September): 35-47.

Claessens, S., and M. A. Kose. 2014. "Financial Crises: Explanations, Types and Implications." In Financial Crises: Causes, Consequences, and Policy Responses, edited by S. Claessens, M. A. Kose, L. Laeven, and F. Valencia, 3-60. Washington, DC: International Monetary Fund.

Claessens, S., M. A. Kose, L. Laeven, and F. Valencia. 2014. Financial Crises: Causes, Consequences, and Policy Responses. Washington, DC: International Monetary Fund.

Collyns, C., and R. Koepke. 2015. "Which EMs Would Suffer from a Risk Shock?” Institute of International Finance, Washington, DC. Memo.

Comelli, F. 2015. "Estimation and Out-of-sample Prediction of Sudden Stops: Do Regions of Emerging Markets Behave Differently from Each Other?" IMF Working Paper No. 15/138. International Monetary Fund, Washington, DC.

Committee on the Global Financial System. 2014. "Market-Making and Proprietary Trading: Industry Trends, Drivers and Policy Implications." CGFS Papers No. 52. Bank for International Settlements, Basel.

Corsetti, G., K. Kuester, A. Meier, and G. J. Müller. 2013. "Sovereign Risk, Fiscal Policy, and Macroeconomics." Economic Journal 123 (566): F99-F132.

Council of Economic Advisers. 2014. "The Labor Force Participation Rate since 2007: Causes and Policy Implications." Council of Economic Advisers, Washington, DC.

Cowan, K., and C. Raddatz. 2013. "Sudden Stops and Financial Frictions: Evidence from Industry- Level Data." Journal of International Money Finance 32: 99-128.

Craighead, W. D., and D. R. Hineline. 2013. "Current Account Reversals and Structural Change in Developing and Industrialized Countries." Wesleyan Economics Working Papers 2013-001. Wesleyan University Department of Economics, Middleton, CT.

Dahlhaus, T., and G. Vasishtha. 2014. "The Impact of U.S. Monetary Policy Normalization of Capital Flows to Emerging-Market Economies." Working Paper 2014-53. Bank of Canada, Ottawa.

Davies, G., M. Obstfeld, A. M. Taylor, and D. Wilson. 2014. "Will Emerging Market Jitters Morph into a Crisis?" Fulcrum Research Paper.

https://www.fulcrumasset.com/assets/2/1608_document.pdf?1398878033.

Dell'Ariccia, G., L. Laeven, and G. Suárez. 2013. "Bank Leverage and Monetary Policy's Risk-Taking Channel: Evidence from the United States." IMF Working Paper No. 13/143. International Monetary Fund, Washington, DC. 
Didier, T., P. Mauro, and S. Schmukler. 2008. "Vanishing Financial Contagion?” Journal of Policy Modeling 30 (5): 775-791.

Diebold, F. X., and Yilmaz, K. 2015. Financial Connectedness: A Network Approach to Measurement and Monitoring. Oxford, U.K.: Oxford University Press.

Díez, F. J. 2014. "The Emerging Market Economies in Times of Taper-Talk and Actual Tapering." Current Policy Perspectives No. 14-6. Federal Reserve Bank of Boston.

Ding, D. and I. Masha. 2012. "India's Growth Spillovers to South Asia." IMF Working Paper 12/56. International Monetary Fund, Washington, DC.

Druck, P., N. Magud, and R. Mariscal-Paredes. 2015. "Collateral Damage: Dollar Strength and Emerging Markets' Growth", IMF Working Paper WP/15/179. International Monetary Fund, Washington, DC.

Dudley, W. 2014. "U.S. Monetary Policy and Emerging Market Economies." Speech at the Roundtable Discussion in Honor of Terrence Checki, "Three Decades of Crises: What Have We Learned?" Federal Reserve Bank of New York, New York, March 27.

Dupor, W. 2015. "Liftoff and the Natural Rate of Interest." Economic Synopses (June), Federal Reserve Bank of St. Louis.

Edwards, S., 2004. "Thirty Years of Current Account Imbalances, Current Account Reversals and Sudden Stops." IMF Staff Papers 51(0): 1-49. International Monetary Fund, Washington, DC.

Eichengreen, B., and P. Gupta. 2014. "Tapering Talk: The Impact of Expectations of Reduced Federal Reserve Security Purchases on Emerging Markets." Policy Research Working Paper 6754. World Bank, Washington, DC.

Eichengreen, B., and A. Rose. 2003. "Does It Pay to Defend against a Speculative Attack?" In Managing Currency Crises in Emerging Markets, edited by M. Dooley and J. Frankel. Chicago, IL: University of Chicago Press.

Escolano, J., C. Kolerus, and C. L. Ngouana. "Global Monetary Tightening: Emerging Markets Debt Dynamics and Fiscal Crises." IMF Working Paper No. 14/215. International Monetary Fund, Washington, DC.

Fender, I., and U. Lewrick. 2015. "Shifting Tides -Market Liquidity and Market-Making in Fixed Income Instruments." BIS Quarterly Review (March): 97-109.

Fernald, J. and B. Wang. 2015. "The Recent Rise and Fall of Rapid Productivity Growth." Economic Letter 2015-04, Federal Reserve Bank of San Francisco.

Feyen, E., S. Ghosh, K. Kibuuka, and S. Farazi. 2015. "Global Liquidity and External Bond Issuance in Emerging Markets and Developing Economies", Policy Research Working Paper 7363. World Bank, Washington, DC.

Fischer, S. 2014. "The Federal Reserve and the Global Economy." Speech at the 2014 Annual Meetings of the International Monetary Fund and the World Bank Group, Washington, DC. October 11.

2015. "The Federal Reserve and the Global Economy." Speech at the conference held in honor of Professor Haim Ben-Shahar, former president of Tel Aviv University, Tel Aviv University, Tel Aviv, Israel, May 26.

Forbes, K. J., and M. W. Klein. 2015. "Pick Your Poison: The Choices and Consequences of Policy Responses to Crises." IMF Economic Review 63: 197-237. 
Forbes, K. J., and F. E. Warnock. 2012. "Capital Flow Waves: Surges, Stops, Flight, and Retrenchment." Journal of International Economics 88 (2): 235-51.

Frankel, J., and S. Wei. 2004. "Managing Macroeconomic Crises." NBER Working Paper No. 10907. National Bureau of Economic Research, Cambridge, MA.

Fratzscher, M., 2012. "Capital Flows, Push versus Pull Factors and the Global Financial Crisis." Journal of International Economics 88 (2): 341-56.

Gallego, F., and J. Tessada. 2012. "Sudden Stops and Reallocation: Evidence from Labor Market Flows in Latin America." Journal of Development Economics 97 (2): 257-68.

García-Luna, P., and A. van Rixtel. 2013. "Emerging Markets and Talk of Tapering." BIS Quarterly Review (December): 16-17.

Gordon, R. J. 2014. "The Demise of U.S. Economic Growth: Restatement, Rebuttal, and Reflections." NBER Working Paper No. 19895. National Bureau of Economic Research, Cambridge, MA.

Gruić, B., and P. Wooldridge. 2013. "Who is Issuing International Bonds Denominated in Emerging Market Currencies?" BIS Quarterly Review (December): 22-23.

Guidotti, P., F. Sturzenegger, and A. Villar. 2004. "On the Consequences of Sudden Stops." Economia 4 (2): 171-214.

Hall, R. E. 2014. "Quantifying the Lasting Harm to the U.S. Economy from the Financial Crisis." In J. Parker and M. Woodford (eds.) NBER Macroeconomics Annual 2014, Volume. 29.

Hamilton, J. D., E. S. Harris, J. Hatzius, and K. D. West. 2015. "The Equilibrium Real Funds Rate: Past, Present, and Future." Working Paper. University of California, San Diego, CA.

Hunter, D. M., and D. P. Simon. 2005. "A Conditional Assessment of the Relationships between the Major World Bond Markets." European Financial Management 11 (4): 463-82.

Hutchison, M., and I. Noy. 2006. "Sudden Stops and the Mexican Wave: Currency Crises, Capital Flow Reversals and Output Loss in Emerging Markets." Journal of Development Economics 79 (1): 22548.

Hutchison, M. M., I. Noy, and L. Wang. 2010. "Fiscal and Monetary Policies and the Cost of Sudden Stops." Journal of International Money and Finance 29: 973-87.

Ikeda, Y., D. Medvedev, and M. Rama. 2015. "Advanced-Country Policies and Emerging-Market Currencies: The Impact of U.S. Tapering on India's Rupee." Policy Research Working Paper 7219. World Bank, Washington, DC.

Institute of International Finance. 2015. "Heat Map of EM Vulnerabilities." (May).

IMF. 2013. Global Financial Stability Report: Transition Challenges to Stability (October). Washington, DC: International Monetary Fund. 2014a. Global Financial Stability Report: Risk Taking, Liquidity, and Shadow Banking: Curbing Excess While Promoting Growth (October). Washington, DC: International Monetary Fund. 2014b. "IMF Multilateral Policy Issue Report: 2014 Spillover Report." Washington, DC: International Monetary Fund.

2014c. Regional Economic Outlook: Western Hemisphere (April). Washington, DC: International Monetary Fund. 
2014d. The Liberalization and Management of Capital Flows: An Institutional View. Washington, DC: International Monetary Fund.

2015a. Global Financial Stability Report: Navigating Monetary Policy Challenges and Managing Risks (January). Washington, DC: International Monetary Fund.

2015b. "IMF Multilateral Policy Issue Report: 2015 Spillover Report." Washington, DC: International Monetary Fund.

IMF. 2015c. "United States - IMF Article IV Consultation. “IMF Country Report No. 15/168. Washington, DC: International Monetary Fund.

Kaminsky, G. 2008. "Crises and Sudden Stops: Evidence from International Bond and Syndicated-Loan Markets." NBER Working Paper No. 14249. National Bureau of Economic Research, Cambridge, MA.

Koepke, R. 2015a. "What Drives Capital Flows to Emerging Markets? A Survey of Empirical Literature." IIF Working Paper. Institute of International Finance, Washington, DC.

2015b. "Fed Policy Expectations and Portfolio Flows to Emerging Markets." IIF Working Paper. Institute of International Finance, Washington, DC.

Kose, M. A., and E. Prasad. 2010. Emerging Markets: Resilience and Growth amid Global Turmoil. Washington, DC: Brookings Institution Press.

Kose, M. A., E. Prasad, K. Rogoff, and S. Wei. 2010. "Financial Globalization and Economic Policies." In D. Rodrik and M. R. Rosenzweig (eds.). Handbook of Development Economics, Volume 5, 4283-362. Oxford, U.K.: North-Holland.

Lavigne, R., S. Sarker, and G. Vasishtha. 2014. "Spillover Effects of Quantitative Easing on EmergingMarket Economies." Bank of Canada Review (Autumn): 23-33.

Levchenko, A., and P. Mauro. 2007. "Do Some Forms of Financial Flows Protect from Sudden Stops?" World Bank Economic Review 21 (3): 389-411.

Lee, H., C. Park, and H. Byun. 2013. “Do Contagion Effects Exist in Capital Flow Volatility?” Journal of the Japanese and International Economies 30: 76-95.

Lee, J. 2015. "Bank of Korea's 65th Anniversary." Speech at the Bank of Korea, Seoul, Korea, June 12

Lim, J., S. Mohapatra, and M. Stocker. 2014. "Tinker, Taper, QE, Bye? The Effect of Quantitative Easing on Financial Flows to Developing Countries." Policy Research Working Paper 6820. World Bank, Washington, DC.

Lo Duca, M. 2012. "Modeling the Time Varying Determinants of Portfolio Flows to Emerging Markets." Working Paper Series 1468. European Central Bank, Frankfurt.

Lo Duca, M., G. Nicoletti and A. V. Martinez. 2014. "Global corporate bond issuance: What role for US quantitative easing?” Working Paper Series No 1649. European Central Bank, Germany.

Matheson, T. and E. Stavrev. 2014. "News and Monetary Shocks at a High Frequency: A Simple Approach." IMF Working Paper No. 14/167. International Monetary Fund, Washington, DC.

McCauley, R. N., P. McGuire, and V. Sushko. 2015. "Global dollar credit: Links to US monetary policy and leverage." BIS Working Papers No 483. Bank for International Settlements, Basel.

Meinusch, A., and P. Tillmann. 2015. "Quantitative Easing and Tapering Uncertainty: Evidence from Twitter." Joint Discussion Paper Series in Economics, No. 09-2015. University of Marburg, Marburg, Germany. 
Mishra, P., K. Moriyama, P. N'Diaye, and L. Nguye. 2014. "Impact of Fed Tapering Announcements on Emerging Markets." IMF Working Paper WP/14/109. International Monetary Fund, Washington, DC.

Mohan, R and M. Kapur. 2014. "Monetary Policy Coordination and the Role of Central Banks." IMF Working Paper 14/70. International Monetary Fund, Washington, DC.

Obstfeld, M. 2015. "Trilemmas and tradeoffs: Living with financial globalization." BIS Working Papers No 480. Bank for International Settlements, Basel.

Obstfeld, M. and Rogoff, K. 2002. "Global Implications of Self-Oriented National Monetary Rules." Quarterly Journal of Economics 117(2), pp. 503-35.

Opazo, L., C. Raddatz, and S. Schmukler. 2014. "Institutional Investors and Long-Term Investment: Evidence from Chile." Policy Research Working Paper 6922. World Bank, Washington, DC.

Ortiz, A., Ottonello, P., Sturzenegger, F., Talvi, E. 2009. "Monetary and Fiscal Policies in a Sudden Stop: Is Tighter Brighter?" In Dealing with an International Credit Crunch: Policy Responses to Sudden Stops in Latin America, edited by E. Cavallo and A. Izquierdo, 23-73. Washington, DC: Inter-American Development Bank.

Ostry, J. and A. Ghosh. 2013. "Obstacles to International Policy Coordination, and How to Overcome Them." IMF Staff Discussion Note (December).

Park, K. Y., and J. Y. Um. 2015. "Spillover Effects of U.S. Unconventional Monetary Policy on Korean Bond Markets: Evidence from High-Frequency Data." Working Paper. Yonsei University, Seoul, South Korea.

Perotti, R. 1999. "Fiscal Policy in Good Times and Bad." Quarterly Journal of Economics 114 (4): 13991436.

Raddatz, C., and S. Schmukler. 2012. "On the International Transmission of Shocks: Micro-Evidence from Mutual Fund Portfolios." Journal of International Economics 88: 357-74.

Rai, V., and L. Suchanek. 2014. "The Effect of the Federal Reserve's Tapering Announcements on Emerging Markets." Bank of Canada Working Paper. Bank of Canada, Ottawa.

Rajan, R. 2014a. "Containing Competitive Monetary Easing." Project Syndicate. April 28. . 2014b. "Concerns about Competitive Monetary Easing." Speech at Bank of Japan, Tokyo, May 30.

Reifschneider, D., W. Wascher and D. Wilcox. 2015. "Aggregate Supply in the United States: Recent Developments and Implications for the Conduct of Monetary Policy." IMF Economic Review 201563, 71-109. Rey, H. 2013. "Dilemma not Trilemma: The Global Financial Cycle and Monetary Policy Independence." In Proceedings of the Federal Reserve Bank of Kansas City Economic Symposium at Jackson Hole, Federal Reserve Bank of Kansas City.

Rothenberg, A., and F. Warnock. 2011. "Sudden Flight and True Sudden Stops." Review of International Economics 19 (3): 509-24.

Roubini, N. 2015. “Emerging Markets after the Fed Hikes Rates." Project Syndicate. June 29.

Sahay, R., V. B. Arora, A. V. Arvanitis, H. Faruqee, P. N'Diaye, and T. M. Griffoli. 2014. "Emerging Market Volatility: Lessons from the Taper Tantrum." IMF Staff Discussion Notes No. 14/9. International Monetary Fund, Washington, DC. 
Sánchez, M. 2013. "The Impact of Monetary Policies of Advanced Countries on Emerging Markets." Remarks at the 55th Annual Meeting of the National Association of Business Economists, San Francisco, September 9.

Santacreu, A. M. 2015. "The Economic Fundamentals of Emerging Market Volatility." Economic Synopses (January), Federal Reserve Bank of St. Louis.

Schularick, M., and A. M. Taylor. 2012. “Credit Booms Gone Bust: Monetary Policy, Leverage Cycles, and Financial Crises, 1870-2008." American Economic Review 102 (2): 1029-61.

Shin, H. 2013: "The Second Phase of Global Liquidity and Its Impact on Emerging Economies." Speech at the Asia Economic Policy Conference, sponsored by the Federal Reserve Bank of San Francisco, November 3-5.

Sobrun, J. and P. Turner. 2015. "Bond markets and monetary policy dilemmas for the emerging markets." BIS Working Papers No 508. Bank for International Settlements, Basel.

Summers, L. 2015. “Why the Fed Must Stand Still on Rates." Larry Summers' Blog. September 9. http://blogs.ft.com/larry-summers/

Sutherland, A. J. 1997. "Fiscal Crises and Aggregate Demand: Can High Public Debt Reverse the Effects of Fiscal Policy?" Journal of Public Economics 65 (2): 147-62.

Taylor, J. 2013. "International monetary policy coordination: past, present and future." BIS Working Papers No 437, December 2013.

Weidner, J. and J. C. Williams. 2015. "Update of "How Big is the Output Gap?"” Federal Reserve Bank of San Francisco, June.

Williams, J. C. 2015. "The Decline in the Natural Rate of Interest." Federal Reserve Bank of San Francisco, manuscript based on the presentation for the NABE panel "The Outlook for the U.S. and Global Economy: Headwinds, Tailwinds and Whirlwinds," January 3.

Williamson, S. 2015. "Monetary Policy Normalization in the United States." Federal Reserve Bank of St. Louis Review 97 (2): 87-108.

World Bank. 2014a. Global Economic Prospects: Coping with Policy Normalization in High-Income Countries (January). Washington, DC: World Bank. . 2014b. "Financial Market Outlook" (February). World Bank, Washington, DC.

2014c. “"Growth Strategies: G20 Emerging Market Economies. World Bank Staff Assessment."”' (November). World Bank, Washington, DC.

2015a. Global Economic Prospects: Having Fiscal Space and Using It (January). Washington, DC: World Bank.

2015b. Global Economic Prospects: The Global Economy in Transition (June). Washington, DC: World Bank.

2015c. Commodity Markets Outlook (July). Washington, DC: World Bank.

Yellen, J. 2015a. Comments after speech at "Finance and Society," a conference sponsored by Institute for New Economic Thinking, Washington, DC, May 6.

http://www.bloomberg.com/news/articles/2015-05-06/yellen-s-focus-on-term-premium-gettingnoticedin-bond-market. 
2015b. "Normalizing Monetary Policy: Prospects and Perspectives". Speech at "The New Normal Monetary Policy," a research conference sponsored by the Federal Reserve Bank of San Francisco, San Francisco, March 27.

2015c. "The Outlook for the Economy." Speech at the Providence Chamber of Commerce, Providence, Rhode Island, May 22.

Zhao, Y., J. de Haan, B. Scholtens, and H. Yang. 2014. "Sudden Stops and Currency Crashes." Review of International Economics 22 (4): 660-85. 